Projeto de um Processador Open Source em Bluespec Baseado no Processador Soft-core Nios II da Altera

\author{
Erinaldo da Silva Pereira
}


SERVIÇO DE PÓS-GRADUAÇÃO DO ICMC-USP

Data de Depósito:

Assinatura:

\title{
Projeto de um Processador Open Source em Bluespec Baseado no Processador Soft-core Nios II da Altera
}

\author{
Erinaldo da Silva Pereira
}

Orientador: Prof. Dr. Eduardo Marques

Dissertação apresentada ao Instituto de Ciências Matemáticas e de Computação - ICMC-USP, como parte dos requisitos para obtenção do título de Mestre em Ciências - Ciências de Computação e Matemática Computacional. VERSÃO REVISADA 
Ficha catalográfica elaborada pela Biblioteca Prof. Achille Bassi e Seção Técnica de Informática, ICMC/USP, com os dados fornecidos pelo(a) autor(a)

da Silva Pereira, Erinaldo
Projeto de um Processador Open Source em
Bluespec Baseado no Processador Soft-core Nios II
da Altera / Erinaldo da Silva Pereira; orientador
Eduardo Marques. -- São Carlos, 2014.
$77 \mathrm{p}$.
Dissertação (Mestrado - Programa de Pós-Graduação
em Ciências de Computaço e Matemática
Computacional) -- Instituto de Ciências Matemáticas
e de Computação, Universidade de São Paulo, 2014.
1. Processador soft-core. 2. Bluespec. 3. FPGA.
Embarcados. I. Marques, Eduardo, orient. II. Título.
Computac̃o Reconfigurável. 5. Sistemas





\section{Agradecimentos}

Agradeço a Deus por ter cuidado de mim em todos os momentos da minha vida e que sempre me deu forças para superar as dificuldades ao longo desta caminhada.

À minha família, em especial a minha Mãe, Jurânia e aos meus irmãos, Eduardo, Erivalda e Dilmara, e a minha esposa Maria Adelina que souberam entender a minha ausência, transformando saudade em paciência e estímulo, contribuindo, incansavelmente, para que fosse vencida mais uma batalha.

Ao meu orientador Eduardo Marques, pela confiança depositada, apoio, injeções de ânimo, sugestões e pela competente orientação, viabilizando a concretização de um sonho. A todos os professores, em especial aos professores Vanderlei Bonato e João Cardoso pelos conselhos, pelos momentos de orientação, profissionalismo, e incentivo, fatores que muito contribuíram para a conclusão deste trabalho.

Muito obrigado aos colegas do LCR que ao longo de todo esse período, mostraram-se grandes amigos (Antônio, Tiago Lobo, Carlão, Lucas, Helson, Jean, Arnaldo, Alexandre, Hélio, Marcilyanne, Cristiano, Gustavo, Maikon, Cristiane, Valéria, Marcio Crocomo, Bruno, Leandro Rosa, Leandro Martinez, André, Valmir e aos demais) em meio às dificuldades, e também nos momentos de alegria. De modo especial agradeÃß̧o ao amigo Paulo Matias por todo apoio no desenvolvimento do trabalho.

Aos amigos de Portugal (Pedro Pinto, Tiago Carvalho, João Bispo, Ricardo Nobre, Ali Azarian e André Santos) pelos momentos de alegria e por tornar a estadia no Porto mais agradável.

Aos funcionários do ICMC que, direta ou indiretamente, contribuíram significativamente para que este objetivo fosse alcançado.

À FAPESP pelo apoio financeiro que viabilizou o trabalho.

A todos vocês, muito obrigado! 

Por vezes sentimos que aquilo que fazemos não é senão uma gota de àgua no mar. Mas o mar seria menor se lhe faltasse uma gota.

Madre Teresa de Calcutá 

Este trabalho apresenta o desenvolvimento de um processador open source baseado no processador Nios II da Altera. O processador desenvolvido permite a customização de instruções, a inclusão de componentes que possibilitem um estudo detalhado da memória cache, tal como um monitor de cache, definir o tamanho da cache, dentre outras características. Além disso, o processador é baseado na arquitetura do Nios II e implementa $90 \%$ do ISA do Nios II, o mesmo está integrado aos ambientes Qsys e SOPC Builder da ferramenta Quartus II da Altera, sendo possível utilizar todo o conjunto de IP (Propriedade Intelectual) e ferramentas disponíveis pela Altera. Assim, este trabalho tem como propósito colaborar com o desenvolvimento de arquiteturas de hardware com uma unidade de processamento configurável e customizável facilmente pelo usuário, uma vez que o seu código fonte em Bluespec SystemVerilog está aberto a todos os usuários, diferente do Nios II da Altera, que tem o código encriptado, inviabilizando fornecer qualquer mudança no processador a nível RTL (Register Transfer Level). Para o desenvolvimento do processador foi utilizada a Linguagem de Descrição de Hardware Bluespec SystemVerilog, pelo fato de ser uma ESL (Electronic System Level) que acelera o processo de desenvolvimento de hardware. 

This work presents the development of an open source based Nios II processor from Altera. The developed processor allows custom instructions, use of components that allows a detailed study of the cache memory, among other features. In addition, the processor is based on the Nios II architecture, which can be integrated into the Qsys and SOPC Builder of the Altera Quartus II environment tool as well as use the entire set of IP (Intellectual Property) and tools available from Altera. This work contributes to the development of hardware architectures with a processing unit configurable and easily customizable by the user, since its source code in Bluespec SystemVerilog is open to all users, other than the Nios II from Altera which has encrypted code, making it impossible to do any changes in the processor at RTL (Register Transfer level) level. For the development of the processor hardware the description language Bluespec SystemVerilog was used, which is an ESL (Electronic System Level) that speeds up the development of the hardware. 

1 Introdução 1

1.1 Contextualização . . . . . . . . . . . . . . . . . . . . . . . . 1

1.2 Objetivo . . . . . . . . . . . . . . . . . . 3

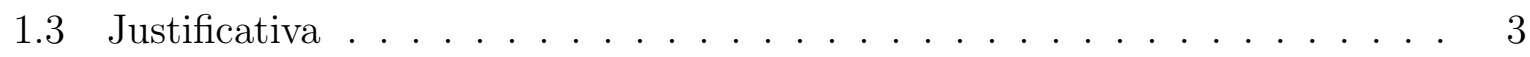

1.4 Organização . . . . . . . . . . . . . . . . . . . . 3

2 Fundamentação Teórica 5

2.1 Considerações Iniciais . . . . . . . . . . . . . . . . . . . . . . . 5

2.2 Computação Reconfigurável . . . . . . . . . . . . . . . . 5

2.2 .1 FPGA . . . . . . . . . . . . . . . . . 9

2.3 Processadores Soft-Core . . . . . . . . . . . . . . . . . . 10

2.3 .1 Nios II . . . . . . . . . . . . . . . . . . . . . . . . 13

2.3.2 Arquitetura do Nios II . . . . . . . . . . . . . . . . . . 14

2.3.2.1 Registradores . . . . . . . . . . . . . 15

2.3.2.2 ULA . . . . . . . . . . . . . . . . . . . . . . 16

2.3.2.3 Controladores de exceção e interrupção . . . . . . . . . . . 18

2.3.2.4 Barramentos . . . . . . . . . . . . . . . 19

2.3.2.5 Memória e Organização dos dispositivos de I/O . . . . . . 20

2.3.2.6 Memórias Cache . . . . . . . . . . . . . . 23

2.3.2.7 Módulo JTAG . . . . . . . . . . . . . . . . . . . . . . . 23

2.4 Electronic System Level (ESL) . . . . . . . . . . . . . . . . . . . . . . . . . 24

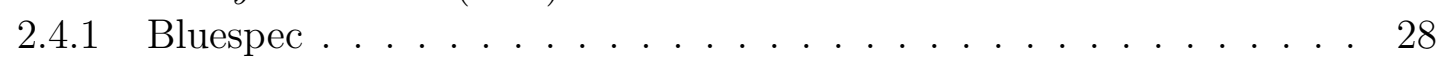

2.4.1.1 Módulos - Interfaces - Métodos . . . . . . . . . . . 30

2.4.1.2 Regras..................... 32

2.4.2 Processadores em Bluespec SystemVerilog . . . . . . . . . . . . . 33

2.5 Considerações Finais . . . . . . . . . . . . . . . . . . . . . 39

3 Metodologia 41

3.1 Considerações Iniciais . . . . . . . . . . . . . . . . . . . . . . . . . . . . . . . . .

3.2 Preparação e Ambiente de Desenvolvimento . . . . . . . . . . . . . . . . 41

3.3 Planejamento e Condução do Projeto . . . . . . . . . . . . . . . . . . . . . . . . . . 42

3.4 Considerações Finais . . . . . . . . . . . . . . . . . . . 47 
4 Bluespec Soft-Processor $\quad 49$

4.1 Considerações Iniciais . . . . . . . . . . . . . . . . . . . . . . . . . . . . . 49

4.2 Bluespec Soft-Processor . . . . . . . . . . . . . . . . . . . . 49

4.2 .1 Arquitetura BSP . . . . . . . . . . . . . . 50

4.2 .2 Conjunto de Instruções do BSP . . . . . . . . . . . . . . . . 53

4.3 Considerações Finais . . . . . . . . . . . . . . . . . . . . 54

5 Preparação e Execução dos Experimentos Realizados 55

5.1 Considerações Iniciais . . . . . . . . . . . . . . . . . . . . . . 55

5.2 Preparação para os Testes . . . . . . . . . . . . . . . . 55

5.2 .1 Ambiente de Testes . . . . . . . . . . . . . . 56

5.3 Execução dos Testes . . . . . . . . . . . . . . . . . . 56

5.3 .1 Resultados . . . . . . . . . . . . . . . . . . 59

$5.3 .1 .1 \quad$ Experimento I . . . . . . . . . . . . . . . . . 59

$5.3 .1 .2 \quad$ Experimentos II e III . . . . . . . . . . . . . . . 60

5.3.1.3 Experimento IV . . . . . . . . . . . . . . . . 60

5.4 Considerações Finais . . . . . . . . . . . . . . . . . . . . . . 67

6 Conclusão $\quad 69$

6.1 Caracterização da Pesquisa Realizada . . . . . . . . . . . . . . . . . . 69

6.2 Dificuldades e Limitações . . . . . . . . . . . . . . . . . . . . . . . . . . 69

6.3 Trabalhos Futuros . . . . . . . . . . . . . . . 70

$\begin{array}{ll}\text { Referências } & 77\end{array}$ 
2.1 Exemplo de arquitetura reconfigurável (Hsiung et al., 2009) . . . . . . . . 8

2.2 Estrutura de um FPGA (Bobda, 2007) . . . . . . . . . . . . . . 9

2.3 Conexão IPs Qsys (Altera, 2011d) . . . . . . . . . . . . . . . . . . 12

2.4 Exemplo de um sistema do processador Nios II (Altera, 2011b) . . . . . . . 13

2.5 Diagrama de bloco do processador Nios II (Altera, 2011c) . . . . . . . . 16

2.6 Adição de uma instrução customizda(personalizada) a ULA do processador Nios II (Altera, 2011b) . . . . . . . . . . . . . . . . . . . 17

2.7 Hardware para controle de interrupção do Nios II (Altera, 2011b) . . . . . 19

2.8 Estrutura da memória e organização dos dispositivos de I/O do Nios II. (Altera, 2011c) . . . . . . . . . . . . . . . . . . . . . 21

2.9 Fluxo de modelagem em ESL (Rigo et al., 2011) . . . . . . . . . . . . . 26

2.10 Fluxo de compilação bluespec (Stump e Harper, 2011) . . . . . . . . . . . 29

2.11 Diagrama de bloco do processador descrito em (Dave, 2005) . . . . . . . . 34

2.12 Estrutura de pipeline do processador BlueJEP (Gruian e Westmijze, 2007) 35

2.13 Visão geral do processador powerPC em BSV (Ekanadham et al., 2008) . . 36

2.14 Arquitetura do processador Caliburn (Chu et al., 2013) . . . . . . . . . 36

2.15 Arquitetura do processador BERI (Watson, 2014) . . . . . . . . . . 37

2.16 Estrutura de pipeline do processador Cyan (Moore, 2010a) . . . . . . . . 38

2.17 Arquitetura do processador UT Nios (Plavec, 2004) . . . . . . . . . . . 39

2.18 Microarquitetura do processador SMIPS (Spring, 2005) . . . . . . . . 40

3.1 Disassembly da sequência de Fibonacci escrita em $C$. . . . . . . . . . . 43

3.2 Infraestrutura criada para debug e validação do processador . . . . . . . . 44

3.3 Estrutura interna do script programbuild.sh . . . . . . . . . . . . . . . . 44

3.4 Janela principal da Bluespec workstation . . . . . . . . . . . . . . . . . 45

3.5 Simulação do processador com a funcionalidade de trace . . . . . . . . . . 46

3.6 Processador integrado ao ambiente Qsys . . . . . . . . . . . . . 47

4.1 Diagrama de bloco do Bluespec Soft-Processor . . . . . . . . . . . . . . . 50

4.2 Módulos do Bluespec Soft-Processor . . . . . . . . . . . . . . . . 52

4.3 Formato binário das instruções dos tipos I, J e R . . . . . . . . . . . 53

5.1 Estrutura interna do script make_isa.sh . . . . . . . . . . . . 58 
5.2 Speedup cores Nios II em relação ao BSP . . . . . . . . . . . . . . . . . . 62

5.3 Relação de elementos lógicos utilizados entre o BSP ISA reduzido específico X BSP ISA completo . . . . . . . . . . . . . . . . . . . . 64

5.4 Relação de registradores utilizados entre BSP ISA reduzido específico X BSP ISA completo . . . . . . . . . . . . . . . . . . . 64

5.5 Estrutura de ALM FPGA Stratix V . . . . . . . . . . . . . 65

5.6 Relação de Fmax alcançada pelos cores específicos com ISA reduzido em relação ao ISA completo . . . . . . . . . . . . . . . . . . . 66

5.7 Relação de potência estimada pelos cores específicos com ISA reduzido em relação ao ISA completo . . . . . . . . . . . . . . . . . . . . 66

5.8 Número de DSPs utilizados nos ISAs reduzidos específicos em relação ao BSP ISA completo . . . . . . . . . . . . . . . . . . 67

6.1 Manipulador de exceção/interrupção . . . . . . . . . . . . . . . . . . 71

6.2 Proposta de arquitetura multicore . . . . . . . . . . . . . . . . 71

6.3 Exemplo de um trace do BSP executando em modo simulado . . . . . . . . 72

6.4 Exemplo de características a serem analisadas nos experimentos . . . . . . 72 


\section{Lista de Tabelas}

2.1 Cores da família Nios II (Altera, 2007) . . . . . . . . . . . . . . . . . 14

2.2 Possíveis configurações de cache do Nios II . . . . . . . . . . . . . . . . 24

4.1 Instruções implementadas pelo BSP em relação ao ISA Nios II . . . . . . . 54

5.1 Benchmarks utilizados para realização dos testes . . . . . . . . . . . . . 57

5.2 Dados obtidos na execução dos benchmarks descritos no Experimento I . 59

5.3 Dados obtidos na execução dos benchmarks descritos nos Experimentos II e III . . . . . . . . . . . . . . . . . . . . . . . . . . . . 61

5.4 Dados obtidos na execução dos programas descritos no Experimento IV 63

6.1 Características das arquiteturas Nios II x BSP X BSP V2 . . . . . . . . . 70 


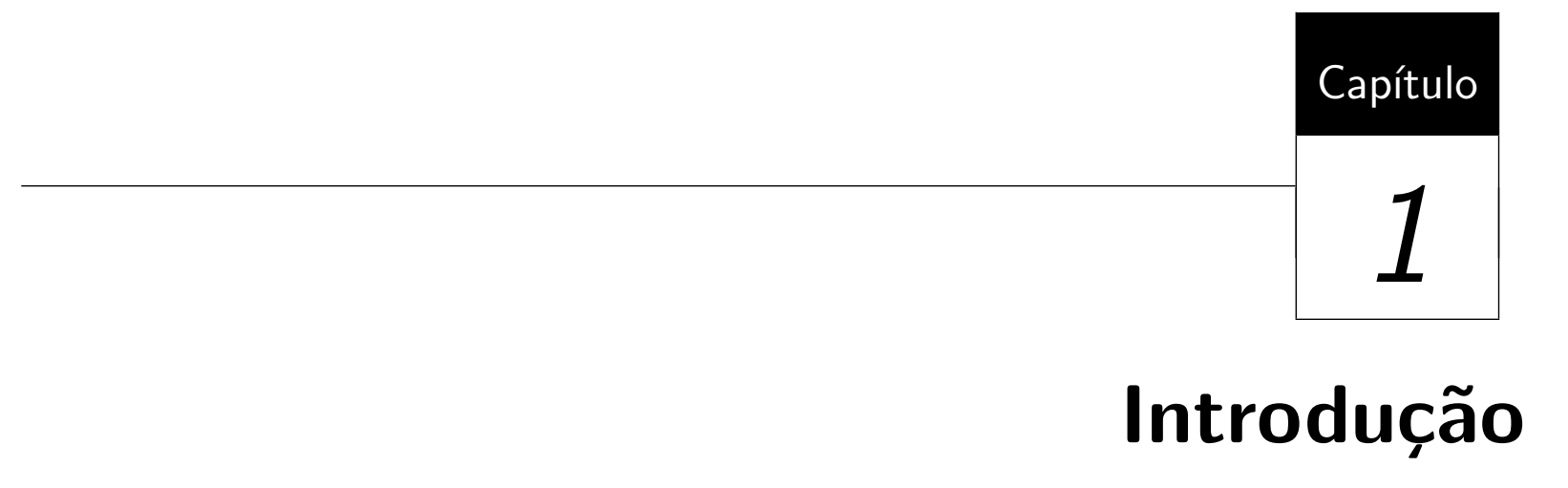

\subsection{Contextualização}

Os sistemas embarcados estão cada vez mais presentes em diversas áreas, tais como: automobilística, aviação, telecomunicação, eletrodomésticos, militar, segurança, eletrônica, robótica, dentre outras. Algumas características são comuns a esses sistemas como: segurança, tratando-se de sistemas críticos que envolvem vida humana; eficiência, considerando consumo de energia, execução, tamanho do código, etc; existência de sensores e atuadores para comunicação com o meio; restrição de tempo real, dentre outras (Marwedel, 2011).

Há muitas definições para sistemas embarcados, porém todas convergem ao considerarem a existência de capacidade computacional embutida num hardware para um propósito em específico. Entretanto, as restrições de recursos existentes nesses tipos de sistemas impede-os de realizar outras tarefas para as quais não foram projetados (Marwedel, 2011).

Nesse contexto, os dispositivos reconfiguráveis destacam-se em razão de sua flexibilidade que os permitem serem modificados para atender mais de um propósito, como por exemplo, pode-se implementar um hardware dedicado para filtro de imagem num momento, e em outra ocasião pode-se reconfigurar o dispositivo para um hardware que calcule inversão de matriz, sem a necessidade de adquirir um novo dispositivo de hardware. Os FPGAs (Field-Programmable Gate Arrays) (Hsiung et al., 2009) (Hauck e DeHon, 2008) (Bobda, 2007) (Gokhale e Graham, 2005) são um exemplo de dispositivo 
reconfigurável, que estão sendo cada vez mais utilizadas como aceleradores de hardware em computação científica. Isso acontece em decorrência de poder customizar sua lógica funcional, baixo consumo de energia, comparado aos dispositivos convencionais, e por possibilitar a customização desde operadores aritméticos a funções especiais para atender as necessidades da aplicação (Bobda, 2007) (Lima et al., 2008) (Bacon et al., 2013).

Como conseqüência do aumento da complexidade dos projetos de sistemas embarcados ao longo do tempo, projetar cada um dos componentes de hardware de um sistema sem reutilizar nenhum componente tornou-se pouco prático e caro para a maioria dos projetistas. Com isso, a ideia de utilizar IPs (Propriedade Intelectual) pré-concebidas e pré-testadas em conjunto com processadores soft-core tornou-se uma alternativa atraente e de baixo custo relativo para projetistas e empresas (Xie et al., 2007).

Nesse contexto, este projeto de mestrado visa contribuir neste cenário, estabelecendo e implementando um processador soft-core com um conjunto de instruções compatíveis ao Nios II da Altera. Esse processador, denominado BSP (Bluespec Soft-Processor), foi desenvolvido em sintonia com os pontos básicos de implementação utilizando a HDL (Linguagem de Descrição de Hardware) Bluespec.

O processador Nios II disponibilizado pela Altera permite pequenas alterações na memória cache de dados e de instrução, e a customização de algumas instruções (Altera, 2011b). O processador soft-core BSP proposto por este trabalho, além de buscar atender as customizações permitidas pelo Nios II, possibilita alterações a nível de seu código, seja para acelerar uma aplicação de hardware ou para otimizar um componente existente. Desta forma, é possível acrescentar níveis de pipeline, realizar estudos mais detalhados da memória cache e outras características que possam ser customizadas (pipeline, tamanho da cache, reduzir o conjutno de instruções), pois o código fonte do processador é open source em contraste com o do Nios II da Altera, cujo código fonte está encriptado.

Por fim, o BSP está integrado ao framework da Altera, isto possibilita a utilização do grande conjunto de IPs e todo o ecossistema de ferramentas (Quartus II, Qsys e SOPC Builder) disponibilizadas pela Altera, e proporciona a criação de novas arquiteturas de hardware otimizadas que utilizam o Nios II como processador de referência no Laboratório de Computação Reconfigurável - LCR do ICMC-USP. Este é o caso de muitos projetos desenvolvidos LCR e já possuem muitos aplicativos de software desenvolvidos exclusivamente para o processador Nios II da Altera. Desta forma, com o processador BSP é possível manter toda esta base de software instalada, pois ele é capaz de executar código objeto do Nios II. 


\subsection{Objetivo}

O objetivo principal deste trabalho é o desenvolvimento de um processador soft-core e de código aberto compatível com o ISA do Nios II, utilizando-se a HDL Bluespec, proporcionando a utilização e integração do mesmo com o conjunto de IPs e as ferramentas (Quartus II, Qsys e SOPC Builder, nios2-elf-gcc) disponibilizadas pela Altera. Como objetivo secundário, é a disponibilização deste processador para o ensino de Arquitetura de Computadores, uma vez que ele possui uma enorme flexibilidade para o teste de diferentes conceitos de arquiteturas.

\subsection{Justificativa}

O Nios II disponibilizado pela Altera permite pequenas alterações na memória emphcache e customização de algumas instruções. No entanto, tais alterações são padronizadas pela Altera, ou seja, se o projetista desejar realizar alguma alteração além das disponíveis não é possível, uma vez que o código fonte do Nios II é encriptado.

Prover acesso ao código fonte do processador BSP e disponibilizá-lo abertamente, permite uma melhor compreensão dos detalhes intrínsecos da arquitetura e funcionamento do processador. Além de viabilizar financeiramente muitos projetos, oferece a oportunidade de profissionais da área participarem do processo de desenvolvimento e até melhorarem diretamente alguns componentes e prover portabilidade do processador para diferentes plataformas de FPGAs.

Nesse cenário, este trabalho contribui com uma versão de um soft-core open source compatível com o ISA (Instruction Set Architecture) do Nios II, desenvolvido em Bluespec, e sua integração com o conjunto de ferramentas da Altera, pois todo o ferramental para utilizar o processador BSP está disponível e testado.

\subsection{Organização}

No Capítulo 2 é apresentada a Fundamentação Teórica, abordando os fundamentos da computação reconfigurável, processadores soft-core, arquitetura do Nios II e a HDL Bluespec. No Capítulo 3 é apresentada a Metodologia, abordando a estratégia utilizada para condução do projeto e as ferramentas utilizadas para a implementação do mesmo. No Capítulo 4 é apresentado o processador BSP desenvolvido. No Capítulo 5 são apresentadas as fases de preparação e execução dos experimentos realizados com o processador, a análise e interpretação dos dados obtidos. Por fim, no Capítulo 6 são apresentadas as conclusões do trabalho. 



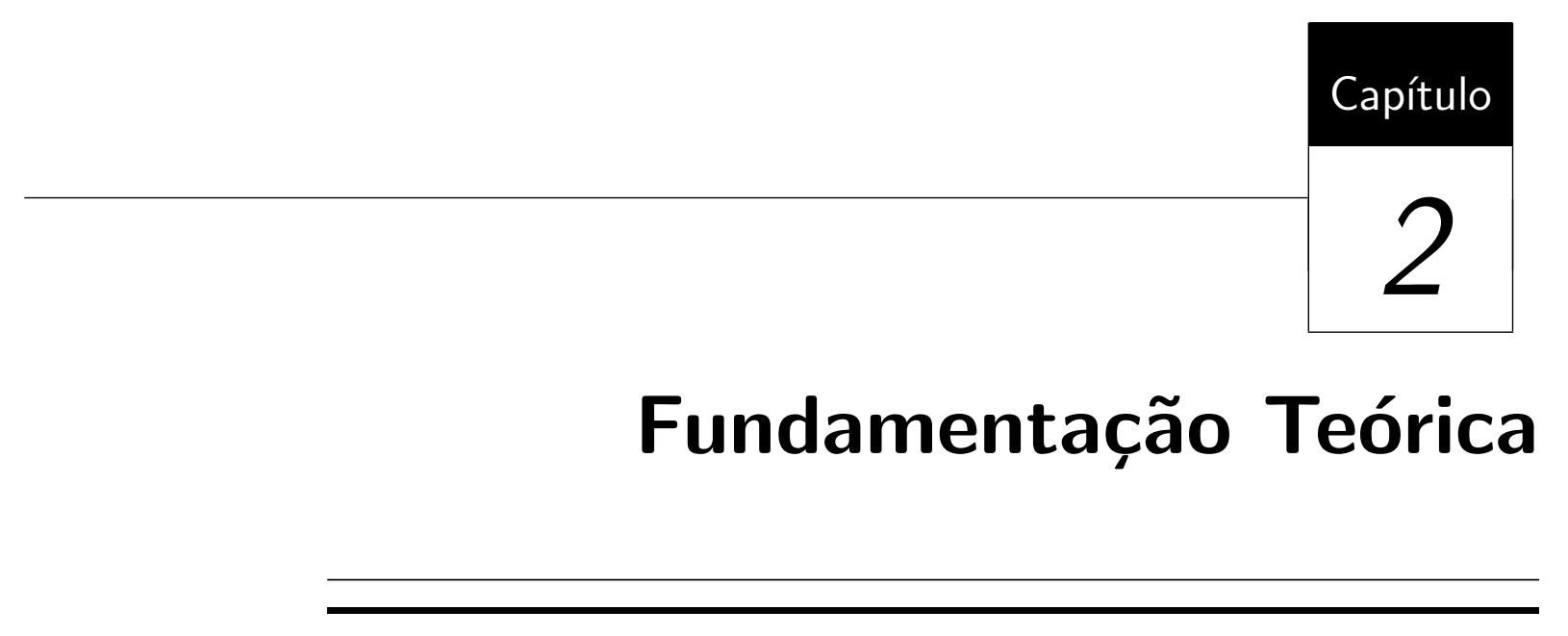

\subsection{Considerações Iniciais}

Neste capítulo são apresentados conceitos relacionados à fundamentação teórica do trabalho, os quais são: Computação Reconfigurável, Processadores Soft-core, e Electronic System Level (ESL).

O conhecimento desses fundamentos faz-se necessário para a compreensão dos aspectos explorados nos capítulos seguintes.

O capítulo está organizado da seguinte forma: na Seção 2.2 são apresentados os principais conceitos sobre computação reconfigurável, considerando-se os dispositivos existentes e utilizados nesse tipo de computação, com ênfase nos FPGAs. Na Seção 2.3 são apresentados conceitos sobre processadores soft-core, o Nios II e sua arquitetura. Na Seção 2.4 são apresentados conceitos sobre ESL, a linguagem de descrição de hardware Bluespec e exemplos de processadores em Bluespec. Na Seção 2.5 são apresentados trabalhos relacionados com o projeto desenvolvido e na Seção 2.6 estão às considerações finais deste capítulo.

\subsection{Computação Reconfigurável}

O desenvolvimento tecnológico induziu mudanças no paradigma da computação. A invenção do microprocessador programável em 1974 resultou numa mudança de paradigma 
da computação, pois esta que antes era puramente baseada em hardware passou a ter seu foco no software.

Em 1965, Gordon Moore publicou um artigo constatando que a miniaturização dos componentes eletrônicos vinha permitindo dobrar o número de transistores em circuitos integrados a cada ano, enquanto que o custo dos componentes permaneceria constante, e esta tendência deveria manter-se por pelo menos mais dez anos. Em 1975, Moore atualizou seus dados, prevendo que a cada vinte e quatro meses o número de transistores em circuitos integrados iria dobrar. De fato, a previsão de Moore veio a concretizar-se, pois o número de transistores presentes em uma minúscula área de silício aumentou a tal ponto que um sistema completo, podendo envolver hardware e software, pode ser implementado em um único chip, surgindo assim os chamados System-on-Chip (SoC) (Hsiung et al., 2009).

Tradicionalmente, a computação foi classificada em computação de propósito geral, realizada por um processador de propósito geral (PPG) e de aplicações específicas de computação, realizada por um circuito integrado de aplicação específica os chamados ASIC - Application-Specific Integrated Circuit. A computação de propósito geral foi a primeira a ser realizada pelo Electronic Numerical Integrator and Computer (ENIAC), construído por J. Presper Eckert e John Mauchly. Posteriormente, conhecido como computador de Von Neumann em razão da evolução na arquitetura original do ENIAC realizada por John Von Neumann.

Um computador de propósito geral constitui-se de um chip de silício contendo milhares de transistores, também chamado de microprocessador, que podem ser programados para resolver qualquer tarefa de computação. Enquanto que um ASIC pode ser entendido como um circuito integrado concebido especificamente para a execução de uma determinada função. Chips ASIC podem substituir chips de propósito geral, integrar várias funções ou o controle de blocos lógicos em um único chip, diminuindo o custo de fabricação e simplificação do projeto do ASIC. Além disso, os ASICs são caracterizados pelo alto desempenho e baixo consumo de energia. Contudo, por possuírem arquitetura fixa e alto custo de fabricação, acarretam em desvantagens a escolha por este tipo de computação para aplicações com pouca demanda, como por exemplo, um ASIC que realiza apenas o cálculo de inversão de matriz.

Com o surgimento dos SOCs os projetos de produtos eletrônicos de consumo, convergiram para a "era" digital e com foco na integração de diferentes aplicações em um único dispositivo como, por exemplo, o telefone celular, que integra Câmera Digital, Player de MP3, Decodificadores de Vídeo, Rádio FM, Wi-Fi, Bluetooth, GPS, dentre outras. Contudo, tal integração ocasionou no alto consumo de energia, aumento no custo de desenvolvimento do projeto, baixa confiabilidade, aumento nos riscos de segurança e uma 
série de conflitos. Todavia, segundo Hsiung et al. (2009), muitos destes problemas podem ser resolvidos com a introdução da lógica reconfigurável no sistema.

Em 1960 G. Estrin foi o primeiro a propor o termo computação reconfigurável. No entanto, sua popularização ocorreu no final dos anos 80, com o intuito de utilizar lógica programável para acelerar a computação de aplicações, a computação reconfigurável ganhou mais força e utilização com a ampla disponibilidade comercial dos FPGAs. O desenvolvimento inovador dos FPGAs, cuja configuração pode ser reprogramada inúmeras vezes, permitiu que um mesmo algoritmo pudesse ser executado em diferentes configurações de hardware, utilizando um único dispositivo (o FPGA), assim como a possibilidade de diferentes algoritmos serem executados por um processador (neste caso um soft-core) convencional que pode ser programado em um FPGA (Gokhale e Graham, 2005).

De acordo com Hsiung et al. (2009), a lógica reconfigurável é um tipo especial de circuito de hardware que pode ser reconfigurado, após a fabricação, em qualquer lógica que o utilizador desejar. O processo de reconfiguração, na maioria dos casos, ocorre com a programação de algum tipo de memória do dispositivo reconfigurável. Contudo, apesar de já existirem dispositivos que possuam lógica reconfigurável incorporados ao sistema, uma grande parcela dos produtos de consumo ainda não seguiu essa tendência. Estudos na computação reconfigurável demonstram que a utilização de FPGAs como computadores reconfiguráveis oferece significativas vantagens sobre microprocessadores e DSPs de alto desempenho, quando aplicados a um grupo aplicações, particularmente aplicações que podem explorar o uso de instruções customizadas e paralelismo maciço em nível de instrução (Gokhale e Graham, 2005).

A computação reconfigurável representa a quebra de uma das barreiras existentes entre o hardware e o software. A separação entre os dois tornou-se cada vez mais indistinta, pois, agora ambos são programáveis. Além disso, ela pode ser vista como um trade-off entre a computação de propósito geral e o projeto de circuitos integrados específicos de computação, uma vez que tenta alcançar um equilíbrio entre desempenho, consumo de energia, custo e flexibilidade do projeto.

Em geral, a concepção de uma arquitetura reconfigurável ocorre de forma simétrica, uma vez que esta pode ser dividida em partes semelhantes ou blocos que contenham a mesma funcionalidade. Na maioria dos casos, arquiteturas reconfiguráveis são construídas com o intuito de atingir uma significativa melhoria no desempenho de aplicações que realizam computação intensiva, buscando explorar o paralelismo em nível de instrução, velocidade de execução diretamente no hardware, dentre outras.

Uma característica que define uma arquitetura de computação reconfigurável é o tipo de granulação utilizada, que pode ser fine-grained ou coarse-grained, visto que sistemas diferentes possuem granulações diferentes. Uma arquitetura é dita fine-grained, quando 
manipula dados a nível de bits similarmente aos FPGA's comerciais. Já uma arquitetura coarse-grained é aquela que manipula grupos de bits por meio de complexas unidades funcionais, tais como ULAs (Unidades lógica e aritmética) e Multiplicadores (Hauck e DeHon, 2008).

A Figura 2.1 representa um exemplo de arquitetura de computação reconfigurável, composta por um processador de propósito geral e blocos lógicos de hardware reconfigurável. Na qual, cada bloco lógico executa tarefas específicas de uma aplicação de computação intensiva, por exemplo, uma tarefa de criptografia e outra de processamento de imagem, representadas respectivamente por (C1) e (C5). Neste exemplo de arquitetura, o processador é usado para controlar o comportamento das tarefas (C1 e C5) em execução no hardware reconfigurável e as funções de I/O. Quando uma tarefa completar sua execução o processador reconfigura a lógica do hardware para que a outra possa ser executada. Essa arquitetura de computação reconfigurável também pode ser descrita como utilização do hardware sob demanda ou uma abordagem híbrida entre ASIC e PPG (Hsiung et al., 2009).

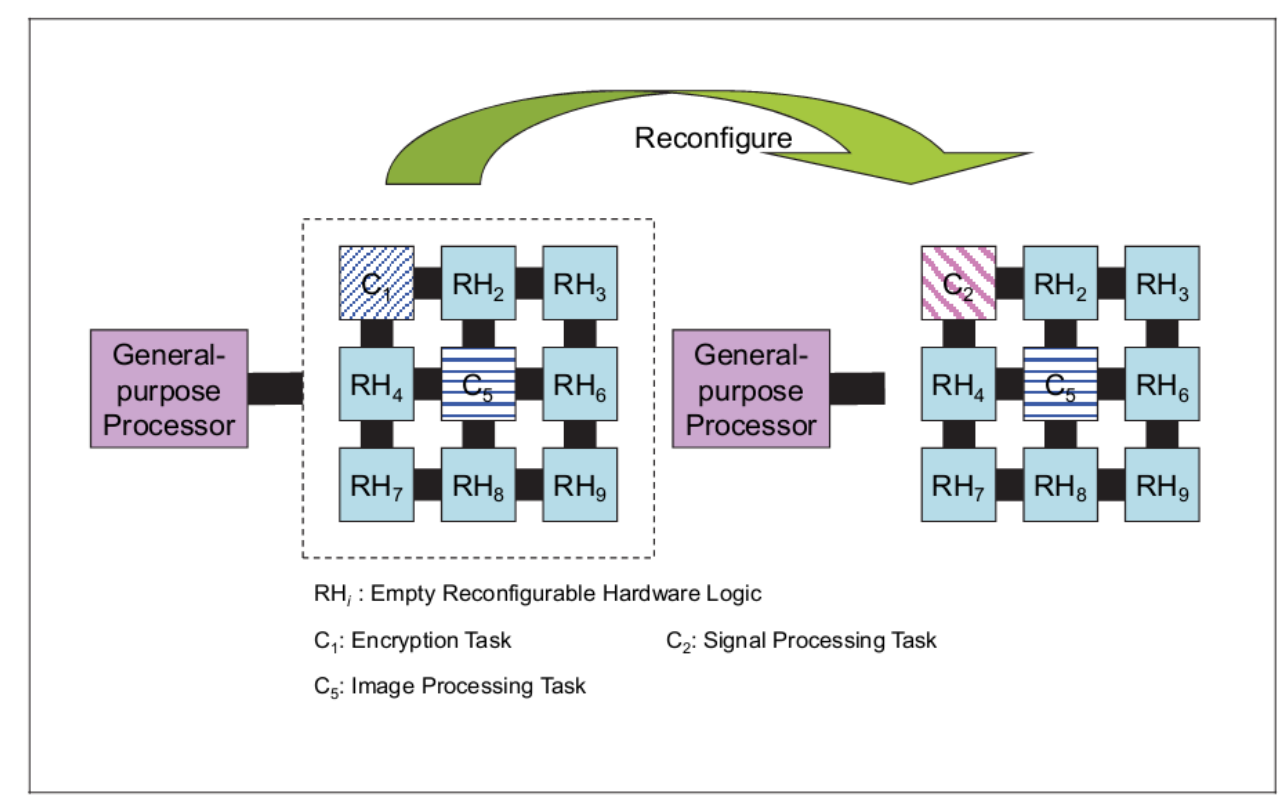

Figura 2.1: Exemplo de arquitetura reconfigurável (Hsiung et al., 2009)

Sendo assim, com a utilização da computação reconfigurável é possível flexibilizar o projeto de hardware e a arquitetura alvo. Tais fatores têm colaborado para acelerar o progresso em tecnologias de co-design hardware-software, e tem melhorado o desempenho de aplicações em diversos domínios, incluindo Sistemas Embarcados, Computação Científica, Bioinformática, Inteligência Artificial, Processamento de Sinal, Robótica, Segurança Computacional, Processamento de Imagem, Aplicações Espaciais e Militares, dentre outras. 


\subsubsection{FPGA}

Introduzido em 1985 pela empresa Xilinx, um FPGA consiste de um dispositivo programável composto por três partes principais: um conjunto de blocos lógicos configuráveis, uma matriz programável de interconexões e um conjunto de células de entrada e saída em torno do dispositivo, como ilustrado na Figura 2.2 (Bobda, 2007).

Neste contexto, as unidades lógicas podem ser vistas como componentes padrões que podem ser configurados independentemente e interconectados a partir de uma matriz de trilhas condutoras e switches programáveis. Todos os componentes básicos de um FPGA podem ser programados pelo usuário, e um FPGA pode ser programado uma ou várias vezes, dependendo da tecnologia utilizada (Bobda, 2007).

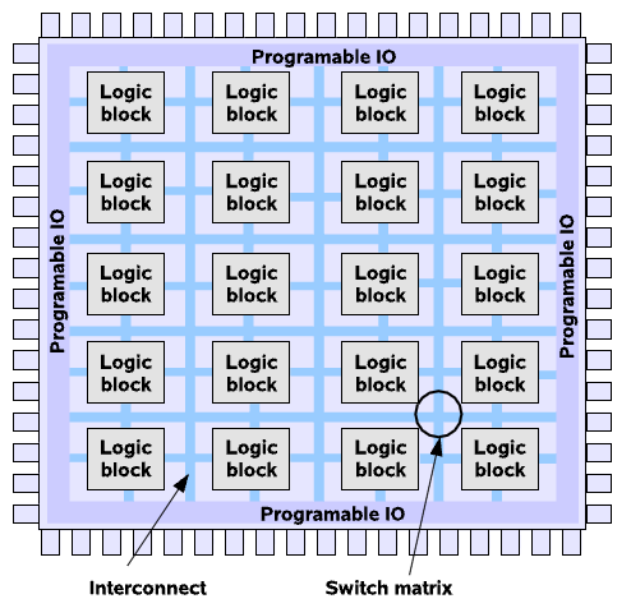

Figura 2.2: Estrutura de um FPGA (Bobda, 2007)

Nos últimos anos, os FPGAs têm apresentado um grande desenvolvimento nos quesitos densidade, velocidade e capacidade de armazenamento. Essas características tornaram possível a construção, em FPGA, de sistemas complexos formados por um ou mais processadores, blocos de propriedade intelectual e lógica definida pelo usuário. Sistemas tais como esses são chamados de SOPC (System-On-a-Programmable-Chip).

SOCs baseados em FPGA (ou SOPC) têm se mostrado como uma excelente opção de implementação para sistemas que necessitam de um alto desempenho. Uma das áreas que se beneficiam de implementações SOC é a robótica móvel, uma vez que os algoritmos envolvidos são computacionalmente complexos. Por exemplo, Bonato et al. (2004) usa soluções System-On-Chip baseadas em FPGA para implementar algoritmos de reconhecimento de gestos. Além dessa, podem-se citar outras aplicações móveis que demandam um grande poder computacional, tais como reconhecimento de voz em tempo real e análise e transmissão de vídeo. 
Os FPGAs são predominantemente programados usando HDLs (linguagens de descrição de hardware), como Verilog e VHDL. Estas linguagens, remontam à década de 1980, e em termos de nível de abstração provida ao usuário são consideradas de muito baixo nível. Um projetista de hardware pensa no projeto em termos de portas lógicas, registradores, e multiplexadores, e para esse nível de abstração, VHDL e Verilog são adequados para descrever um projeto. Outra questão é que apenas um subconjunto restrito de VHDL e Verilog é sintetizável e não há uma padronização dos recursos suportados pelas diferentes ferramentas de EDA (Electronic Design Automation) (Bacon et al., 2013).

Além disso, as ferramentas EDA de um modo geral são complexas (aprendizado e domínio da mesma) e o processo de síntese é demorado. O processo de síntese de um projeto consiste em gerar a partir do seu código fonte um arquivo chamado bitstream, o qual é utilizado para programar o FPGA. O tempo de síntese pode variar entre alguns minutos a alguns dias, dependendo das restrições do projeto e sua complexidade (Bacon et al., 2013).

\subsection{Processadores Soft-Core}

A implementação de sistemas embarcados, em FPGAs, em que se encaixa um sistema completo em um único chip programável (SOPC) tornou-se cada vez mais comum em razão da inclusão de memória cada vez maior nos FPGAs. Devido a sua flexibilidade e implementação em uma HDL, processadores soft-core são utilizados como unidade de processamento em sistamas do tipo SOPC. Um soft-core trata-se de um microprocessador descrito em uma HDL, que pode ser sintetizado em hardware programável, tal como FPGA. Por ser descrito em uma HDL, um soft-core implementado em um FPGA pode ser facilmente customizado para atender às necessidades de uma aplicação alvo (Plavec et al., 2005) e facilmente portado para uma outra plataforma.

Segundo Sheldon et al. (2006), no âmbito da computação reconfigurável, a implementação de microprocessadores soft-core em FPGA tem-se popularizado em razão da lógica personalizada, redução de custos no projeto de hardware e por melhorar o desempenho do sistema.

Os principais fabricantes de FPGA, Xilinx e Altera, oferecem cada uma, um soft-core específico para ser utilizado em seus FPGAs. A Xilinx fornece o MicroBlaze, e a Altera o Nios II. Além do MicroBlaze e do Nios II há no mercado diversos modelos diferentes de processadores soft-core, cabendo destaque para o LEON3, um processador soft-core de código aberto, que possui um conjunto de instruções de 32 bits, e é baseado na arquitetura SPARC V8 (Gaisler, 2011). 
Otimizado para implementação em FPGAs das famílias Virtex e Spartan da Xilinx, o processador soft-core MicroBlaze possui um conjunto reduzido de instruções (RISC) de 32 bits, inclui um conjunto de parâmetros configuráveis, tais como Unidade de Ponto Flutuante, cache de dados e de instrução, lógica de hardware de depuração e alguns recursos adicionais. A Xilinx também oferece o Kit de Desenvolvimento Integrado (EDK), que inclui a Xilinx Platform e um conjunto de IP (Propriedade Intelectual), necessários para o desenvolvimento de sistemas embarcados usando MicroBlaze (Tong et al., 2006). Contudo, modificações a nível de otimização do código e integração com outras IP's que não sejam da Xilinx, não são possíveis, pois o código do MicroBlaze é proprietário.

O processador LEON3 é inerentemente portátil podendo ser implementado na maioria das tecnologias FPGA e ASIC. Ele é projetado para aplicações embarcadas, combinando alto desempenho, com baixo consumo de energia e altamente configurável. Possui uma versão tolerante a falhas que lhe proporciona imunidade para efeitos de radiação, tornando-o ideal para aplicações aero espacial e outras de alto desempenho. Entretanto, o código fonte dessa versão não é aberto (Gaisler, 2011). O LEON3 é um processador complexo e ocupa uma grande área de sílicio em comparação com outros processadores de 32 bits tais como Nios II e MicroBlaze.

O processador embarcado Nios II exemplifica a reconfiguração e customização de aplicações em FPGA, pois fornece processamento de baixo custo para aplicações que não necessitam de um grande poder de processamento, assim como para aplicações de computação intensiva. Embarcado em uma FPGA, o Nios II provê poder computacional para trabalhar com aplicações genéricas, em particular, aplicações como gateways de multimídia digital, switches low-end, roteadores e sistemas de entretenimento automotivo, que se beneficiam de uma abordagem dos sistemas on-chip. Tais sistemas são caracterizados por possuírem uma unidade de processamento combinada com blocos de IPs e lógica definida pelo usuário. Sua arquitetura é simples e é baseada no processador MIPS (Altera, 2011b).

O processador soft-core Nios II, do mesmo modo que o LEON3 e o MicroBlaze, é um IP configurável, ou seja, seu núcleo não é fixo em uma placa de silício (processadores hard-core). Essa flexibilidade é umas das diferenças notáveis entre o Nios II e um hard-core, pois sua implementação em lógica programável permite construir projetos com um conjunto específico de componentes necessários para uma aplicação alvo (Altera, 2011b). Por ser projetado como um soft-core e não em hard-core como os processadores mais comuns, é possível prover alterações ao processador ainda em fase de configuração do hardware, antes mesmo da transferência do projeto de hardware para um dispositivo reconfigurável, como por exemplo, uma FPGA.

O Nios II foi implementado com base na arquitetura RISC (Reduced Instruction Set Computer), o que o caracteriza como um processador que possui um conjunto de in- 
struções reduzido, porém altamente otimizado. Essas instruções podem ser adaptadas para obedeceram a uma determinada aplicação, como exemplo, a aceleração de um determinado trecho de código na execução de um algoritmo, permitindo flexibilizar e adicionar funcionalidades a Unidade Lógica e Aritmética do Nios II (Lima et al., 2008).

A Altera fornece um conjunto de IPs comumente usados em microcontroladores e em sistemas que utilizam o Nios II como processador, alguns dos IPs desse conjunto podem ser vistos na Figura2.4 (Altera, 2011b). Utilizando a ferramenta Quartus II, disponibilizada pela Altera para projeto e síntese de hardware, é possível utilizar de forma intuitiva esse conjunto de IPs por meio da interface gráfica fornecida pelo Qsys.

O Qsys é um sistema de integração de ferramentas que economiza tempo e esforços significativos no processo de projeto para FPGA, gerando automaticamente a lógica de interconexão para conectar IPs, funções e subsistemas. A ferramenta Qsys dispõe da tecnologia NoC (network-on-a-chip) e dos mecanismos de otimização das novas FPGAs, oferecendo maior desempenho, reuso de projeto e rápida verificação comparado ao SOPC Builder (Altera, 2011d).

A conexão de IPs desenvolvida para FPGAs da Altera era um dos grandes problemas antes do Qsys, pois era necessário criar uma interface de comunicação com o Avalon, barramento de comunicação padrão da Altera. Contudo, este problema foi solucionado com a presença de uma rede NoC no Qsys para realizar a comunicação entre as IPs, que podem ser de diferentes fabricantes, dispensando a necessidade de prover uma interface padrão de comunicação para tal integração, pois Qsys suporta uma mistura de interfaces como ilustrado na Figura 2.3.

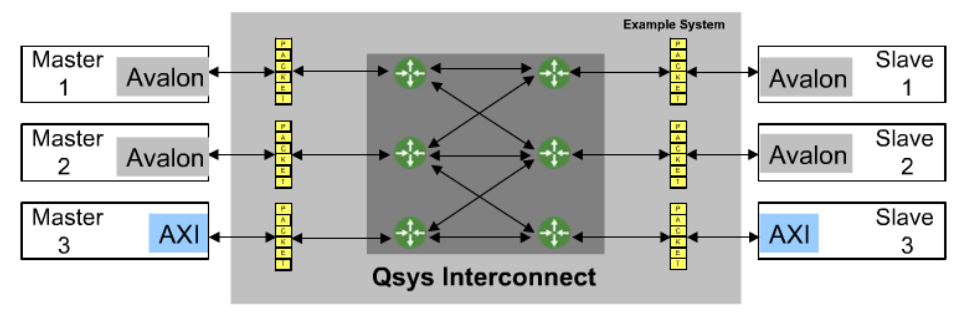

Figura 2.3: Conexão IPs Qsys (Altera, 2011d)

No processo de configuração do Nios II juntamente com os IPs que irão compor o projeto de hardware, utilizando a ferramenta Quartus II, é gerado um código fonte, a escolha do projetista, em VHDL ou Verilog do Nios II e das IPs utilizadas no projeto, sendo possível dessa forma alterá-las internamente, com exceção do Nios II que tem o seu código encriptado não permitindo nenhuma alteração do processador em nível de código. O Nios II da Altera, permite ao usuário especificar o tamanho da cache de dados e de instrução, dentro de um conjunto de variações pré-determinado, e a customização de 
algumas instruções. Dessa forma, modificações a nível de otimização e/ou customização do código fonte do Nios II não são permitidas em decorrência da encriptação do mesmo.

\subsubsection{Nios II}

Desenvolvido pela Altera, o Nios II é um processador reconfigurável de propósito geral com um conjunto de instruções de 32 bits. De modo que, o Nios II é também um sistema equivalente a um microcontrolador, que possui uma unidade central de processamento, memória, um conjunto de periféricos on-chip e interfaces para utilização de memória externa, como indicado na Figura 2.4 (Altera, 2011b).

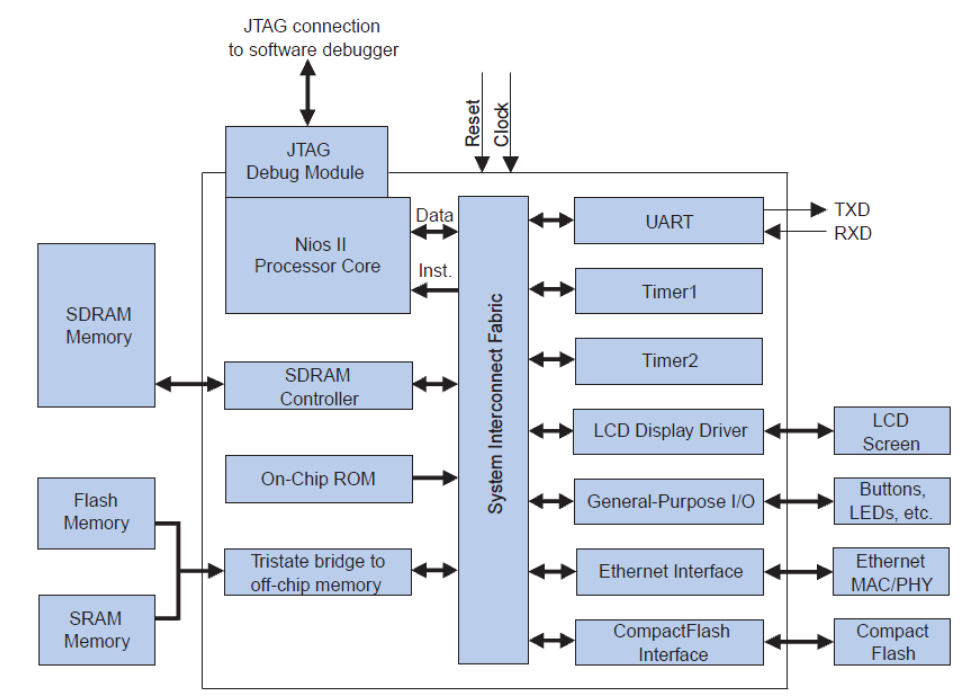

Figura 2.4: Exemplo de um sistema do processador Nios II (Altera, 2011b)

Utilizando a ferramenta EDA (Electronic Design Automation) Quartus II é possível configurar o Nios II em conjunto com as IPs disponibilizadas pela Altera, por meio da interface fornecida Qsys e ou SOPC Builder (ferramentas EDA acopladas ao Quartus II). Além disso, com o Quartus II é possível adicionar e/ou eliminar recursos e periféricos desnecessários do Nios II visando atender especificações do projeto de hardware (Altera, 2011b).

A família do processador soft-core Nios II é composta por três versões de cores: 1) Nios II fast core (Nios II/f) otimizada para oferecer um melhor desempenho, 2) Nios II economy core (Nios II/e) otimizada para prover menor tamanho e quantidade de recursos ocupados no FPGA, e 3) Nios II standard core (Nios II/s) que representa um equilíbrio entre desempenho e tamanho. Embora cada um deles seja otimizado para classes específicas de custo e desempenho, possuem o mesmo conjunto de instruções de 32 bits e código 
binário 100\% compatíveis. A Tabela 2.1 apresenta as principais características dos cores que formam a família de processadores Nios II.

\begin{tabular}{|l|c|c|c|}
\hline Pipeline & $\begin{array}{c}\text { Nios II /f } \\
\text { Fast }\end{array}$ & $\begin{array}{c}\text { Nios II /s } \\
\text { Standard }\end{array}$ & $\begin{array}{c}\text { Nios II /e } \\
\text { Economy }\end{array}$ \\
\hline Multiplicador * & $\mathbf{6}$ Estágios & $\mathbf{5}$ Estágios & Não \\
\hline Branch Prediction & Dinâmico & $\mathbf{3}$ Ciclos & Não \\
\hline Cache de Instrução & Configurável & Configurável & Não \\
\hline Cache de Dados & Configurável & Não & Não \\
\hline
\end{tabular}

*Usa blocos de processador digital de sinal (PDS) nos FPGAs da família Stratix

Tabela 2.1: Cores da família Nios II (Altera, 2007)

De acordo com a Gartner Research ${ }^{1}$, o Nios II é o processador mais versátil do mundo e o soft-core mais utilizado pela indústria de FPGA. Projetado para sistemas embarcados baseados em FPGA, o Nios II substitui o Nios original de 16 bits, oferecendo suporte para vários sistemas operacionais, aplicações de processamento dedicado e suporta todos os atuais FPGAs da Altera. Também está disponível para alguns dispositivos ASICs da Synopsys $^{2}$ (Altera, 2011b).

\subsubsection{Arquitetura do Nios II}

O Nios II possui uma arquitetura RISC em pipeline, um ISA (Instruction Set Architecture) com instruções de 32 bits, um conjunto de 32 registradores de propósito geral, dentre outras características que serão abordadas nessa secção. De forma geral, o ISA serve de fronteira entre o hardware e o software de baixo nível, sendo esta a parte visível do processador ao programador. Contudo, nesse tipo de arquitetura, para implementar as instruções faz-se necessário um conjunto de unidades funcionais (Altera, 2011c), que na arquitetura do Nios II são formadas por:

- Banco de registradores (register file);

- Unidade lógica e aritmética - ULA ;

- Interface para personalização de instruções lógicas;

- Controlador de exceções;

\footnotetext{
${ }^{1}$ www.gartner.com

${ }^{2}$ www.synopsys.com
} 
- Controlador de interrupção interno e/ou externo;

- Barramento de dados e instrução;

- Unidade de gerenciamento de memória - MMU;

- Unidade de proteção de memória - MPU;

- Memória cache de dados e instrução;

- Interfaces de memória fortemente acopladas para instruções e dados;

- Um módulo de debug - JTAG.

A Figura 2.5 representa a união das unidades funcionais que compõe o soft-core Nios II (Altera, 2011c).

As unidades funcionais formam a base para a implementação do conjunto de instruções do Nios II. No entanto, nem todas são implementadas em hardware, uma vez que a arquitetura do Nios II descreve um conjunto de instruções e não uma implementação de hardware em particular. Com isso, a implementação de uma unidade funcional pode ser feita totalmente em hardware, emulada via software, ou ainda omitida por completo (Altera, 2011c).

Logo, o fato deste processador possuir três cores diferentes, proporciona que cada implementação alcance objetivos específicos, tais como menor tamanho do core ou alto desempenho. Esta flexibilidade de implementação proporciona à arquitetura do Nios II adaptar-se a diferentes aplicações alvo (Altera, 2011c).

\subsubsection{Registradores}

A arquitetura do Nios II suporta um banco de registradores de 32 bits, consistindo em registradores de inteiros, de propósito geral e de controle, e esta também permite a adição de registradores de ponto flutuante. A arquitetura suporta dois modos, um supervisor e outro usuário, permitindo ao sistema proteger os registradores de controle de código errôneo de aplicações.

Entretanto, de forma opcional, o Nios II pode ter imagens do conjunto de registradores, sendo cada imagem um conjunto completo dos registradores de propósito geral. Um uso típico de imagem é acelerar a mudança de contexto, pois, quando implementada permite ao Nios II utilizar duas instruções especiais, rdprs e wrprs, para mover dados entre os conjuntos de registradores. De modo geral, as imagens do conjunto de registradores são manipuladas por um kernel de sistema operacional; são transparentes na codificação de aplicações e o processador Nios II pode possuir até 63 imagens do conjunto de registradores (Altera, 2011c). 


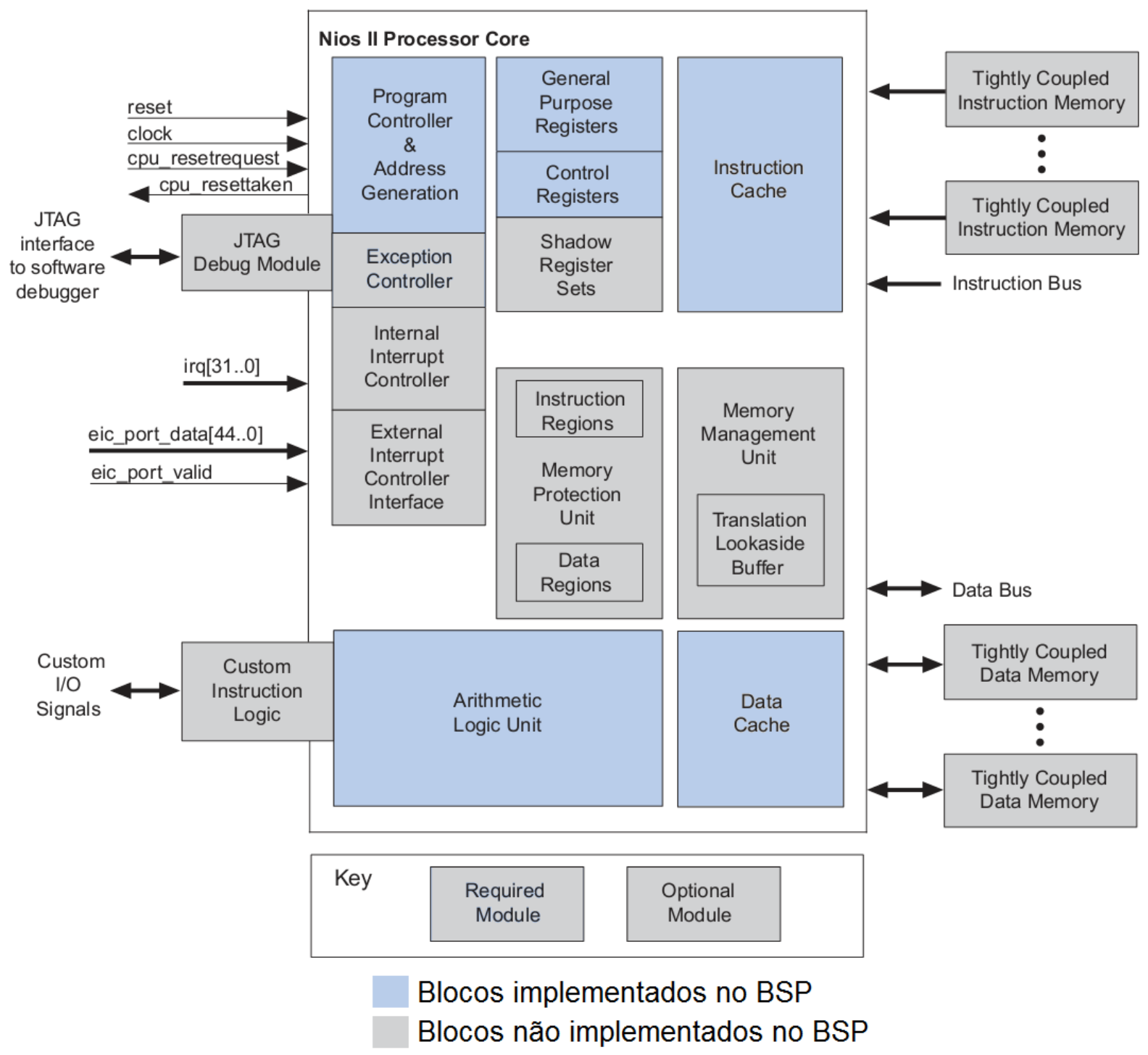

Figura 2.5: Diagrama de bloco do processador Nios II (Altera, 2011c)

\subsubsection{ULA}

A ULA do Nios II realiza operações aritméticas, relacionais, lógica, e de deslocamento e rotação de bits e opera sobre dados armazenados em registradores de propósito geral. Na realização de uma operação, a ULA lê uma ou duas entradas de registradores e armazena o resultado desta em um outro registrador.

Algumas implementações do Nios II não dispõem de hardware necessário para oferecer suporte a todo o conjunto de instrução do Nios II. Nessas implementações, o processador gera uma exceção quando encontra uma instrução não implementada, esta por sua vez é tratada chamando uma rotina para emular a instrução em software.

O Nios II oferece suporte para que o usuário possa definir instruções personalizadas em sua arquitetura. Uma instrução personalizada conecta-se diretamente a ULA do Nios 
II, permitindo-lhe realizar as operações por ela definidas diretamente no hardware, como se fossem instruções nativas da arquitetura. O uso de instruções personalizadas permite reduzir uma sequência de instruções padrão para uma única instrução implementada em hardware. Esse recurso pode ser utilizado para uma variedade de aplicações, como exemplo, otimização na execução de loops, processamento digital de sinal (DSP), computação intensiva, dentre outras. Além disso, o Nios II permite a adição de até 256 instruções personalizadas em um projeto. A Figura 2.6 representa a ligação de uma instrução personalizada à ULA do Nios II.

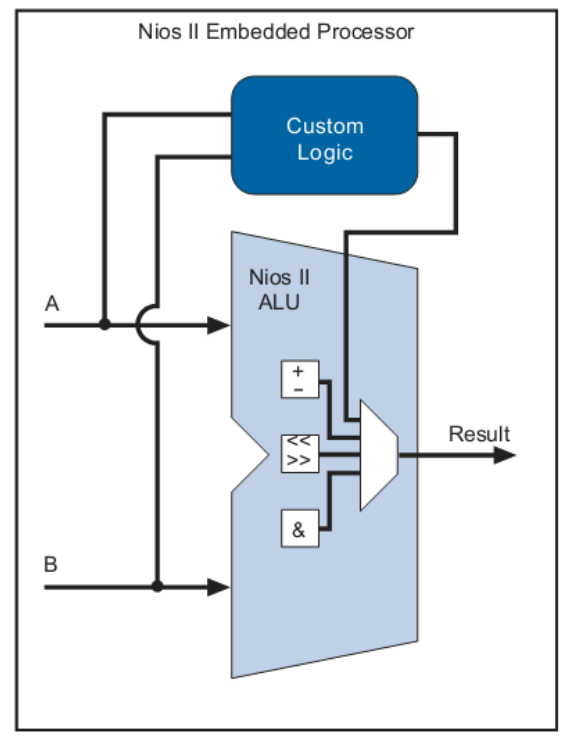

Figura 2.6: Adição de uma instrução customizda(personalizada) a ULA do processador Nios II (Altera, 2011b)

Um exemplo de instrução personalizada é a FPU (Floating Point Unit). A arquitetura do Nios II suporta FPU de precisão simples. Esta por sua vez, incluem as operações de adição, subtração e multiplicação, como um conjunto básico das instruções permitidas. Apesar de não compor esse conjunto, a operação de divisão está disponível como uma extensão para ele.

Quando instruções personalizadas para operações de ponto flutuante estão presentes no core do processador, o compilador do Nios II compila o código a ser executado para usar estas instruções. Caso contrário estas são emuladas em software. Dessa forma, pode-se adicionar instruções de ponto flutuante para qualquer projeto do Nios II. Contudo, a operação de divisão requer mais recursos de hardware do que as outras operações. Todavia, esta operação pode ser omitida em situações que o código em execução no projeto de hardware não a utiliza de forma intensiva. Entretanto, ao omitir a instrução de divisão de ponto flutuante, o compilador do Nios II a implementa em software. As instruções per- 
sonalizadas de ponto flutuante são especificadas pelo padrão IEEE Std 754-1985, inclusive as implementadas em software são 100\% compatíveis com esse padrão (Altera, 2011c).

\subsubsection{Controladores de exceção e interrupção}

O Nios II possui hardware para tratamento de exceções e interrupções. De forma opcional, ele também inclui uma interface para um controlador de interrupção externa (EIC). Esta interface permite acelerar o tratamento de interrupção em um sistema complexo. Isso é proporcionado devido a adição de um controlador de interrupção personalizado. Normalmente, ela é utilizada em conjunto a uma imagem do conjunto de registradores, e quando há necessidade de mais do que as 32 interrupções fornecidas pelo controlador interno de interrupção do Nios II (Altera, 2011c).

O controlador de exceção presente na arquitetura do Nios II, para lidar com todos os tipos de exceção, é do tipo não vetorizado. O que significa dizer que o endereço da rotina que irá executar tem que ser passada no momento em que a exceção foi gerada. Dessa forma, o processador transfere a execução para o endereço da exceção, em que um manipulador de exceção determina a causa da exceção e à trata enviando a rotina a ser executada (Altera, 2011c).

Quando utilizada em um sistema Nios II, a EIC seleciona uma das interrupções ativas e a envia para o processador Nios II com o endereço do manipulador da interrupção e salva as informações do contexto do processador em registradores. O algoritmo de seleção da interrupção é específico para cada implementação de EIC. Tipicamente, ele é baseado em prioridades de interrupção (Altera, 2011c). Todavia, para cada interrupção externa, a EIC apresenta um nível de interrupção. O Nios II utiliza esse nível para determinar quando o serviço será interrompido. Entretanto, qualquer interrupção externa pode ser configurada como non-maskable interrupt - NMI, uma vez que NMIs não são mascaradas por status de bit e não possuem nível de interrupção (Altera, 2011c).

A arquitetura do Nios II suporta até 32 interrupções internas de hardware, sendo que o core do processador possui 32 níveis de detecção de entradas de interrupção (IRQ), proporcionando uma entrada única para cada fonte de interrupção. A arquitetura suporta interrupções aninhadas e a prioridade de cada IRQ é determinada pela aplicação. O software pode habilitar e desabilitar qualquer fonte de interrupção individualmente por meio do registrador de controle ienable e globalmente usando o bit de status PIE do registrador de controle (Altera, 2011c).

Utilizando a ferramenta SOPC Builder é possível adicionar ao Nios II uma instrução personalizada para um vetor de interrupção. Isso acelera o tratamento da interrupção e reduz a latência de interrupção da aplicação. Contudo, a instrução personalizada é menos eficiente do que o uso da interface EIC com o controlador de interrupção vetorizado da 
Altera. Por sua vez, o uso dessa instrução é obsoleto no Qsys, e a Altera recomenda o uso da interface EIC (Altera, 2011c). A Figura 2.7 ilustra o hardware para controle interrupção do Nios II.

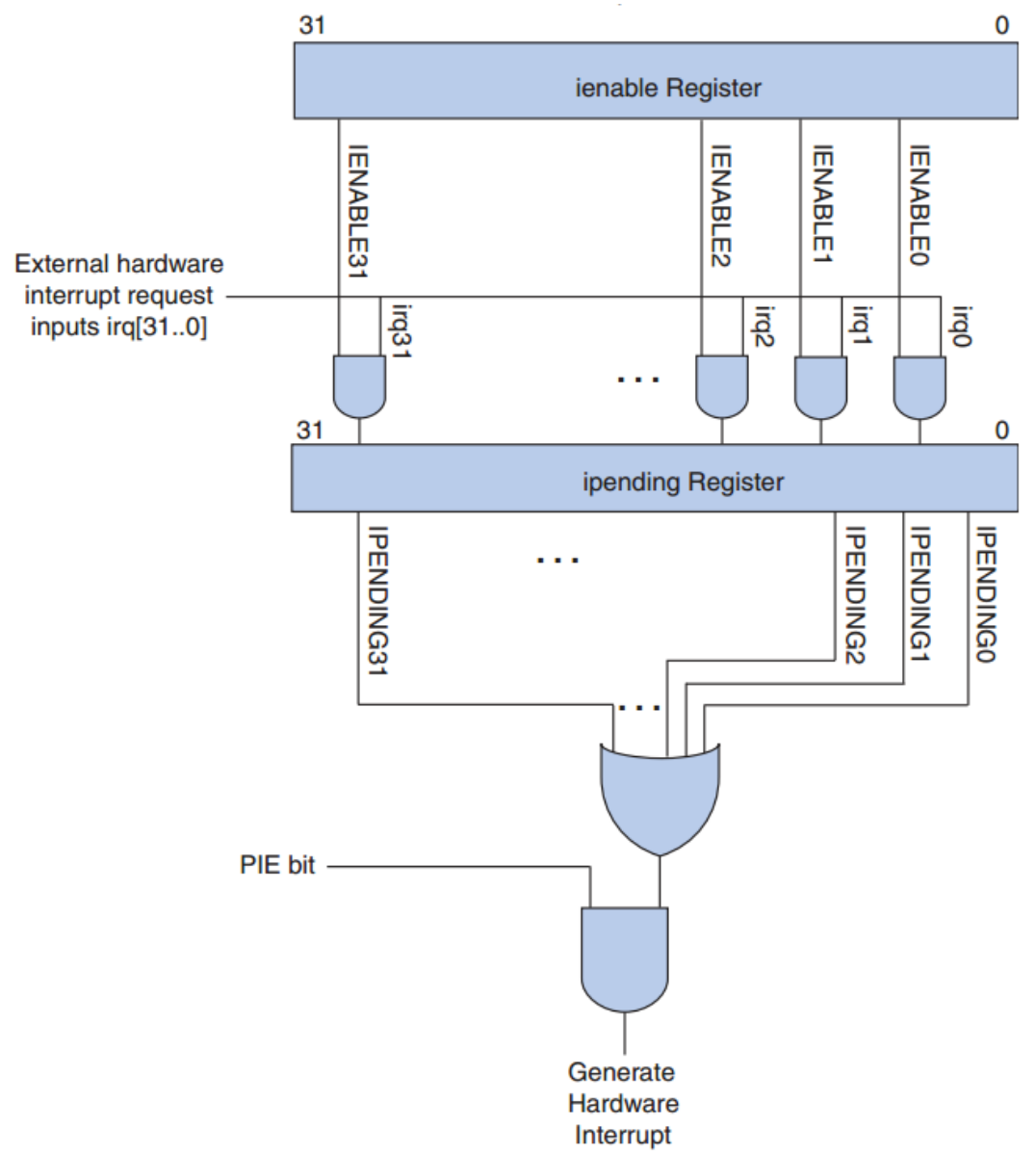

Figura 2.7: Hardware para controle de interrupção do Nios II (Altera, 2011b)

\subsubsection{Barramentos}

O Avalon é o barramento de comunicação padrão dos dispositivos da Altera, e este possui uma arquitetura simples, projetada para conectar o processador Nios II e periféricos em um SOPC. Ele também é responsável por especificar as conexões entre componentes mestres e escravos, e o tempo de comunicação entre os componentes.

De forma independente, a arquitetura do Nios II suporta um barramento para dados e outro para instruções, classificando-a como uma arquitetura Harvard. Esses barramentos são implementados como portas Avalon-MM mestre de 32 bits e seguem a especificação de interface dessas portas. A porta mestre de dados prover conexão com componentes da memória e periféricos, enquanto que a porta mestre de instrução apenas com os componentes da memória. 
No barramento de instrução, a porta mestre é responsável apenas por buscar as instruções a serem executadas pelo processador. Ela funciona como um pipeline, com o objetivo de reduzir o impacto de sincronização da memória com a latência do pipeline. Com isso, o Nios II pode realizar prefetch nas instruções sequenciais e previsão de desvios para manter o pipe de instrução o mais ativo possível.

Enquanto que, no barramento de dados, a porta mestre de dados é responsável por ler ou escrever dados na memória principal do sistema ou de um periférico quando o processador executa uma instrução de load ou store, respectivamente. Contudo, sinais enviados à porta mestre de dados habilitam bytes que especificam qual dos quatro caminhos de bytes será utilizado durante a instrução de escrita. Além disso, quando o core do Nios II é configurado com um tamanho de linha da cache de dados superior a quatro bytes, a porta de dados mestre suporta um pipeline para transferências de dados. Entretanto, quando o tamanho da linha de cache é de apenas quatro bytes, qualquer latência entre o pipeline e a memória é percebida pela porta mestre de dados como estados de espera.

Logo, as interfaces do barramento Avalon simplificam o projeto do sistema, permitindo de forma simples a conexão dos componentes em um FPGA da Altera. Além disso, o Avalon dispõe de interfaces apropriadas para transmissão de dados em alta velocidade, leitura e escrita na memória e em registradores, controle de dispositivos off-chip. A utilização dessas interfaces aumenta a interoperabilidade de projetos.

\subsubsection{Memória e Organização dos dispositivos de I/O}

A arquitetura do Nios II abstrai os detalhes de hardware para o programador, de modo que ele possa desenvolver aplicações para o Nios II sem o conhecimento específico da implementação de hardware. Dessa forma, em razão da natureza configurável da memória e organização dos dispositivos de I/O do Nios II, surge uma notável diferença entre os sistemas do processador Nios II e os microcontroladores tradicionais. Uma vez que os sistemas do Nios II são configuráveis, estas características variam de um sistema para outro. A Figura 2.8 representa a estrutura da memória e a organização do dispositivos de I/O do processador Nios II.

Além disso, o core do Nios II pode comunicar-se com a memória ou com um dispositivo de I/O por meio de uma Avalon Memory-Mapped(Avalon-MM), que é uma porta de instrução principal que conecta as instruções à memória por meio de: 1) uma estrutura de interconexão do sistema. 2) ou ainda, por meio da cache de instrução, 3) ou através de uma porta de dados principal que conecta dados da memória e periféricos através de uma estrutura de interconexão do sistema, 4) ou ainda por meio de uma instrução fortemente acoplada ou uma porta de dados de memória, que serve de interface entre a memória on-chip e a memória fora do core do Nios II. 


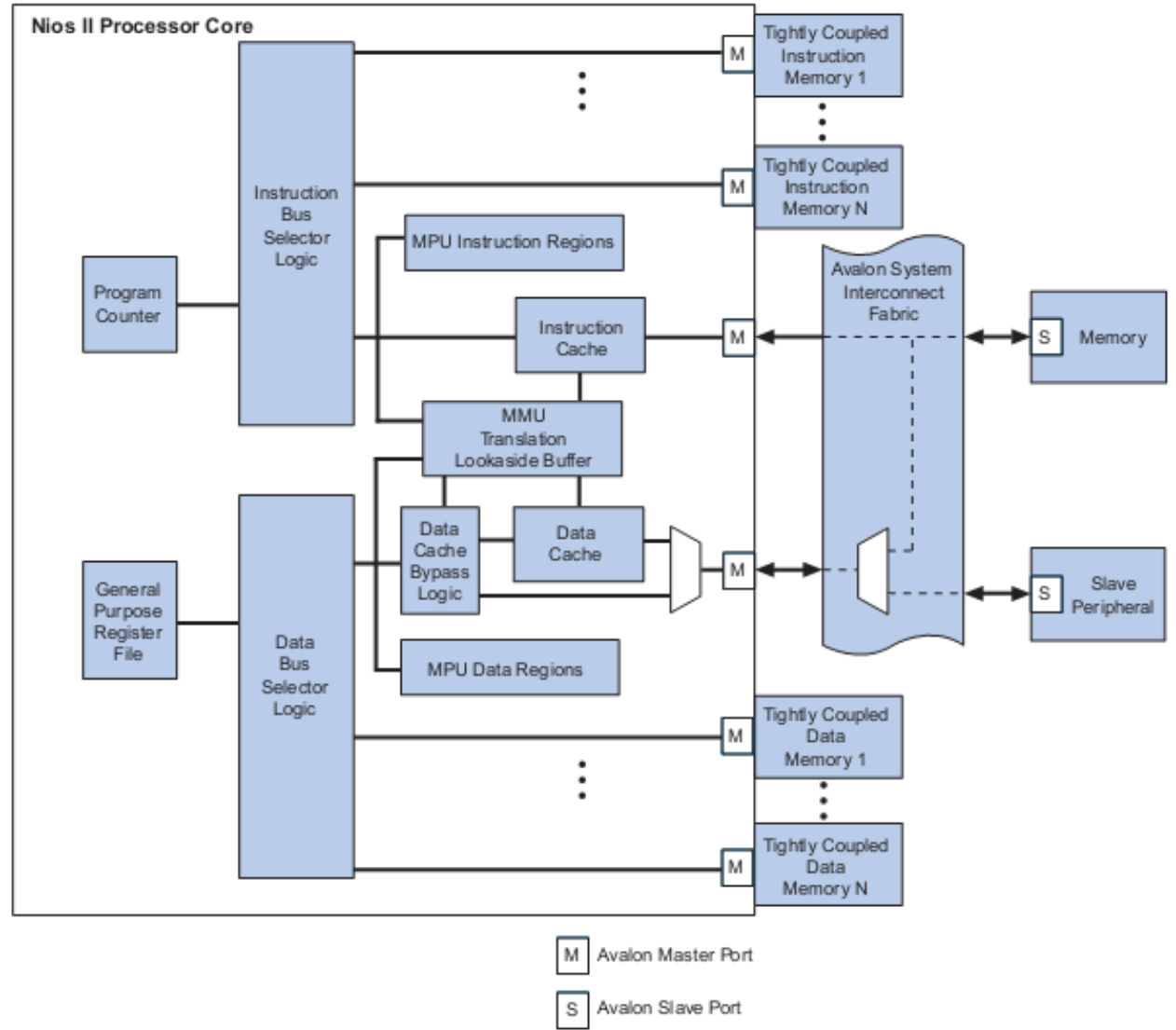

Figura 2.8: Estrutura da memória e organização dos dispositivos de I/O do Nios II. (Altera, 2011c)

Ademais, a arquitetura do Nios II fornece acesso aos dispositivos de I/O mapeado em memória. Sendo assim, tanto a memória de dados, quanto os periféricos são mapeados no espaço de endereço da porta mestre de dados. Para representar os dados na memória o Nios II utiliza a ordenação little-endian, ou seja, os bytes mais significativos de uma palavra são armazenados na memória nos endereços de numeração mais elevada.

Contudo, a arquitetura não especifica nada sobre a existência de memória e periféricos, bem como a quantidade, o tipo, ou a conexão de memória e periféricos, sendo esta dependente do sistema. Normalmente, os sistemas do processador Nios II contêm uma mistura de memórias on-chip e off-chip. Já os periféricos residem de forma on-chip, apesar de existirem interfaces para acesso a periféricos off-chip.

Normalmente, portas mestre de instruções e dados compartilham uma única memória que armazena dados e instruções. Porém, o core do processador possui barramentos separando instruções dos dados. Contudo, um sistema Nios II pode apresentar um único barramento, compartilhando dados/instruções com o mundo exterior. Segundo Altera (2011c) portas mestre de instruções e dados não geram condição de travamento, na qual uma porta espera pela outra. Entretanto, para melhor desempenho, pode-se especificar 
uma prioridade arbitrária para uma porta mestre de dados numa memória que é compartilhada para instruções e dados.

Presentes na arquitetura do Nios II, as memórias fortemente acopladas fornecem acesso à memória com baixa latência, garantindo um melhor desempenho de aplicações críticas. Se comparadas com a memória cache, elas provêm um desempenho semelhante, podendo armazenar programas que exigem um desempenho crítico ou dados.

De forma semelhante a uma porta mestre de instrução ou de dados, fisicamente, uma porta de memória firmemente acoplada é separada do core do Nios II. Este por sua vez, pode possuir nenhuma ou várias memórias fortemente acopladas para acesso a dados ou instruções. Sendo que cada porta de memória acoplada conecta-se diretamente a uma memória externa ao core do Nios II localizada on-chip.

Todavia, uma aplicação de software tem acesso a uma memória fortemente acoplada por meio das instruções load e store. Do ponto de vista do software, não há diferença no acesso a uma memória firmemente acoplado em comparação com outra memória, pois elas ocupam espaço de endereço normal (o mesmo que outros dispositivos de memória interligados do sistema). Também, as faixas de endereço das memórias fortemente acopladas são determinadas no momento da geração do sistema.

O mapa de endereço para as memórias e periféricos em um sistema do processador Nios II é dependente do projeto, visto que ele pode ser especificado na concepção do projeto utilizando o Qsys ou o SOPC Builder. Além disso, o fato de possuir um mapa de endereço flexível, isto não afeta os desenvolvedores de aplicativos, pois o acesso à memória e a periféricos feito por eles é realizado com o uso de macros e drivers.

Em um projeto de hardware do processador Nios II, pode-se incluir, de forma opcional, uma Unidade de Gerenciamento de Memória - MMU. Quando presente, a MMU está sempre ativa, e as caches de instrução e de dados são virtualmente indexadas e fisicamente elas são marcadas. A MMU do Nios II permite a configuração de alguns parâmetros, permitindo-lhe ser otimizada para as necessidades do seu sistema alvo. Além disso, ela oferece os seguintes recursos e funcionalidades:

- Mapeamento de endereços virtuais em endereços físicos;

- Proteção da Memória;

- Permissão de leitura, escrita e execução controladas por página;

- Endereços físicos e virtuais de 32 bits, mapeamento de até 4 GB de memória física em endereços virtuais;

- 4 KB de tamanho de página; 
- Espaço de endereço físico abaixo de 512 MB disponível para acesso direto;

- Hardware para acelerar a tradução de endereços - Translation Lookaside Buffer(TLB).

De forma similar a MMU, pode-se incluir uma Unidade de Proteção de Memória (MPU) em um projeto de hardware do Nios II no momento de instanciação do processador. Ela permite a configuração de alguns parâmetros visando otimizá-la para atender as necessidades do sistema alvo, e quando presente no processador está sempre habilitada. Contudo, a MMU e a MPU do Nios II são mutuamente excludentes; ou seja, os sistemas podem incluir tanto uma MMU ou uma MPU, mas não ambas num mesmo core do Nios II.

\subsubsection{Memórias Cache}

A arquitetura do Nios II suporta de modo independente memória cache para dados e instrução. Ela por sua vez, é parte integrante do core do Nios II. O fato de serem on-chip, as memórias cache do Nios II provêm uma melhora significativa no tempo médio de acesso a uma memória off-chip, como uma SDRAM por exemplo. Esta normalmente é utilizada nos sistemas do Nios II para armazenamento de programas e dados (Altera, 2011c).

As caches de instrução e dados são habilitadas de forma permanente em tempo de execução. Porém, para os dispositivos que não acessam dados retornados pela cache são disponibilizados métodos para ignorar esses dados, assim como o gerenciamento e a coerência de cache são tratados via software. Contudo, o conjunto de instruções do Nios II contém instruções para a gestão da cache.

Em um sistema Nios II as memórias cache são opcionais. Nesse tipo de sistema a sua utilização está condicionada a aplicação alvo, ao tamanho do core requerido e ao desempenho. O core do Nios II pode incluir uma, ou nenhuma das memórias cache disponíveis, uma vez que a cache não afeta a funcionalidade do programa. Porém, ela impacta na velocidade com que o processador busca instruções, lê e escreve dados. Entretanto, para os cores que dispõem de cache de dados e instrução, o tamanho destas são configuráveis pelo usuário (Altera, 2011c). A Tabela 2.2 apresenta os valores para as caches de dados e instruções do Nios II, que podem ser configuradas pelo usuário.

\subsubsection{Módulo JTAG}

A arquitetura do Nios II suporta um módulo de depuração - JTAG, este oferece a emulação de recursos on-chip para controlar o processador remotamente de um computador convencional (host PC). Com o uso de ferramentas de depuração de software utilizadas nos PCs comunicando com o módulo JTAG é possível fazer o download de programas para a memória do projeto de hardware, iniciar e/ou parar a execução de uma aplicação, 
Tabela 2.2: Possíveis configurações de cache do Nios II

\begin{tabular}{|c|c|c|}
\hline Cache de dados & Cache de instruções & Tamanho da linha cache de dados \\
\hline 512 Bytes & 512 Bytes & 4 Bytes \\
\hline 1 Kbyte & 1 Kbyte & 16 Bytes \\
\hline 2 Kbytes & 2 Kbytes & 32 Bytes \\
\hline 4 Kbytes & 4 Kbytes & - \\
\hline 8 Kbytes & 8 Kbytes & - \\
\hline 16 Kbytes & 16 Kbytes & - \\
\hline 32 Kbytes & 32 Kbytes & - \\
\hline 64 Kbytes & 64 Kbytes & - \\
\hline
\end{tabular}

definir pontos de interrupção, coletar e rastrear dados em tempo de execução e analisar registradores e memória.

O módulo de depuração liga-se ao circuito JTAG presente na FPGA da Altera. Por meio dessa ligação, é possível para o software de debug (depuração) acessar o processador. No lado do processador, o módulo de depuração conecta-se aos sinais no interior do core do processador, passando a ter controle de forma nonmaskable sobre o processador, e este controle não requer que o software de debug (depuração) esteja ligado a uma aplicação teste.

Não obstante, o módulo de depuração obtém o controle do processador na ocorrência de um sinal de pausa emitido pelo hardware ou por uma instrução de pausa escrita no programa em execução na memória. Em ambos os casos, o processador transfere a execução para a rotina localizada no endereço da interrupção de depuração, e esse endereço é especificado no editor de parâmetros (Qsys e/ou SOPC Builder) do Nios II. Ademais, todos os recursos do sistema visíveis ao processador em modo supervisor ficam disponíveis para o módulo de depuração.

Além disso, a interface JTAG presente no FPGA da Altera é responsável por transferir o bitstream (dados de configuração do FPGA) para o FPGA e por conectar o processador soft-core aos pinos do FPGA. Isto proporciona capacidades básicas, tais como iniciar e/ou parar o processador, examinar registradores, memória e etc.

\subsection{Electronic System Level (ESL)}

O avanço contínuo da capacidade dos circuitos integrados e a necessidade de sistemas embarcados cada vez mais complexos para atender as necessidades de mercado e solucionar os problemas atuais, estão direcionando o desenvolvimento de sistemas digitais para ambientes de alto nível de abstração, cada vez mais distantes dos detalhes de hardware (Shukla et al., 2006) (Coussy e Morawiec, 2008) (Coussy et al., 2009). Inicialmente, os sistemas 
eram projetados a nível de portas lógicas (Gates), mais adiante a nível de registradores - RTL (Register Transfer Level) e, atualmente, os projetos tem sido direcionados para o desenvolvimento em ESL, tornando-se cada vez mais comum a utilização desse paradigma no desenvolvimento de sistemas. Esse paradigma também é referenciado na literatura como SLD (System Level Design) (Densmore et al., 2006) (Martin et al., 2007) (Patel e Shukla, 2008).

ESL é geralmente entendida como um conjunto de ferramentas, metodologias e técnicas aplicadas na concepção de projetos de sistemas eletrônicos modernos, sistemas de hardware e software integrados, dentre outros (Rigo et al., 2011). Um dos princípios importantes na especificação de um projeto em ESL é a necessidade de uma análise inicial, ou seja, verificação funcional, análise de desempenho e consumo de energia, antes de diminuir os níveis de abstração do projeto que visam a síntese e otimização. Essa análise inicial é feita através da modelagem de alto nível e da simulação do projeto (Rigo et al., 2011). A Figura 2.9 ilustra o fluxo de modelagem em ESL.

Ademais, sistemas complexos que envolvem diferentes tipos de componentes, tais como: processadores, blocos de IP customizados e software; a simulação de tais sistemas em um baixo nível de representação, em RTL por exemplo, pode ser uma tarefa custosa ou em alguns casos inviável (Rigo et al., 2011).

Por outro lado, uma descrição em alto nível é mais simples de escrever, entender, otimizar e depurar do que os modelos de baixo nível. Além disso, a simulação de um projeto descrito em alto nível é significativamente mais rápida. Quanto mais o projeto pode ser aperfeiçoado, otimizado e verificado em um alto nível de abstração, maior é a sua produtividade, qualidade e consequentemente menor custo (Rigo et al., 2011). No entanto, modelos de alto nível e seus ambientes de desenvolvimento, confrontados com os grandes desafios de complexidade dos sistemas embarcados modernos, possuem suas próprias dificuldades. Além disso, não é uma tarefa simples escrever um modelo de alto nível, com um nível de abstração apropriado que resulte no melhor limiar entre os detalhes arquitetônicos e velocidade de simulação (Gerstlauer et al., 2009) (Rigo et al., 2011).

Contudo, têm-se procurado estabelecer diferentes níveis de abstração de acordo com os tipos de análise que pretende-se fazer no projeto, pois um nível de abstração pode ser mais adequado que outro. Isso aumenta a complexidade do modelo, e no pior dos casos, se vários modelos precisam ser desenvolvidos, pode-se começar a reduzir a vantagem de produtividade provida por uma metodologia de modelagem em alto nível (Rigo et al., 2011).

Segundo Drechsler (2004), o ESL apresenta diversas vantagens em relação ao RTL por facilitar o co-projeto de hardware e software, proporcionar maior velocidade na simulação e permitir o teste e o ajuste da arquitetura do sistema em alto nível. Além disso, permite 


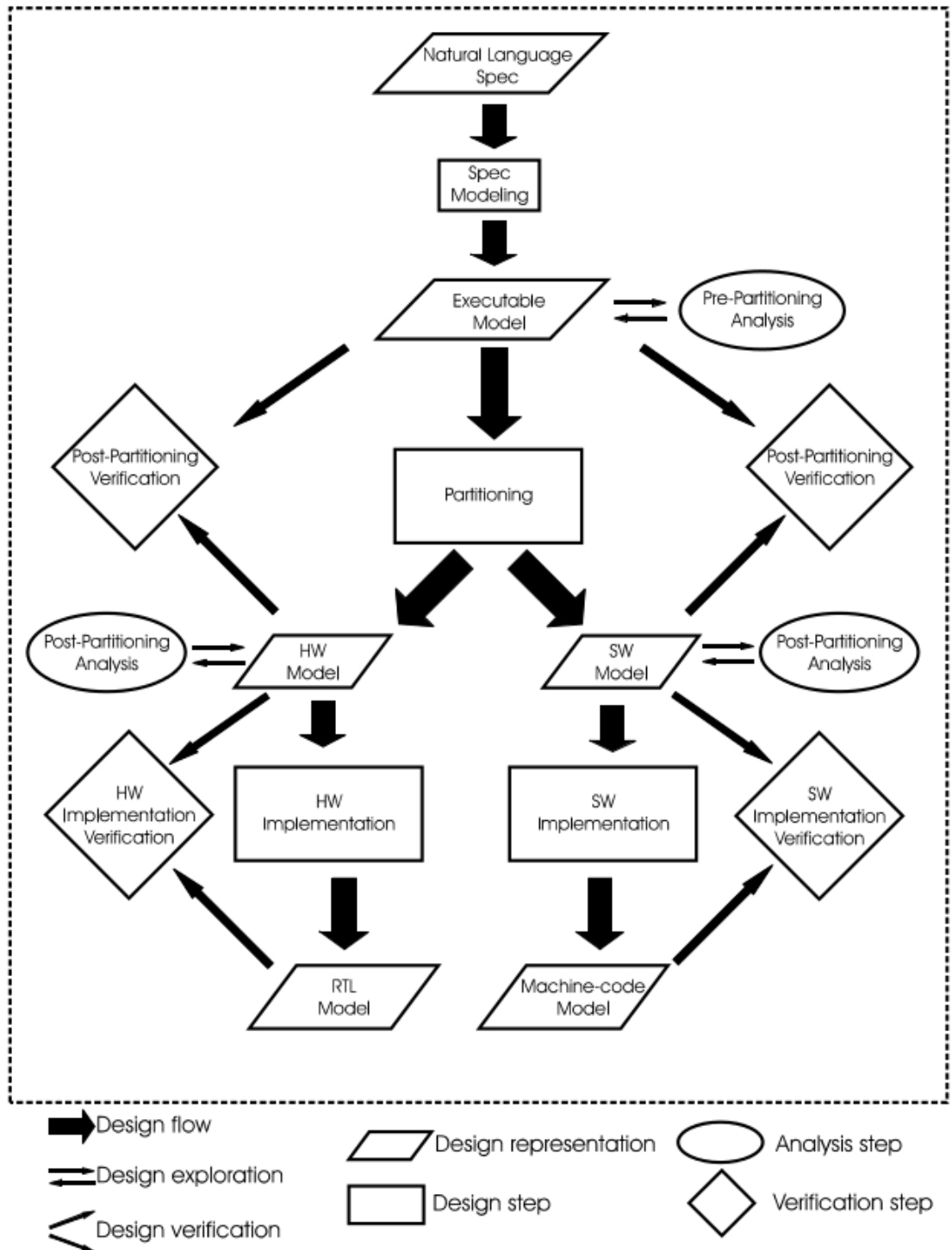

Figura 2.9: Fluxo de modelagem em ESL (Rigo et al., 2011)

o reuso de testbenchs tanto na fase de validação do modelo em nível ESL como no teste da arquitetura do sistema em nível RTL, tornando-se assim um modelo único de referência para todos os níveis (golden reference model).

De acordo com Sangiovanni-Vincentelli (2007), ESL é considerado por muitos como a nova fronteira para as tecnologias EDA (Electronic Design Automation) e, conforme apresentado por Martin e Smith (2009), ao longo dos anos as ferramentas, principalmente os compiladores, evoluíram significativamente ao ponto de atualmente o ESL estar presente no uso de desenvolvimento de circuitos integrados de muitas empresas de grande porte (Nikhil, 2011).

Há diversas linguagens para a modelagem de hardware em ESL, sendo várias delas baseadas na linguagem $C$. Essas linguagens incorporam novos recursos, tais como, 
estruturas de dados, instruções dedicadas à exploração de paralelismo, mecanismos de sincronização e interfaces para comunicação com módulos externos de hardware/software. Essa abordagem tem sido bem sucedida, principalmente para representar e simular o comportamento funcional do hardware em alto nível (Sangiovanni-Vincentelli, 2007).

Em Wain et al. (2006), são listadas diversas linguagens associadas ao $C$, destacando-se o SystemC (Black e Donovan, 2005), como linguagem já estabelecida e amplamente utilizada pelos projetistas. Outras abordagens buscam sintetizar programas escritos em ANSI C diretamente para RTL, como exemplo, o PICO Express da Synfora e o Catapult C Synthesis da Mentor Graphics (Coussy e Morawiec, 2008).

As linguagens oriundas do $C$ são vistas como soluções que foram geradas no sentido top-down. Entretanto, no sentido inverso, o bottom-up, pode-se destacar o SystemVerilog (Sutherland et al., 2006), que é uma extensão da linguagem Verilog. Além de incorporar novos recursos, como programação orientada a objetos, threads dinâmicas e comunicação entre processos, o SystemVerilog também possui recursos avançados para a verificação formal de hardware (Spear, 2008).

O SystemVerilog tem servido de base para outras linguagens ESL, como o Bluespec SystemVerilog (BSV) (Bluespec, 2011) (Nikhil, 2011). O Bluespec tem recebido uma atenção considerável tanto do meio acadêmico como de empresas (Nikhil, 2011) (Bacon et al., 2013), pois possui recursos que permitem controlar a arquitetura de um modo mais transparente do que as linguagens estendidas do $C$ por meio de um esquema denominado transações atômicas, gerando assim arquiteturas confiáveis e eficientes (Gruian e Westmijze, 2008) (Agarwal et al., 2009). Outro ponto forte do Bluespec é que esta é uma linguagem totalmente sintetizável para RTL (Bluespec, 2011) (Nikhil, 2011).

Segundo Bacon et al. (2013), apesar das vantagens oferecidas pela FPGA e seu rápido crescimento, o uso da tecnologia é restringido a um pequeno segmento de programadores de hardware, em virtude da lenta evolução das HDLs. Nesse sentido, há uma grande necessidade de melhorar o aspecto de programação para os FPGAs, pois, no ciclo de projeto uma significativa fatia de tempo é gasta com codificação e verificação.

Nesse contexto, ESL e HLS apresentam um futuro promissor para a melhoria das práticas de programação para o FPGA, porque conseguem aumentar o nível de abstração do projeto, reduzindo o tempo de verificação; parte importante no projeto de hardware que é realizada através de simulações. Em SoCs modernos, o hardware é grande e complexo, e funciona com cargas pesadas de software, tais como sistemas operacionais com todos os recursos e aplicações, sendo o FPGA frequentemente utilizado como plataforma de prototipagem para estes SoCs (Nikhil, 2011) (Bacon et al., 2013). 


\subsubsection{Bluespec}

Ao olhar a história da engenharia de software, pode-se observar um contínuo desenvolvimento de mecanismos para lidar com a crescente complexidade dos projetos. No entanto, para projetos de hardware, esse desenvolvimento não foi tão expressivo. As duas HDLs mais utilizadas, Verilog e VHDL, se comparadas com a evolução das linguagens de programação modernas, elas ficam muito atrás em termos de abstrações estruturais, tipos de dados, encapsulamento, parametrização e reuso de código, até mesmo suas descendentes, SystemVerilog e SystemC, sofrem de tais limitações, e além disso não são totalmente sintetizáveis (Nikhil, 2011).

A arquitetura (descrição) de um projeto de hardware é um de (ou dos) muitos aspectos importantes na produção do mesmo. Ela impacta na área de silício ocupada, consumo de energia, desempenho, dentre outras características. Dessa forma, é de fundamental importância criar, analisar e explorar a arquitetura de forma rápida e eficiente. Com o passar do tempo os projetos tornaram-se demasiadamente grandes e complexos para metodologias tradicionais. E uma vez elevando o nível de abstração e verificação do projeto, testes, otimizações e a validação do mesmo podem ser realizadas de forma mais rápida, eficiente, e com custo reduzido do que em RTL, por exemplo (Bluespec, 2011) (Graphics, 2014).

Segundo Bluespec (2011), as ferramentas que utilizam RTL (Register Transfer Level) para descrever a arquitetura de hardware são muito inseguras, tornando difícil realizar alguma alteração na arquitetura, em alguns casos não sendo possível implementar (sintetizar) a arquitetura especificada no modelo original. Ainda assim, os projetos ficam presos a uma arquitetura inicial em razão da dificuldade de realizar alterações, e esta implicação ocorre antes mesmo que o projetista possa avaliar devidamente o projeto.

Com o propósito de acelerar cada vez mais o ciclo de desenvolvimento de projetos de hardware, a indústria tem voltado seu olhar para linguagens de descrição de hardware com abstrações e síntese em alto nível, e Bluespec é uma dessas linguagens (Dave, 2005).

BSV (Bluespec SystemVerilog), é uma HDL que reutiliza os recursos de SystemVerilog. Suas extensões estruturais, que envolvem tipos mais expressivos, sobrecarga, encapsulamento e parametrização são inspirados por Haskell (Jones, 2014), uma linguagem de programação funcional. Sua semântica comportamental é inspirada em ações atômicas "vigiadas", que são mais adequadas para descrição de hardware complexo (Nikhil, 2011).

BSV é uma linguagem de descrição e síntese de hardware fortemente tipada, que fornece assim como $\mathrm{C}++/$ Java, níveis de abstração com uma semântica simples deixando mais simples a descrição da arquitetura. Utilizando Bluespec o projetista detém a previsibilidade e o controle da arquitetura, proporcionando-o gerar uma implementação de qualidade e 100\% sintetizável (Bluespec, 2011). Bluespec oferece um ambiente para pro- 
jetar, verificar e implementar uma arquitetura com abstração em alto nível e síntese em RTL, como ilustrado na Figura 2.10.

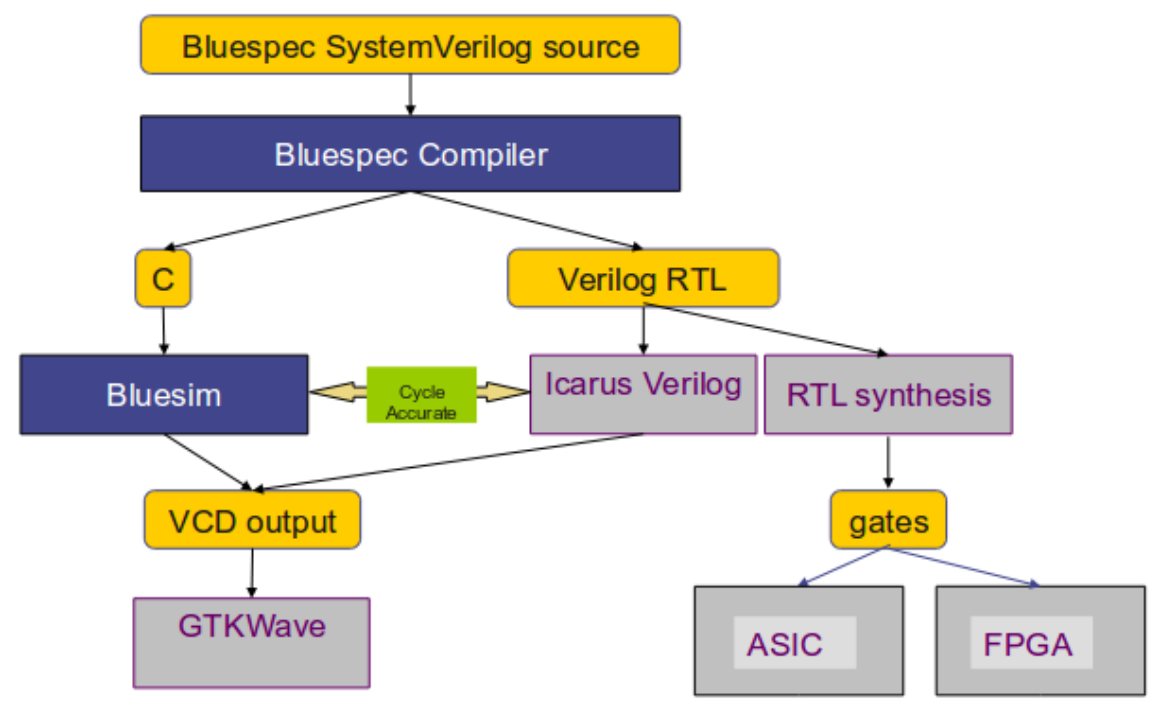

Figura 2.10: Fluxo de compilação bluespec (Stump e Harper, 2011)

Apesar de ser uma HDL relativamente nova, Bluespec parece ter capturado o interesse da indústria e da academia, e isso vem sendo demonstrado nos projetos escritos em BSV, como por exemplo, o processador descrito por Dave (2005), o processador para execução de código Java o BlueJEP (Gruian e Westmijze, 2010). Além desses exemplos, a Bluespec Inc., usou BSV para criar um modelo de comunicação altamente parametrizado para depuração e bibliotecas IP para placas FPGA. Estes mecanismos formam uma espécie de sistema operacional para FPGAs, possibilitando ao usuário dispor de recursos de alto nível para a comunicação com um host e depuração de um modelo ou projeto, em vez da habitual dificuldade com o hardware na placa de FPGA (Bluespec, 2014) (Nikhil, 2011).

De acordo com Bacon et al. (2013), BSV é uma linguagem notável, uma vez que ela incorpora conceitos como módulos, instâncias de módulo e hierarquias de módulo, como Verilog e VHDL, e segue o modelo de interfaces de comunicação entre os módulos do SystemVerilog.

Segundo Bluespec (2011), BSV diferencia-se das abordagens para síntese em alto nível baseadas na linguagem de programação $C$, pois, utiliza uma tecnologia altamente eficaz para simultaneidade na abstração de hardware, e as chamadas transações atômicas. Apesar do compilador Bluespec tentar executar o máximo de instruções (paralelismo de instrução) possíveis em um ciclo de clock, todas elas serão executadas de forma atômica. 
Bluespec permite a rápida criação, avaliação e exploração de arquiteturas. Ao contrário de outras ferramentas de modelagem, Bluespec permite ao projetista expressar a arquitetura diretamente. Com isso, o projetista possui $100 \%$ de controle da arquitetura, podendo refiná-la, eliminando surpresas, visando garantir uma arquitetura de qualidade (Bluespec, 2011).

Outro fator a ser levado em consideração, é o consumo de energia. Para projetos de granularidade fina, clocks em BSV podem ser habilitados e desabilitados com condições de propagação dentro das condições de uma regra, por exemplo. Em blocos de IP mais complexos, BSV prover facilidades para o gerenciamento de energia, de forma a desligar clocks ou escalar a potência de módulos inteiros ou subsistemas de uma forma gerenciada (Nikhil, 2011).

Finalmente, a ferramenta Bluespec forneceu os recursos necessários para implementação do processador open source baseado na arquitetura do Nios II da Altera. Além disso, Bluespec foi escolhida para este projeto, por permitir simulação funcional em ESL com o simulador Bluesim (simulação com precisão de ciclos) que simula diversas vezes mais rápido que a simulação em RTL, por ser totalmente sintetizável, e por ter um compilador capaz de gerar hardware considerado eficiente (Gruian e Westmijze, 2008) (Agarwal et al., 2009) (Nikhil, 2011). Ademais, Bluespec possui licença gratuita para as universidades.

\subsubsection{Módulos - Interfaces - Métodos}

BSV não possui pinos de input e output como Verilog e VHDL. Sinais são movidos para dentro e para fora dos módulos através de métodos. Estes métodos são agrupados em interfaces e módulos que formam o coração do BSV, possibilitando a criação do hardware. Um módulo consiste em três coisas: estado, regras que operam naquele estado, e uma interface com o mundo exterior (Bluespec, 2011). O trecho de código a seguir exemplifica um módulo em BSV.

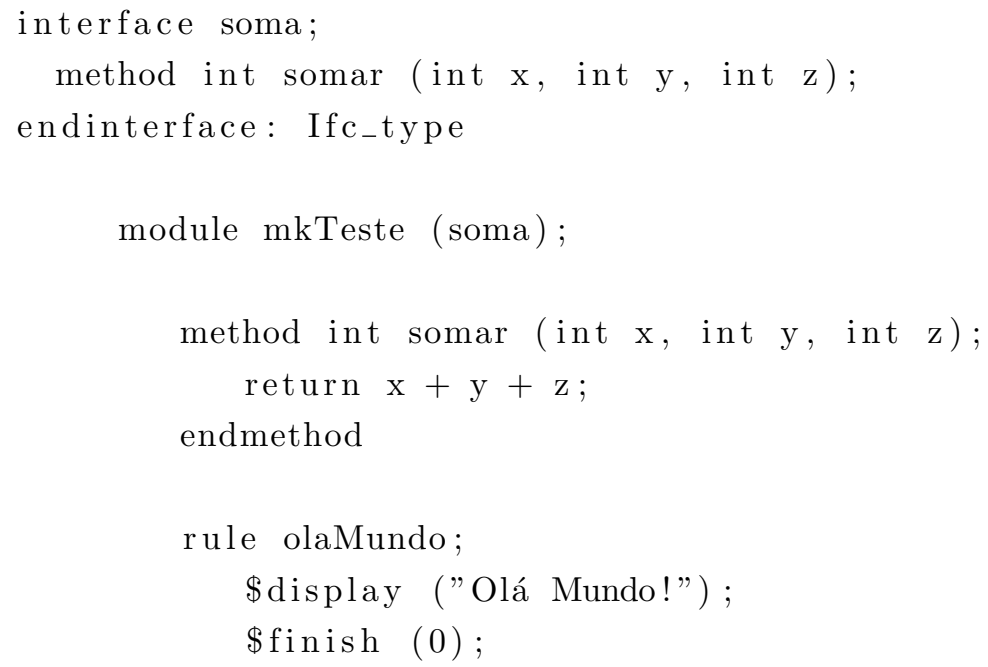




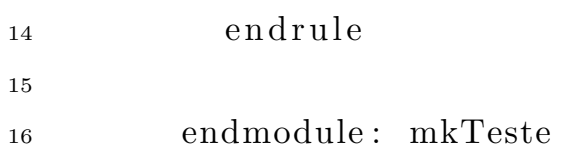

As linhas 1 a 3 do código correspondem a declaração da interface soma que contêm a declaração do método somar, linha 2. As linhas 5 a 16 correspondem a definição do módulo que contém a implementação do método somar que recebe como entrada três inteiros e retorna a soma deles, linhas 7 a 9 . As linhas 11 a 14 correspondem a regra olaMundo que imprime(\$display) a frase "Olá Mundo" e encerra $(\$ f i n i s h(0))$ a execução do módulo.

Módulos podem possuir vários métodos para alterar o estado do módulo ou de outros módulos. Assim como SystemVerilog, BSV separa a declaração de uma interface da definição de um módulo. Isso permite definir interfaces comuns que podem ser utilizadas por vários módulos, sem exigir a repetição da declaração em cada um dos módulos. Todos os módulos que compartilham uma interface comum têm os mesmos métodos, e, portanto, o mesmo número e tipos de entradas e saídas (Bluespec, 2011).

Uma interface pode ser definida como o mecanismo de comunicação do módulo, abstraindo o conceito de uma classe virtual $C++$. Uma interface apenas descreve os métodos externamente visíveis de um módulo. O trecho de código a seguir ilustra a declaração de uma interface em BSV:

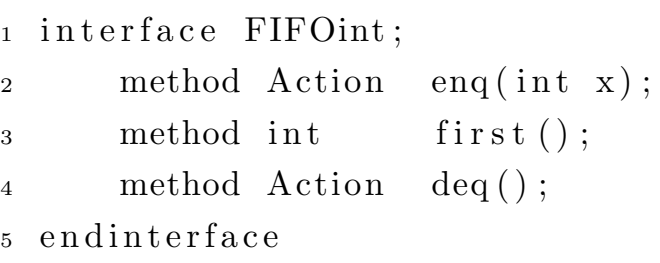

De forma análoga, um método pode ser entendido como uma função, ou seja, ele pode receber zero ou mais argumentos e retorna um resultado. BSV classifica métodos em três tipos:

- Value Methods: são métodos que retornam um valor para o chamador, e não têm ações, ou seja, quando chamados, não há mudança de estado.

- Action Methods: são métodos que ao serem executados causam ações de mudanças de estado.

- ActionValue Methods: são métodos que podem ser definidos como uma fusão dos outros dois tipos, e quando chamados causam uma mudança de estado e retornam um valor para o chamador. 
Declarações de métodos em interfaces são semelhantes com protótipos de função, a única diferença é o uso da palavra-chave method, em vez de function. Quando traduzido em RTL, cada método torna-se um "feixe" de fios. A definição de como um método é implementado está contida na definição da interface com o módulo e pode ser diferente em cada módulo, onde uma interface comum é utilizada. No entanto, os fios que compõem a interface, ou seja, os inputs, outputs e inouts, e os métodos definidos, serão os mesmos em todas as instâncias (Bluespec, 2011). O trecho de código a seguir ilustra a definição de um método em BSV:

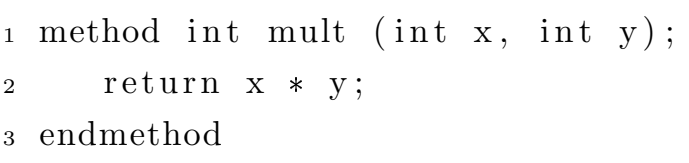

\subsubsection{Regras}

Em Bluespec, o comportamento de um módulo é expresso por meio de ações atômicas guardadas, chamadas de regras (rules), que são basicamente FSMs (Finite State Machines) executando em paralelo; um conceito bem conhecido para os programadores de hardware (Nikhil, 2011) (Bacon et al., 2013). BSV nasce de uma descrição direta do hardware - estados e transição paralela de estados (Nikhil, 2011). O trecho de código a seguir ilustra a sintaxe de rules em BSV, o código tem como objetivo ordenar de forma crescente quatro inteiros.

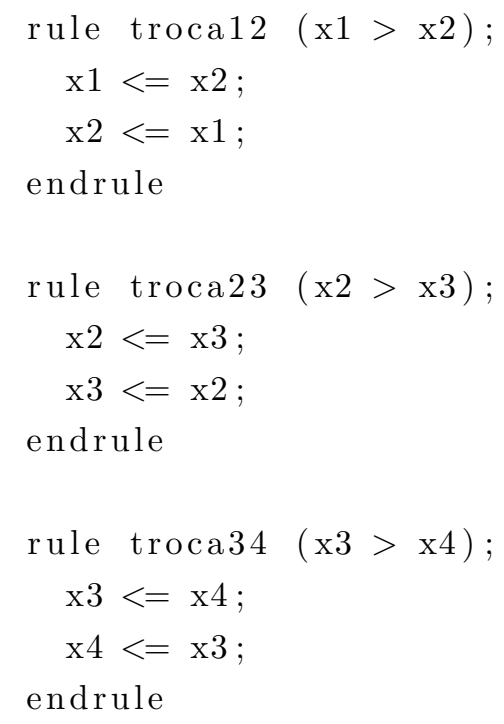

A regra troca12 funciona como um processo reativo, sempre que a condição booleana $x 1>x 2$ for satisfeita a regra é "disparada", cujo efeito é trocar os valores contidos nos dois registradores. Não há uma ordem inerente entre as regras; o que significa dizer que 
uma regra pode disparar sempre que a sua condição é satisfeita. Assim, no trecho de código apresentado, pode acontecer das regras troca12 e troca34 realizarem suas trocas em paralelo.

Entretanto, sobre as regras que atuam sobre um estado compartilhado, como troca12 e troca23, ambas atualizam x2. Regras possuem semântica de transações atômicas, e assim, nesse caso, essas duas regras podem disparar em qualquer ordem. Para este exemplo, não importa qual das duas ordenações possíveis é escolhida, eventualmente os registradores serão ordenados.

Contudo, quando há duas regras conflitantes, o programador não precisa especificar a ordem de execução, o compilador Bluespec resolve o conflito. No entanto, BSV dispõe de mecanismos para especificar a ordem de execução das regras, a linha de código a seguir especifica ao compilador Bluespec qual a ordem de execução das regras.

$1(*$ descending_urgency $=" r 1$, r2, $r 3 " *)$

O atributo descending_urgency permite ao projetista especificar qual regra é mais urgente. A relação de urgência é transitiva, ou seja, se a regra $r 1$ é mais urgente do que a regra r2 e r2 é mais urgente do que r3, então r1 é mais urgente do que r3. Se os atributos de urgência são contraditórios, resultando em um ciclo, o compilador irá relatar um erro (Bluespec, 2011).

Em resumo, regras são parte de uma boa DSL (Domain-Specific Languages) para descrição de hardware, pois seu funcionamento são como as transições de uma máquina de estados, familiares e intuitivas para os engenheiros de hardware. Além disso, regras são paralelas garantindo atomicidade (Nikhil, 2011).

\subsubsection{Processadores em Bluespec SystemVerilog}

Em muitas aplicações processadores soft-cores possibilitam muitas vantagens relacionadas a personalização tais como: redução de custo, flexibilidade, independência de plataforma e imunidade à obsolescência.

A utilização da HDL Bluespec para projetar soft-cores, propicia reduzir o tempo de projeto, refletindo também pelo número de linhas e modularidade do código, e também sendo possível a inserção de código Verilog no código BSV.

BSV é uma HLS que prover prototipagem rápida e exploração arquitetural. Contudo, dadas as restrições de projeto, pode ser necessário reescrever e ou refinar alguns módulos no nível RTL utilizando Verilog ou VHDL (Gruian e Westmijze, 2007).

Em (Dave, 2005), é descrito o projeto de um processador em Bluespec que utiliza o paradigma fora-de-ordem de execução. Neste paradigma, o processador executa as instruções baseado no fluxo de dados, ou seja, pela disponibilidade de dados de entrada, 
em vez da ordem original das instruções em um programa. Ao fazer isso, o processador tenta evitar ficar ocioso, pois enquanto são recuperados os dados necessários para executar a próxima instrução, as instruções capazes de executar são processadas imediatamente.

O processador em Bluespec descrito por (Dave, 2005) implementa o conjunto de instruções da arquitetura do MIPS I. Nesse projeto a memória de instrução é implementada como uma hierarquia de um nível. A Branch Table Buffer Unit (BTB) é uma tabela de cache mapeada diretamente com 8 endereços para os mapas de próximos endereços. O estado Fetch Unit consiste principalmente de um PC, um nextPC, e um epoch register. A unidade decodificadora, decodifica as instruções e insere-as na FIFO 2-way. A ULA possui um ciclo para todas as instruções. A unidade de memória recebe todas as instruções de memória. O arquivo de registro possui 2 portas de escrita e 4 portas de leitura. O Reorder Buffer é o mais complicado de todos os módulos, pois seu desempenho interfere no desempenho do sistema como um todo. No trabalho são descritas algumas otimizações realizadas para melhorar o projeto inicial. Sendo assim, a Figura 2.11 ilustra o diagrama de bloco do processador.

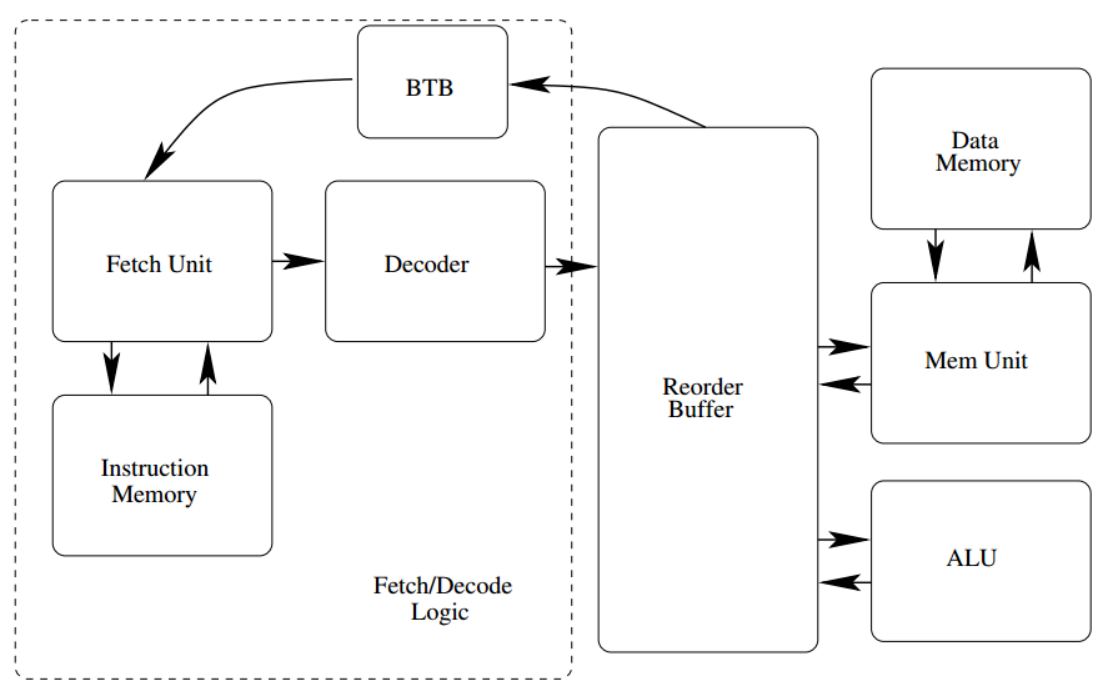

Figura 2.11: Diagrama de bloco do processador descrito em (Dave, 2005)

Em Gruian e Westmijze (2010), é descrito um estudo da linguagem Bluespec e o desenvolvimento de um processador embarcado para execução de código Java, o BlueJEP. Baseado no JOP (Java Optimized Processor) (Schoeberl, 2005), o BlueJEP é um processador desenvolvido em Bluespec SystemVerilog, e possui seis estágios de pipeline mais complexos e um estado adicional em relação ao JOP. Além disso, ele prover flexibilidade para exploração da arquitetura e portabilidade através de interfaces padrão para uma rápida integração com ambientes de desenvolvimento. Testes e experimentos foram re- 
alizadas tanto através de simulação, quanto de implementações executando em FPGAs (Virtex-II, Spartan3 e Virtex 5) (Gruian e Westmijze, 2007).

Cabe ressaltar que em Gruian e Westmijze (2008), é feita uma comparação entre uma descrição VHDL e Bluespec SystemVerilog (BSV). Usando uma arquitetura nativa Java, específica para sistemas embarcados, o processador em VHDL é um versão alterada do processador otimizado Java (JOP) (Schoeberl, 2008) possuindo 4 estágios de pipeline. Já a versão em BSV, é o processador BlueJEP (Gruian e Westmijze, 2007) com 6 estágios de pipeline. As duas implementações foram analisadas de forma qualitativa e quantitativa, focando na exploração arquitetural, prototipagem rápida, tempo de projeto, quantidade de linhas de código, teste e debug, modularidade, flexibilidade, e portabilidade. BSV obteve melhores resultados na maioria dos itens analisados, enquanto que, VHDL obteve melhores resultados em área e disponibilidade. A Figura 2.12 ilustra os estágios de pipeline do processador BlueJEP.

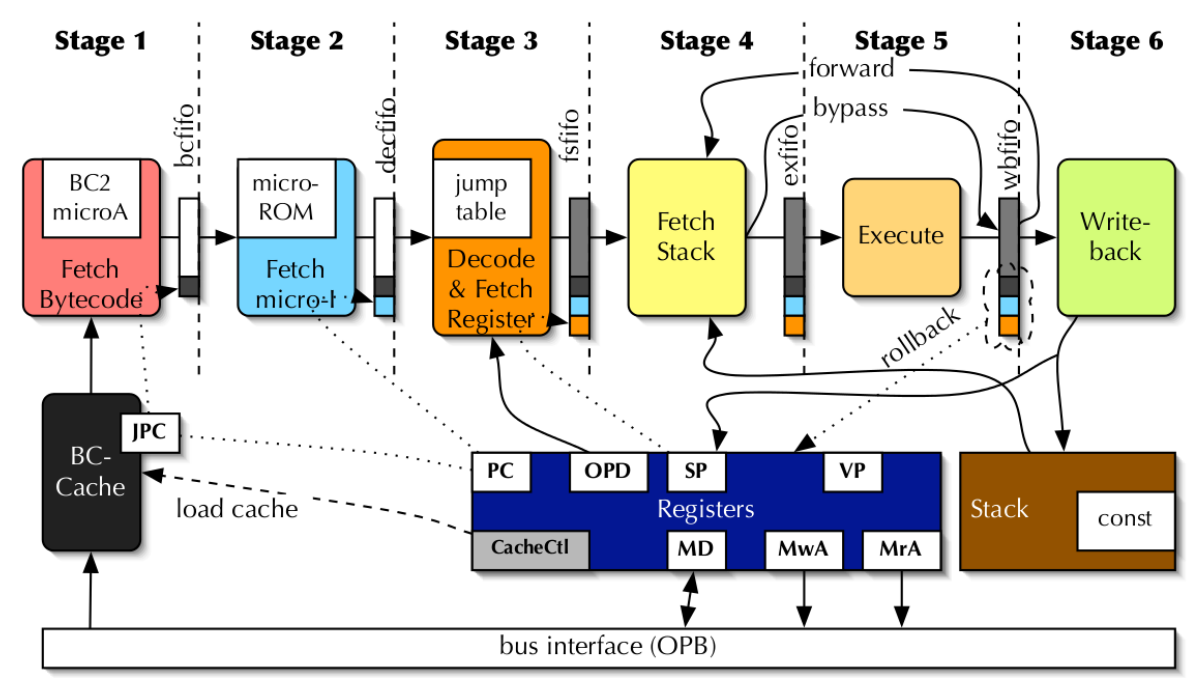

Figura 2.12: Estrutura de pipeline do processador BlueJEP (Gruian e Westmijze, 2007)

Em (Ekanadham et al., 2008), é descrito um processador powerPC multi-threaded em BSV. Ele consiste de uma unidade de instrução e de uma unidade de execução, e cada uma delas é um pipeline com vários estágios. As duas unidades compartilham um hardware de tradução de endereço único (TLB) e uma interface para a memória, e um conjunto de filas de instruções decodificadas conectam as duas unidades. Para o protótipo inicial foi usado um dispositivo Xilinx Virtex-5 LX330 FPGA, com 8M SRAM, que é controlado por um computador. Porém, a implementação descrita no trabalho é de uma versão muito primitiva sem subsistema cache e diretamente conectada à memória. A Figura 2.13 apresenta uma visão geral do processador powerPC.

Em (Chu et al., 2013), é apresentado o Caliburn, um processador com arquitetura MIPS32 VLIW(Very Long Instruction Word). Desenvolvido em BSV e projetado para 


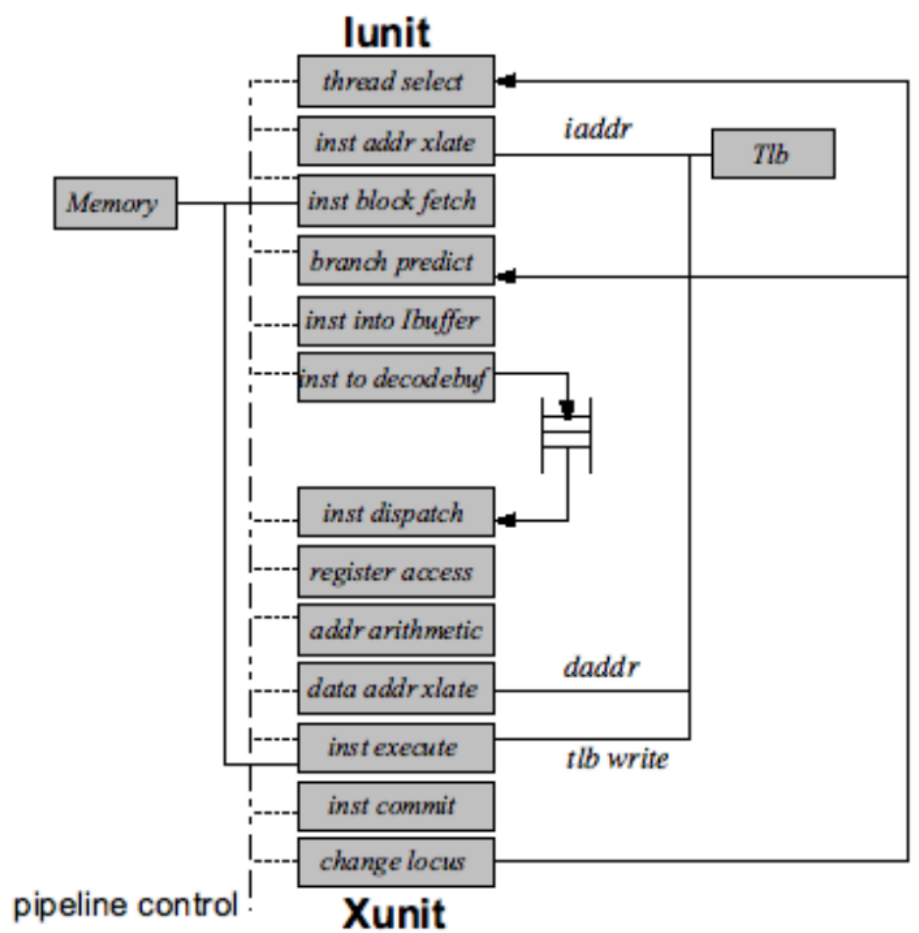

Figura 2.13: Visão geral do processador powerPC em BSV (Ekanadham et al., 2008)

executar código legado do MIPS32, Caliburn possui unidades de execução VLIW em pipeline, e uma unidade de transmissão para decodificar/executar conjuntos de instruções MIPS32. Para escalonar e "transformar" código(binário) legado MIPS32 em instruções VLIW, Caliburn possui uma instrução especial, em hardware, que realiza essas tarefas sem a intervenção de um compilador. A Figura 2.14 ilustra a arquitetura do processador Caliburn.

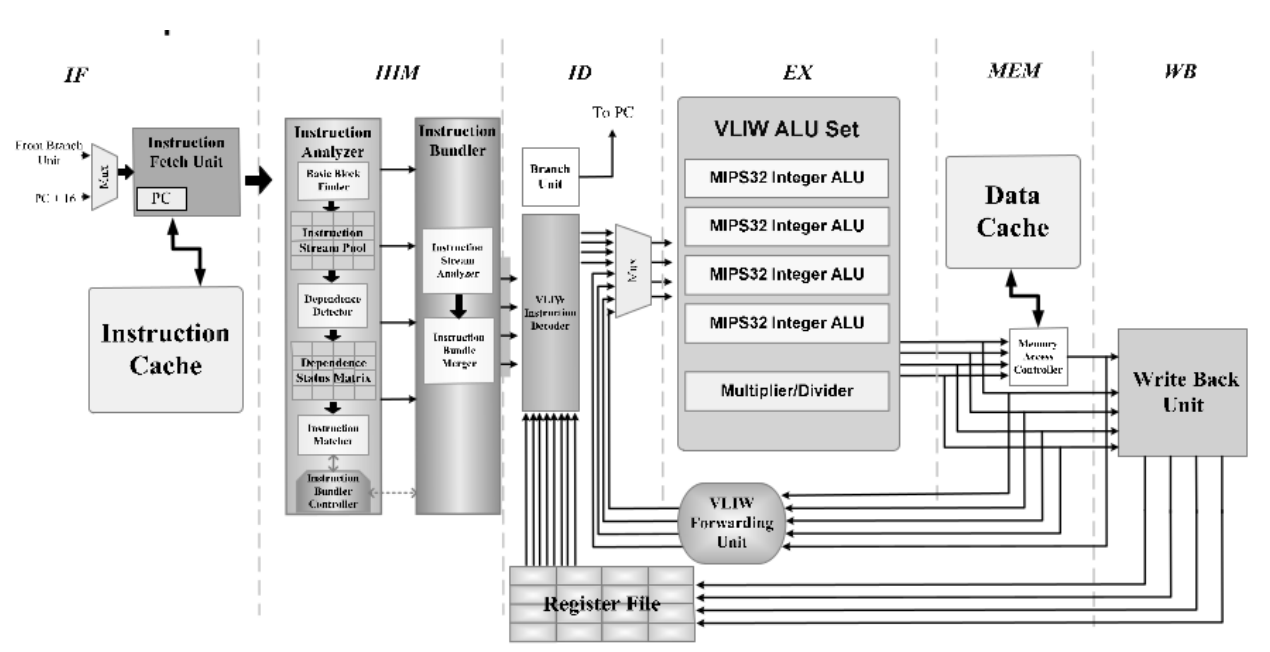

Figura 2.14: Arquitetura do processador Caliburn (Chu et al., 2013) 
Desenvolvido pelo SRI International e a Universidade de Cambridge, BERI (Bluespec Extensible RISC Implementation) é um processador soft-core 64-bits baseado na arquitetura RISC, implementado em BSV. Ele é projetado para uso em FPGA com fins de ensino e pesquisa em sistemas e interfaces de hardware-software. BERI é capaz de inicializar um sistema operacional FreeBSD, executar um servidor SSH, gcc, Apache, e inúmeras outras aplicações. Por fim, ele é independente de plataforma de FPGA, sendo sintetizável para os FPGAs Altera e Xilinx (Watson, 2014). A Figura 2.15 ilustra a arquitetura do BERI.

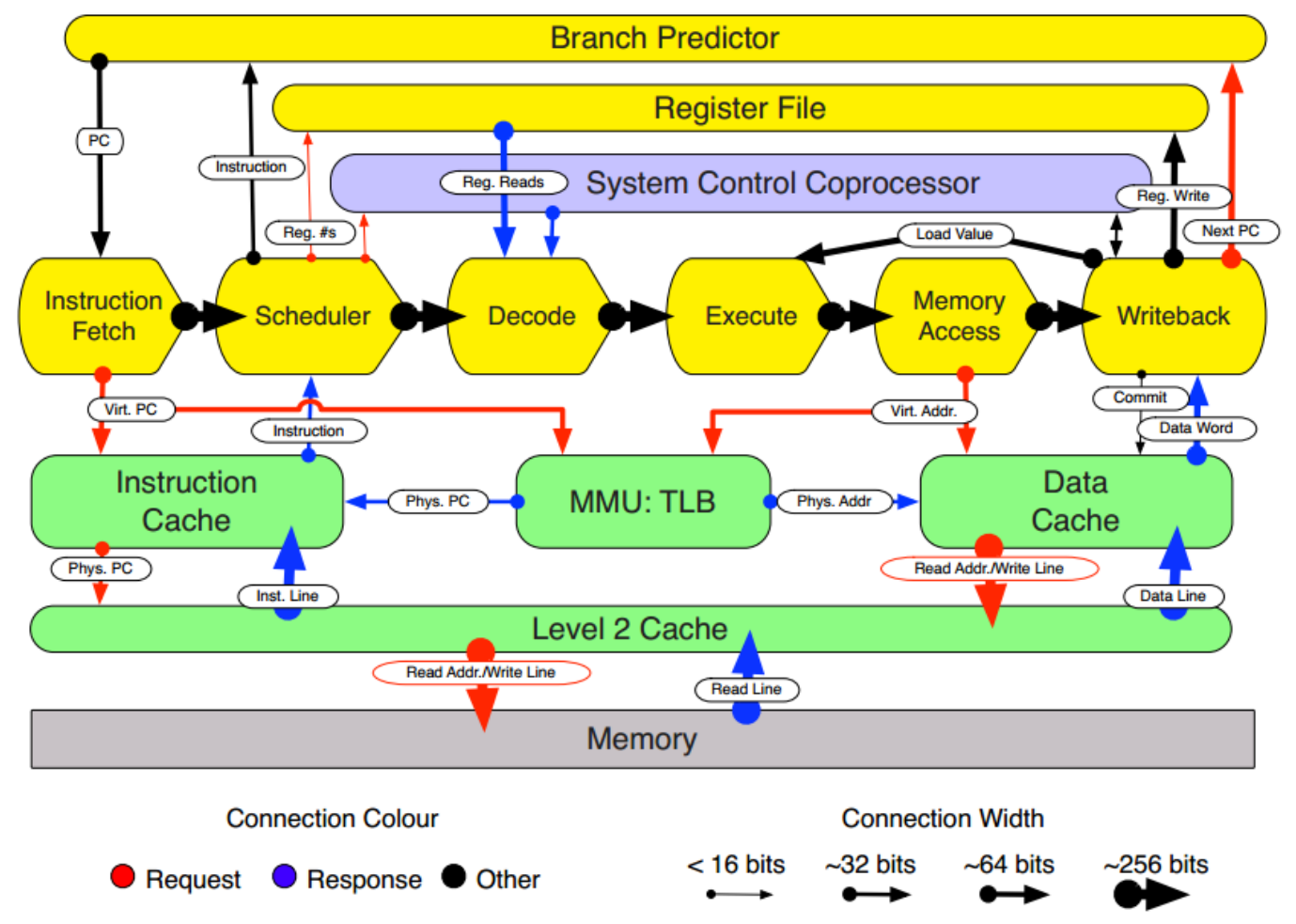

Figura 2.15: Arquitetura do processador BERI (Watson, 2014)

Desenvolvido por Moore (2010a) com fins de ensino para um curso de mestrado, Cyan é um processador escrito em BSV baseado na arquitetura MIPS32. Sua arquitetura é simples; possui memórias separadas para dados e instruções (modelo de arquitetura Harvard); um conjunto de instruções reduzido e uma estrutura de pipeline sequencial. O tamanho do seu código fonte é pequeno e de fácil entendimento, uma vez que é uma implementação simples para fins de aprendizado (Moore, 2010a). A Figura 2.16 ilustra a estrutura de pipeline do processador Cyan.

O processador soft-core UT Nios é o processador que mais se assemelha com este projeto. Em (Plavec, 2004), é descrito um estudo usando o processador Nios (primeira geração do Nios II) da Altera, e também é apresentada uma implementação em Verilog deste processador. 


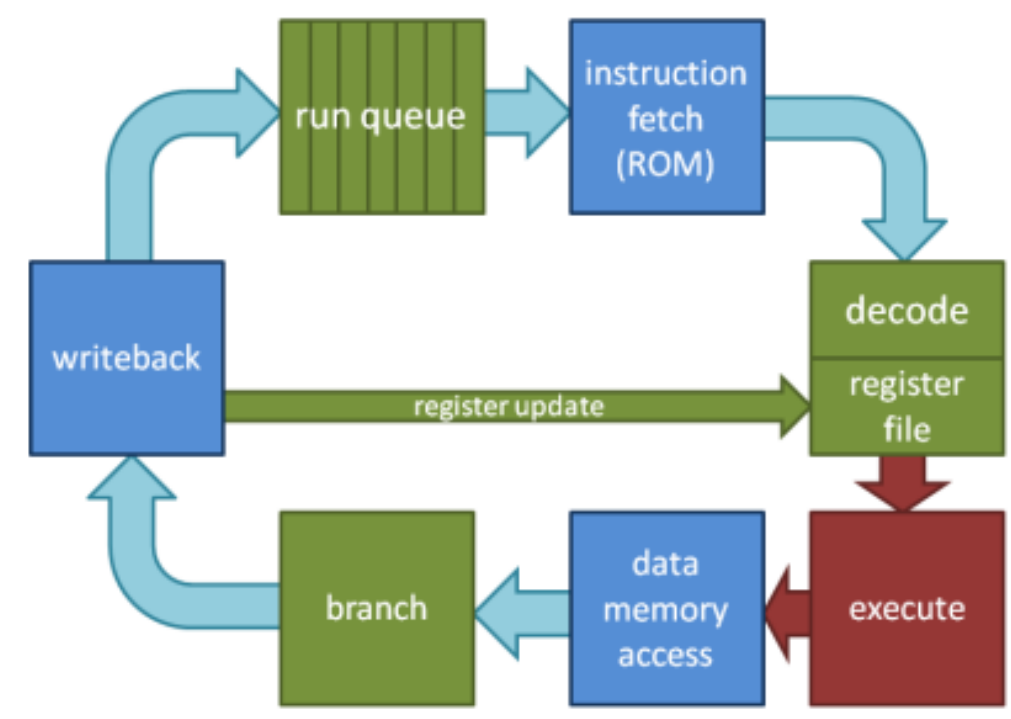

Figura 2.16: Estrutura de pipeline do processador Cyan (Moore, 2010a)

O UT Nios foi implementado usando a HDL Verilog, e optou-se por essa escolha em razão do aumento da popularidade, simplicidade para uso e entendimento da codificação, ao invés de usar VHDL (Plavec, 2004). Seu projeto é otimizado para implementação em FPGAs na família de dispositivos Stratix. Porém, ele pode facilmente ser adaptado para uso em um sistema que suporta projetos descritos em Verilog (Plavec, 2004).

O UT Nios não é customizável como o Nios da Altera, sendo composto por dois módulos principais: caminho de dados e unidade de controle. O caminho de dados é composto por um pipeline de 4 estágios. O caminho de dados define conexões entre os módulos do processador, e define como os dados se propagam entre os estágios de pipeline. A unidade de controle é uma máquina de estados finita que produz os sinais de controle para os módulos no caminho de dados (Plavec, 2004). A Figura 2.17 ilustra a arquitetura do processador UT Nios.

Para realizar as comparações de desempenho entre os dois processadores foi usada a implementação Altera 3.0 da arquitetura Nios, disponível no SOPC Builder 3.0 e o GNUPro Toolkit. O Quartus II, versão 3.0, edição web (versão não paga) foi usada para sintetizar todos os projetos. As comparações de desempenho mostraram que o UT Nios e o Altera Nios possuem desempenho similares (Plavec, 2004).

Em (Moore, 2010b), é apresentado um exemplo de código BSV para a implementação de instrução customizada para o processador soft-core Nios II da Altera. O código implementa um modelo genérico de instrução customizada. Ao compilar o código BSV, o código Verilog gerado pode ser importado para a ferramenta SOPC Builder/Qsys da Altera, descartando intervenções no código para tal finalidade, pois os nomes de instâncias, métodos e variáveis contidas no código BSV foram escolhidos (seguindo o padrão 


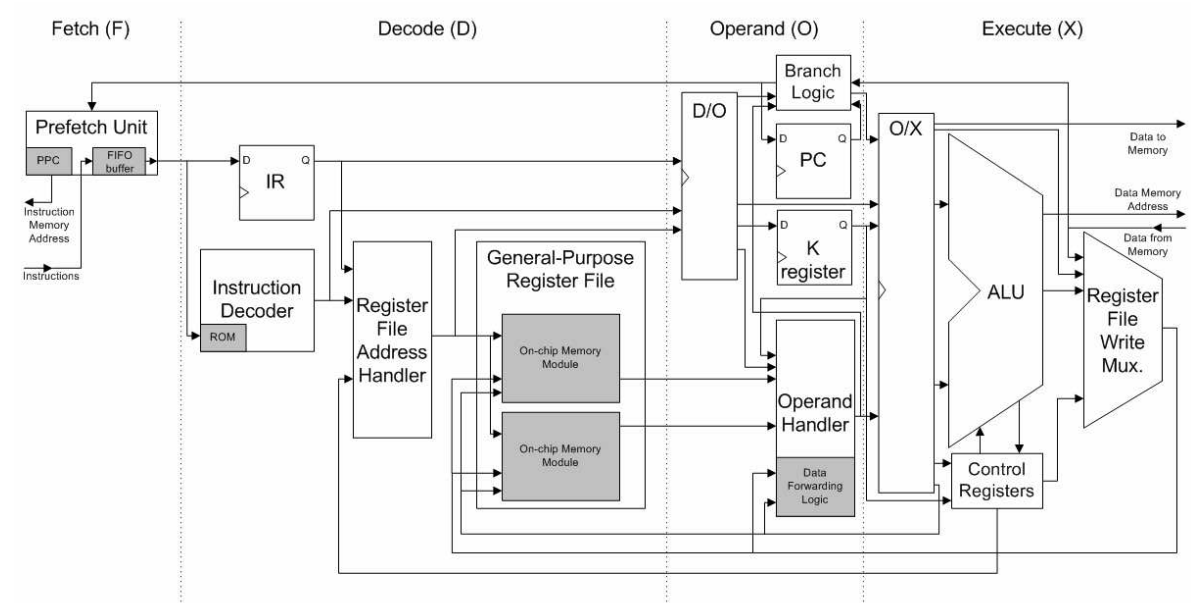

Figura 2.17: Arquitetura do processador UT Nios (Plavec, 2004)

da Altera) de modo que o Verilog produzido seja reconhecido pelas ferramentas da Altera (Altera, 2011b).

O processador SMIPS, o qual serviu de base para o desenvolvimento deste projeto. É um processador de 32 bits descrito em Bluespec, baseado na arquitetura MIPS, e foi desenvolvido no MIT (Massachusetts Institute of Technology) (Arvind e Asanovic, 2005). SMIPS significa um MIPS simples, uma vez que ele implementa um subconjunto ISA do MIPS (Spring, 2005). Ele implementa todas as instruções com inteiros, as de tratamento de exceções e as de load e store. Possui 31 registradores de propósito geral de 32 bits. Há três registradores especiais definidos na arquitetura: dois registradores hi e lo usados para manter os resultados de multiplicação e divisão de inteiros e divide, e o endereço do PC (program counter) (Spring, 2005). A Figura 2.18 ilustra a microarquitetura do SMIPS original.

Por fim, está sub secção teve o intuito de apresentar processadores que foram e estão sendo desenvolvidos em Bluespec SystemVerilog, demostrando o uso do BSV como uma HDL de alto nível, e com síntese em HLS que gera descrições Verilog adequadas para a implementação em FPGA.

\subsection{Considerações Finais}

Neste capítulo foi apresentada uma visão geral sobre os principais conceitos envolvidos neste projeto. Inicialmente, foram descritos os principais conceitos relacionados a computação reconfigurável e FPGA. Em seguida, foram apresentados alguns dos principais soft-cores utilizados no mercado e no meio acadêmico, destacando o Nios II da Altera, objeto de estudo deste trabalho. Definições e aplicações sobre ESL, e Bluespec SystemVerilog 


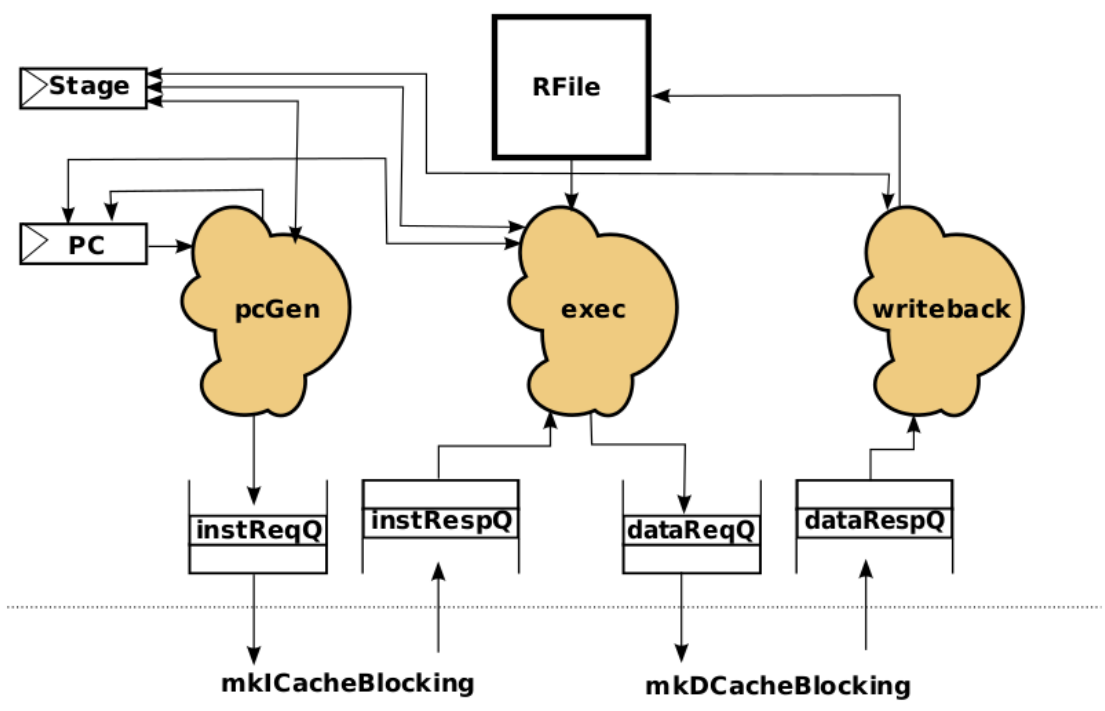

Figura 2.18: Microarquitetura do processador SMIPS (Spring, 2005)

foram apresentados, destacando seus benefícios. Finalizando, foram apresentados alguns trabalhos relacionados com o projeto desenvolvido.

No próximo capítulo será apresentada a metodologia utilizada para condução e desenvolvimento deste trabalho. 


\subsection{Considerações Iniciais}

Neste capítulo é apresentada a metodologia utilizada na realização deste trabalho. Na Seção 3.1 é apresentada a preparação do ambiente de trabalho e as ferramentas utilizadas. Na Seção 3.2 é apresentado o planejamento e a estratégia de condução usada no desenvolvimento do trabalho. Por fim, na Seção 3.3 são apresentadas as considerações finais deste capítulo.

\subsection{Preparação e Ambiente de Desenvolvimento}

Para a realização deste trabalho foi utilizada a metodologia de pesquisa aplicada (Barros e de Souza Lehfeld, 2000), com ênfase no desenvolvimento de um processador soft-core, visando contribuir com o desenvolvimento de sistemas reconfiguráveis em FPGA (Plataforma Altera), disponibilizando um processador soft-core open source customizável para pesquisa e ensino.

Na realização deste trabalho foram utilizadas as seguintes ferramentas da Altera para o desenvolvimento do processador BSP: o software Quartus II da Altera, no qual o processador desenvolvido foi integrado (Qsys/SOPC builder), usado para síntese e projeto da arquitetura de hardware, e transferência do arquivo (bitstream) de configuração da arquitetura sintetizada para o FPGA alvo da família Altera. 
A interligação dos componentes de hardware (IPs), utilizados na arquitetura, foi realizada por meio das ferramentas integrantes do Quartus II, Qsys/SOPC builder. Por meio destas ferramentas é possível configurar a frequência do processador, conectar IPs ao processador desenvolvido e configurar outras características dos IPs da Altera.

Para a geração de código objeto a ser executado pelo processador desenvolvido foi utilizado o NIOS2 GNU Tools que inclui o compilador nios2-elf-gcc e outras ferramentas. O nios2-elf-gcc é o compilador utilizado na geração de código objeto para o Nios II da Altera. Foi também utilizada a IDE (Integrated Development Environment) disponibilizada pela Altera chamada, Nios II EDS (Embedded Design Suite), que possui o NIOS2 GNU Tools incluído, para realizar o disassembly dos programas escritos $C$ na fase de implementação das instruções do processador. Na implementação do processador foi utilizado Bluespec, que pode ser entendido como um conjunto de ferramentas integradas, o qual inclui a linguagem de descrição de hardware Bluespec System Verilog (BSV), o compilador (BSC compiler) BSV e o Bluesim; um simulador para BSV.

A escolha de Bluespec foi motivada pela significativa gama de recursos e vantagens disponíveis. Dentre elas, pode-se destacar que a simulação do hardware projetado ocorre aproximadamente dez vezes mais rápida se comparada a outras ferramentas para síntese de hardware, por ser uma ferramenta HLS e por ser uma HDL que utiliza a metodologia ESL. Além disso, apesar de ser uma ferramenta proprietária, Bluespec dispõe de um programa universitário o qual disponibiliza de forma gratuita uma licença. Por fim, apesar do código BSV exigir uma licença para ser compilado, o Verilog utilizado para construções internas da linguagem é disponibilizado em conjunto com os arquivos utilizados para compilação do código BSV.

\subsection{Planejamento e Condução do Projeto}

O processador soft-core BSP (compatível com o ISA do Nios II) desenvolvido por este projeto teve como parâmetro a versão economy core do Nios II. Esta versão é caracterizada por utilizar aproximadamente 600 elementos lógicos da FPGA e baixo consumo de energia (Altera, 2011b). A implementação do processador teve como base o estudo do processador da arquitetura MIPS de 32 emphbits desenvolvido em BSV em (Arvind e Asanovic, 2005) (Ruggiero e Matias, 2010).

Para o desenvolvimento do processador foi definida uma estratégia de modo a implementar o mesmo de forma modular e incremental. Após estudar as implementações do SMIPS (Arvind e Asanovic, 2005) e do processador desenvolvido por Ruggiero e Matias (2010), foi reutilizado código de ambas as implementações para especificar a arquitetura do processador desenvolvido neste trabalho (descrito no Capítulo 4). 
Após especificar a arquitetura do processador foi implementado o seu conjunto de instruções, obedecendo o tipo e formato das instruções do Nios II, descritas no Handbook (Seção Nios II Set Instruction) disponibilizado pela Altera (Altera, 2011b). Com o intuito de verificar a compatibilidade das instruções implementadas com o ISA do Nios II foi realizada a seguinte abordagem utilizando o mecanismo de debug do compilador do Nios II (que faz parte da IDE Nios II EDS) para execução de programas escritos em $C / C++$. Ao executar um programa em modo Debug na IDE é possível visualizar o disassembly do programa gerado pelo compilador, detalhando cada uma das instruções executadas, como pode ser ilustrado na Figura 3.1.

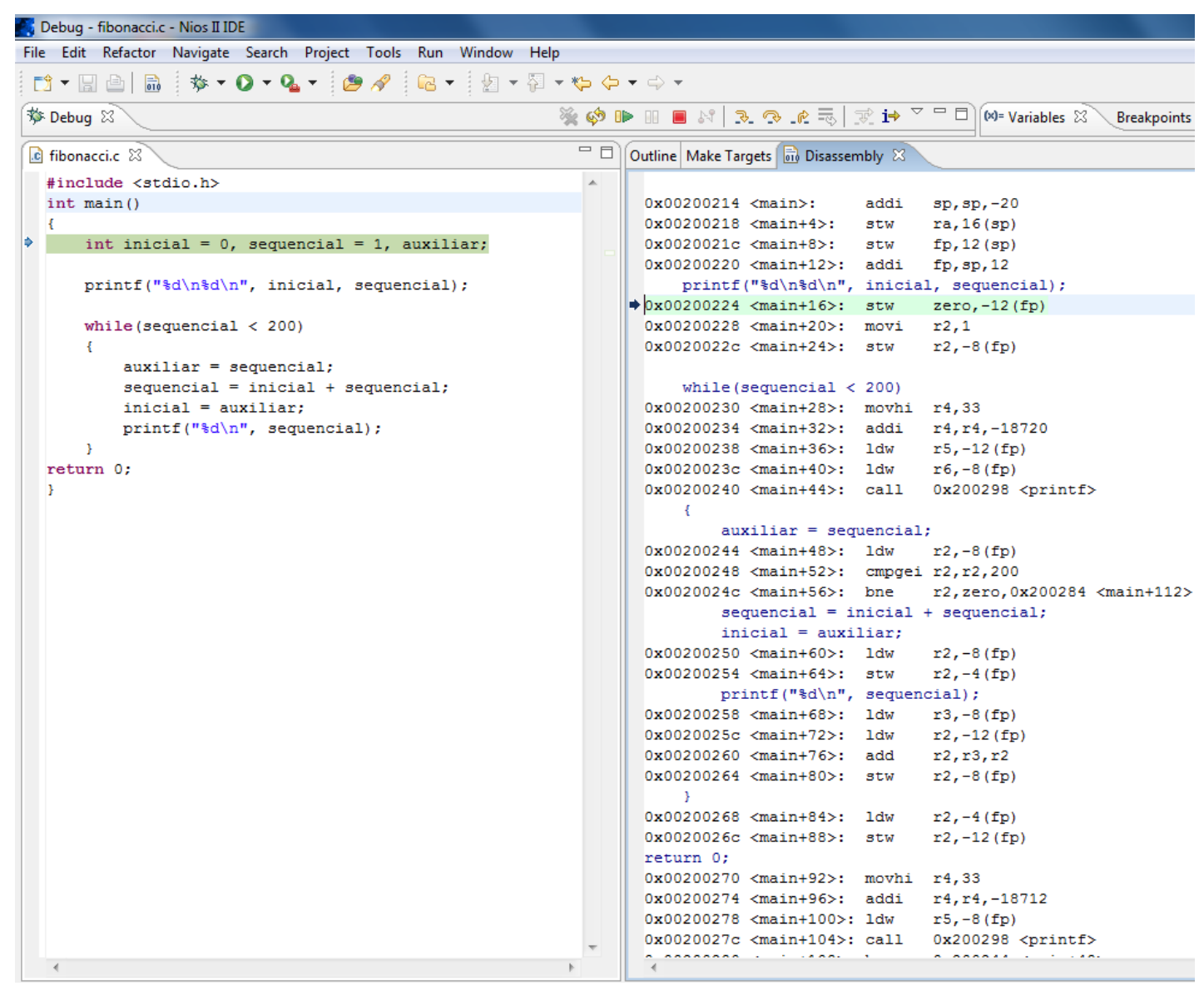

Figura 3.1: Disassembly da sequência de Fibonacci escrita em $C$

Após visualizar o disassembly do programa eram implementadas no processador as mesmas instruções utilizadas pelo Nios II na execução do programa. Desse modo, foi criada uma infraestrutura de depuração para desenvolvimento do processador com o objetivo de avaliar, verificar e validar a implementação, e tal infraestrutura é ilustrada na Figura 3.2.

Com o objetivo de automatizar o processo de compilação do programa em $C$ e a geração do seu disassembly, foram criados dois scripts (programbuild.sh e disasm.sh) utilizando a 


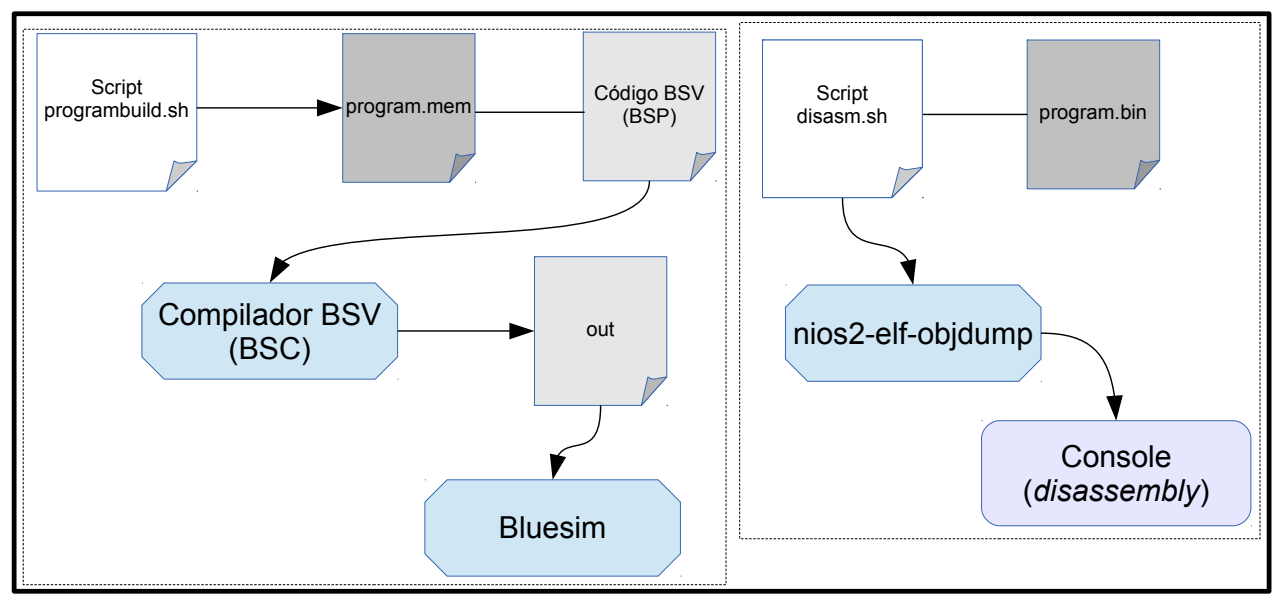

Figura 3.2: Infraestrutura criada para debug e validação do processador

linguagem Shell script. O programbuild.sh é responsável por compilar o programa $C$ invocando o compilador nios2-elf-gcc gerando o program.o, e por sua vez o linker nios2-elf-ld para gerar o arquivo program.bin. Ele também executa o script (bin2vmem.py), escrito em Python, que lê o program.bin e gera o arquivo program.mem contendo os dados e instruções do programa, a estrutura interna do programbuild.sh é ilustrada na Figura 3.3. Já o disasm.sh é responsável por executar o nios2-elf-objdump, que lê o arquivo program.bin e imprime no console o disassembly do programa, como ilustrado na Figura 3.2.

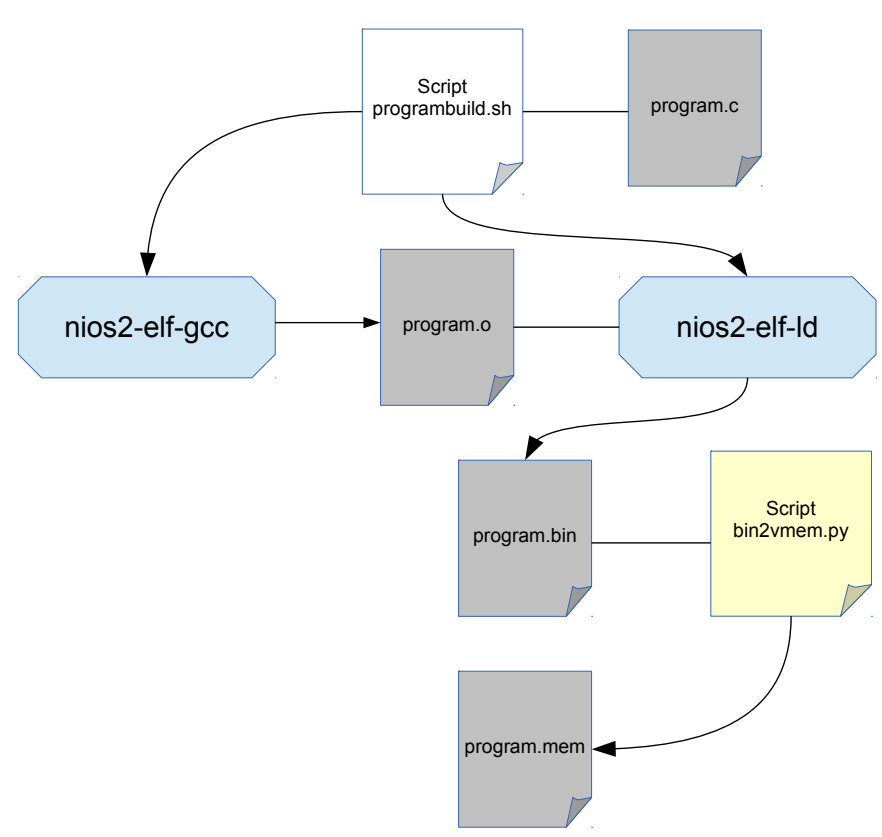

Figura 3.3: Estrutura interna do script programbuild.sh 
Após gerado o arquivo program.mem, o mesmo é utilizado no código BSV do processador, pois internamente ele é colocado em uma estrutura BSV, chamada $B R A M$, que funciona como uma memória simulada. O processo de simulação do processador era iniciado de forma manual usando a Bluespec workstation, que é uma ferramenta com interface gráfica para criação e compilação de projetos BSV, dentre outras características. A interface da Bluespec workstation é ilustrada na Figura 3.4.

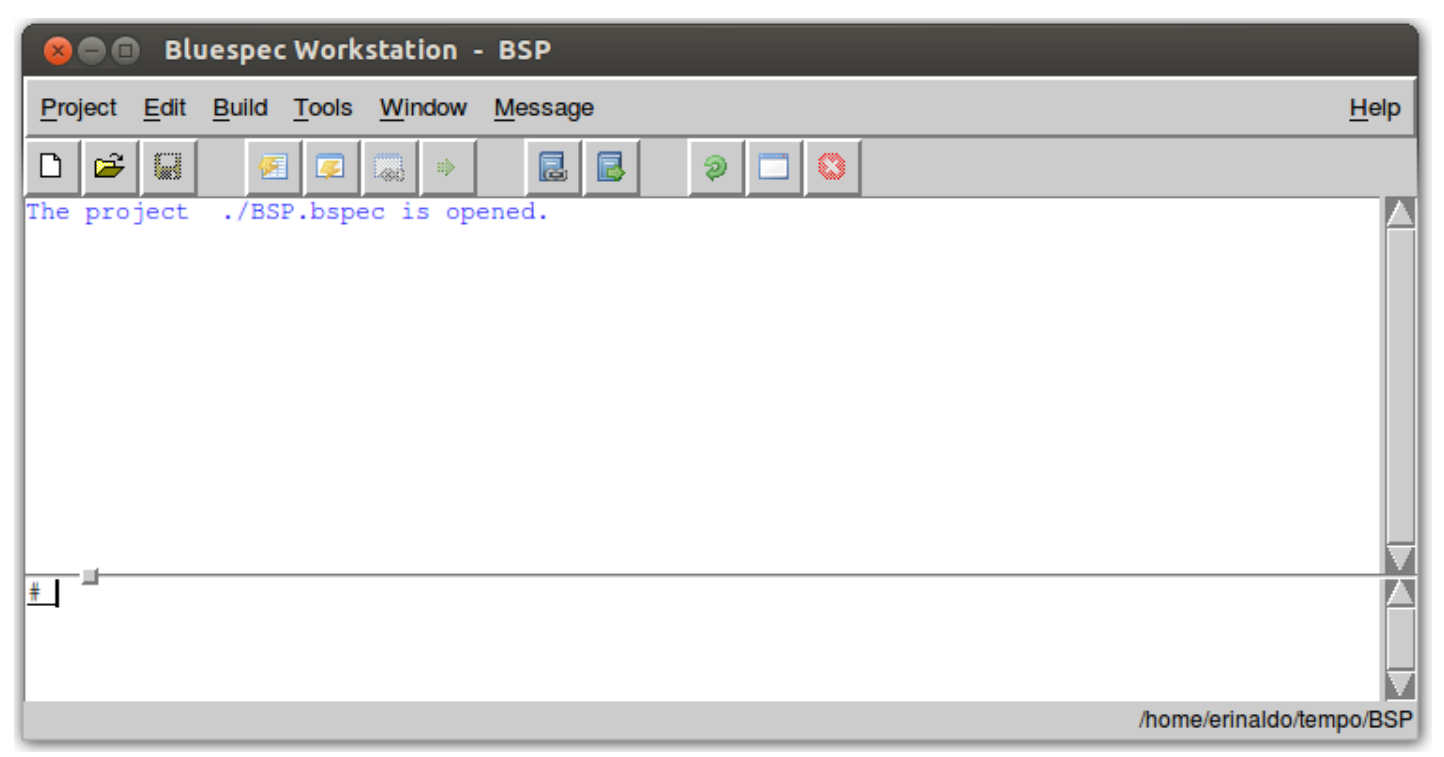

Figura 3.4: Janela principal da Bluespec workstation

No processo de compilação do Bluespec, o usuário pode especificar o produto da compilação, que pode ser a simulação ou geração do Verilog correspondente ao código BSV. Durante a fase de implementação do processador, todos os testes foram feitos por meio de simulação. Nesse sentido, foram criados dois módulos em BSV para geração do processador, o $m k B S P E m u$ e o $m k B S P$. Assim, como um programa de software possui uma função principal, um projeto BSV possui um módulo principal. O módulo principal é onde começa a compilação do código BSV. Logo, quando é feita a simulação o módulo mkBSPEmu é configurado como principal, para o caso em que o código Verilog é gerado é configurado o $m k B S P$. Essa abordagem foi utilizada no sentido de validar a implementação de forma mais rápida, uma vez que todo o processo de síntese e programação do processador no FPGA é muito mais demorado do que a simulação. Além disso, segundo Bluespec Inc., o Bluesim simula com precisão de ciclo, e a simulação do código BSV é feita em $C$ possibilitando Bluespec simular o hardware desenvolvido aproximadamente dez vezes mais rápido do que a simulação em RTL (Bluespec, 2011).

Para auxiliar no debug de execução do processador, foi criada uma funcionalidade de trace em BSV usada na simulação do processador com o Bluesim. Ela possibilita verificar a instrução que está em execução, bem como as que foram executadas, os valores contidos 
nos registradores manipulados pelas instruções, e as saídas do programa executado pelo processador durante a simulação. A Figura 3.5 ilustra uma simulação do processador em execução.

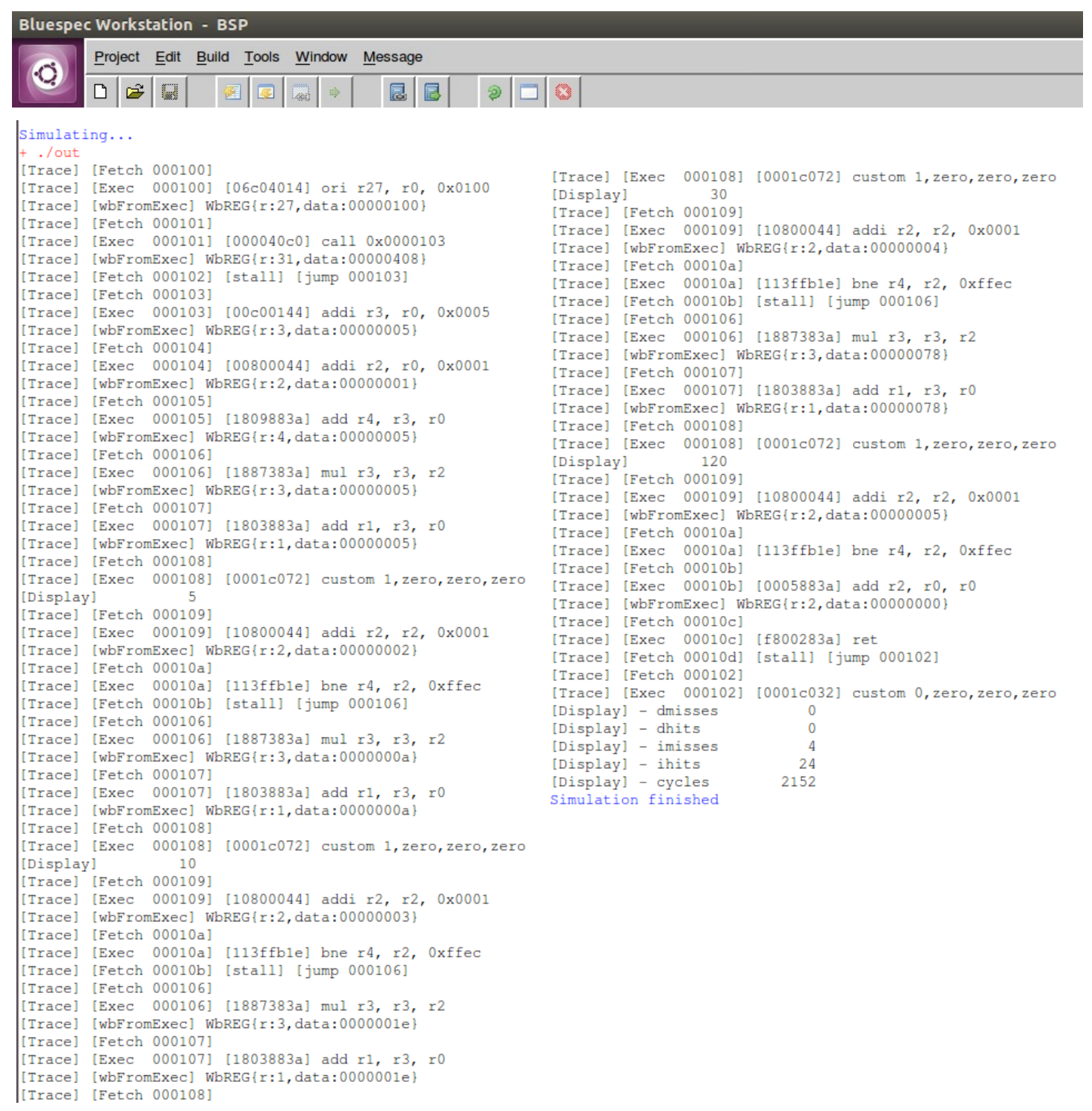

Figura 3.5: Simulação do processador com a funcionalidade de trace

Na Figura 3.5 é possível observar o trace de execução do processador ao realizar o cálculo do fatorial de $\mathrm{N}$ igual a 5 . As saídas do programa também podem ser observadas na Figura 3.5.

Portanto, para os testes no FPGA foi necessário implementar o barramento Avalon (Altera, 2011a) em BSV. A implementação do Avalon tornou possível a integração do proces- 
sador ao ecossistema de ferramentas da Altera (Qsys/SOPC builder), uma vez que para integrar um IP no ambiente Altera de modo a comunicar-se com os IPs ali existentes, faz-se necessário que o mesmo esteja de acordo com o padrão de entrada e saída de sinais da Altera (Altera, 2011b). Além disso, é possível utilizar o conjunto de IPs da Altera em conjunto com o processador desenvolvido. A implementação do Avalon em BSV segue o padrão especificado pela Altera do Avalon (Altera, 2011a), e teve como base as implementações do Avalon em BSV desenvolvidas por (Ruggiero e Matias, 2010) e (Moore, 2011). A Figura 3.6 ilustra o processador integrado no ambiente Qsys.

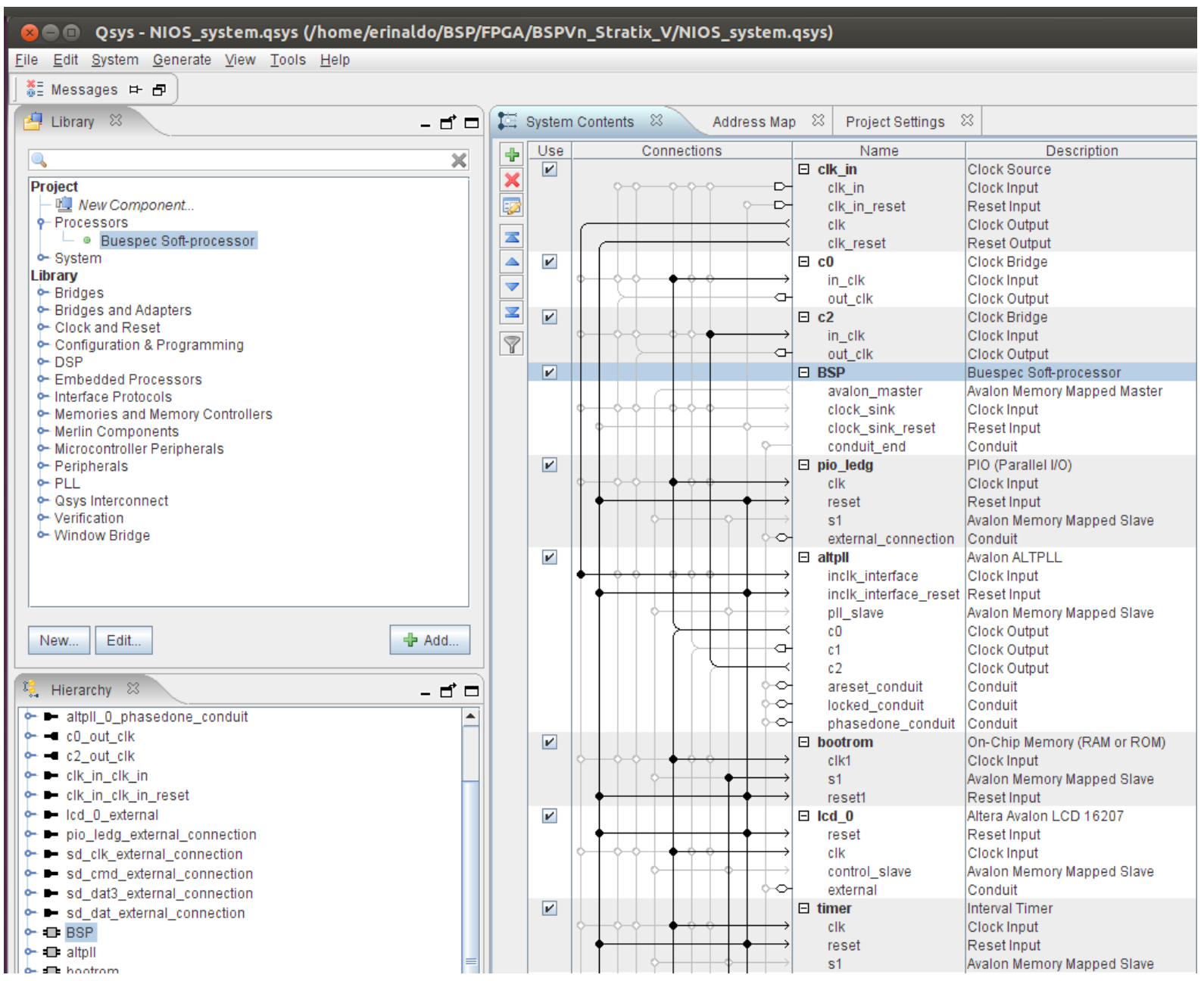

Figura 3.6: Processador integrado ao ambiente Qsys

\subsection{Considerações Finais}

Neste capítulo foi apresentada a metodologia utilizada no desenvolvimento deste trabalho. Procurou-se enfatizar a fase de implementação das instruções do processador, a criação de ambiente de programação do mesmo, com o uso de scripts, a criação de uma estrutura 
de debug e a validação da implementação e a sua integração com as ferramentas Qsys e SOPC builder.

No Capítulo 4 será apresentado o processador desenvolvido, sua arquitetura e detalhes de sua implementação. 


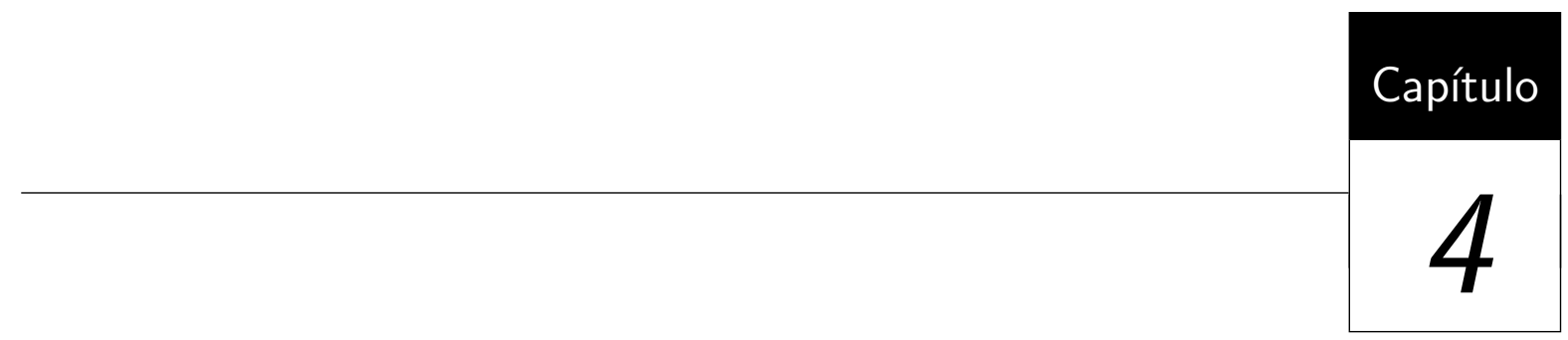

\section{Bluespec Soft-Processor}

\subsection{Considerações Iniciais}

Neste capítulo é apresentando o processador desenvolvido em Bluespec SystemVerilog, o Bluespec Soft-Processor (BSP). Na Seção 4.2 é apresentada uma descrição do processador e sua arquitetura. Na Seção 4.3 são apresentados os módulos que compõe o core do BSP e, na Seção 4.4 são apresentadas as considerações finais deste capítulo.

\subsection{Bluespec Soft-Processor}

A implementação do BSP é baseada num processador MIPS simples (Arvind e Asanovic, 2005) (Ruggiero e Matias, 2010). Além disso, a arquitetura MIPS aproxima a semelhança entre o ISA do BSP e do Nios II, pois o Nios II também é baseado na arquitetura MIPS. Outro fator é a simplicidade da arquitetura, que colabora com um dos objetivos centrais desse projeto, que é disponibilizar um processador de código open source, de forma a possibilitar que um grande grupo de pessoas possam modificar, e disponibilizar as modificações, contribuindo dessa forma com o desenvolvimento desse projeto.

Descrito em Bluespec SystemVerilog, o BSP pode ser utilizado tanto para fins acadêmicos quanto de aprendizagem. O seu código aberto (open source), possibilita que sejam adicionadas ou removidas características do core processador, de acordo com o objetivo 
do usuário. No Capítulo 5 são descritas algumas customizações feitas no código do BSP que justificam sua implementação open source.

\subsubsection{Arquitetura BSP}

O Nios II pode ser configurado tanto para arquiteturas do tipo Von-Neumann, arquitetura caracterizada por armazenar instruções e dados dos programas no mesmo espaço de memória (Hennessy e Patterson, 2003) (Stallings, 2010), como para Harvard (arquitetura que se distingue das outras por possuir duas memórias (dados e instruções) independentes, em termos de barramento e interface com o processador (Hennessy e Patterson, 2003) (Stallings, 2010)), através do Qsys/SOPC Builder.

Com o intuito de aproximar ao máximo o BSP das funcionalidades providas pelo Nios II, foi feita uma implementação do BSP arquitetura Harvard. No entanto, assim como o Nios II por default é configurado para Von-Neumann, o mesmo serve para o BSP. O diagrama de bloco do BSP é ilustrado na Figura 4.1.

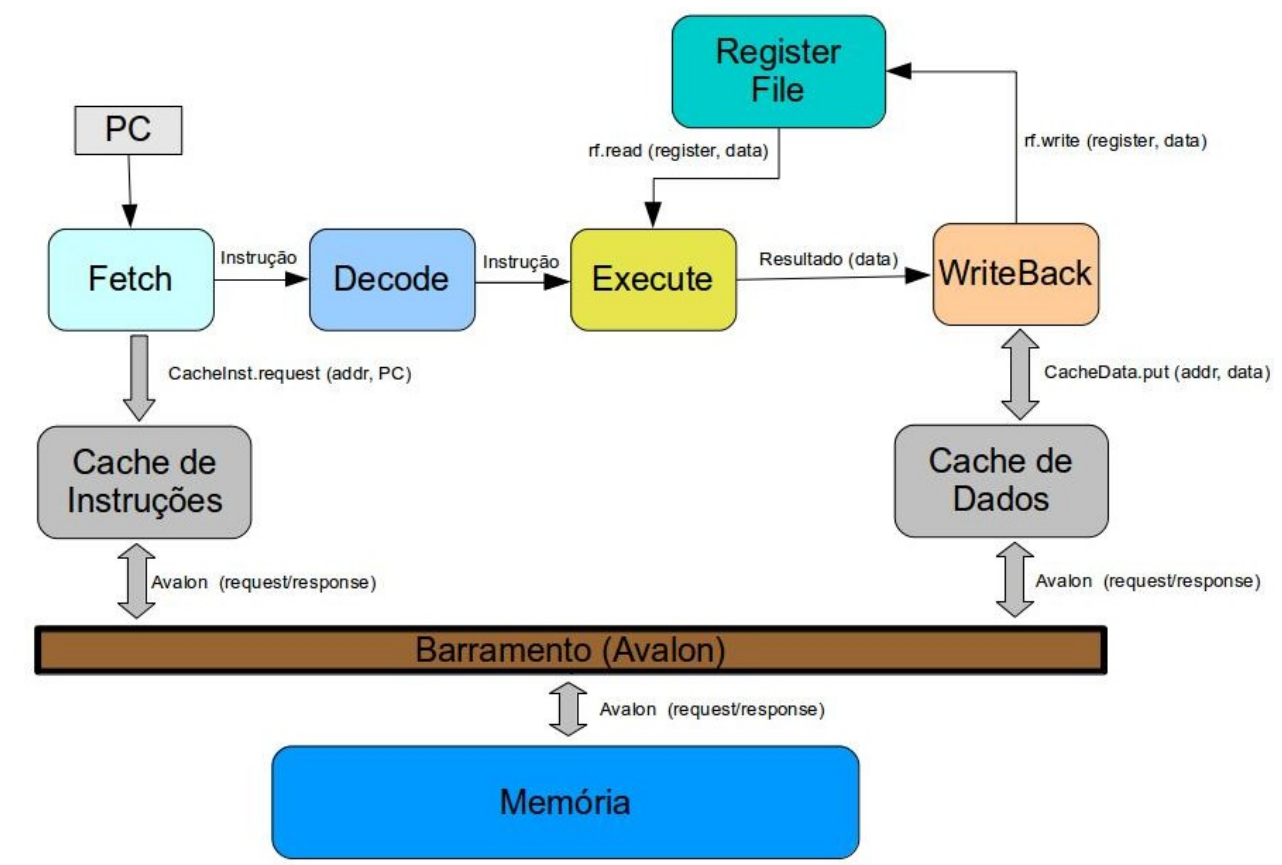

Figura 4.1: Diagrama de bloco do Bluespec Soft-Processor

O pipeline do BSP é inspirado na arquitetura tradicional do MIPS-I (Harris e Harris, 2007) de três estágios. Os 3 estágios do BSP são: Fetch, Execute e Write-Back (ver Figura 4.1). No estágio Fetch as instruções são buscadas na memória cache de instruções e enviadas para o estágio Execute. No estágio Execute as instruções são decodificadas, o Register File é lido acessando os registradores usados na instrução, por fim, a ação 
da instrução é executada e o resultado enviado para o estágio Write-Back. No estágio Write-Back o resultado é escrito no Register File ou no barramento da memória.

O Register File é implementado por um conjunto de registradores de 32 bits, utilizando blocos lógicos do FPGA para multiplexar os acessos. O número de registradores do processador é 32, sendo que o primeiro deles (r0) é hard-wired com zero, ou seja, seu valor é sempre zero e não pode ser modificado. Cabe ressaltar que o registrador zero (R0) em ambas as arquiteturas Nios II e MIPS é hard-wired.

O processador não pode ter um número diferente de 32 registradores. Esse número é fixo e é definido pela arquitetura. Alterar esse número significa modificar a codificação das instruções, que usa 5 bits para identificar os registradores. Além disso, teria que ser alterado o número de bits ocupados por cada instrução, ou ainda, remanejar todos os opcodes das instruções para economizar espaço, o que por si só já transformaria o ISA do processador resultante em outro diferente do Nios II, perdendo dessa forma a compatibilidade alcançada.

A arquitetura do BSP foi projetada de modo que a maioria das instruções executa gastando um ciclo de clock, propriedade desejável para uma arquitetura RISC (Reduced instruction set computing). No entanto, as instruções de divisão foram implementadas usando um divisor sequencial, porque um divisor combinacional teria um caminho crítico grande quando sintetizado para o FPGA, impactando diretamente no clock do processador.

O divisor sequencial usa um esquema de deslocamento de bits, e é capaz de fazer divisões de 32 bits em até 8 ciclos de clock. Por outro lado, as instruções de multiplicação foram implementadas de modo combinacional, usando os blocos DSP (Digital signal processing) do FPGA, e executam em um ciclo de clock.

Contudo, as instruções que armazenam uma palavra (32 bits) ou metade de uma (16 bits), por exemplo, as instruções LDB e LDH, executam em mais de um ciclo de clock. Para simplificar o projeto, optou-se por fazer que no estágio de Write-Back seja feita uma requisição de load na cache de dados, de uma ou meia-palavra que será usada por uma instrução, parar o pipeline até que a requisição tenha sido completada, modificar a palavra, e só então escrevê-la de volta para a memória. Dessa forma, se a palavra inicialmente está na cache de dados, esse tipo de instrução fará com que o pipeline fique um ciclo parado. Caso contrário, o pipeline só será parado quando ocorrer a resposta de um dado solicitado no barramento da memória.

A implementação da memória cache segue um padrão simples, há caches de instruções e dados separadas, tal como apresentado na Figura 4.1. Ambas as caches são implementadas usando FPGA RAM Blocks, que podem responder às solicitações em um ciclo de 
clock. Dessa forma, a cache de instruções está ligada a um circuito de prefetch que lê palavras em sequência a partir do barramento de memória sempre que ele estiver ocioso.

Os acessos feitos pelas caches de dados e instruções ao barramento de memória são arbitrados, ou seja, um por vez - se ambas as caches tentam acessar o barramento no mesmo ciclo, ganha direito ao acesso aquela que perdeu na disputa(conflito) anterior.

O tipo de mapeamento usando na memória cache é o direto. Para consultar ou modificar uma linha da cache são usados os bits menos significativos do endereço. E sua política de substituição de dados foi implementada utilizando o algoritmo Least Recently Used (LRU), em que os itens menos usados recentemente são descartados quando necessário.

As memórias caches de dados e instruções possuem número de linhas configuráveis pelo usuário. No entanto, o tamanho de cada linha é fixo, 32 bits, e não pode ser alterado. O barramento Avalon é configurado para trabalhar com dados do mesmo tamanho de palavra que o processador (32 bits), de forma que todo dado recebido do barramento Avalon tem 32 bits, e os dados são inseridos na cache exatamente como foram recebidos do barramento.

Sendo assim, o desenvolvimento do processador foi realizado de forma modular, uma vez que cada componente da arquitetura pode ser concebido e desenvolvido separadamente, como um sistema independente. Isto é possível porque o BSV é responsável pela comunicação entre os módulos, de acordo com a especificação do projetista. Além disso, o desenvolvimento modular facilita a descrição do projeto, a validação das partes que o compõem, testes e documentação. Os módulos em BSV que compõe o processador podem ser vistos na Figura 4.2.

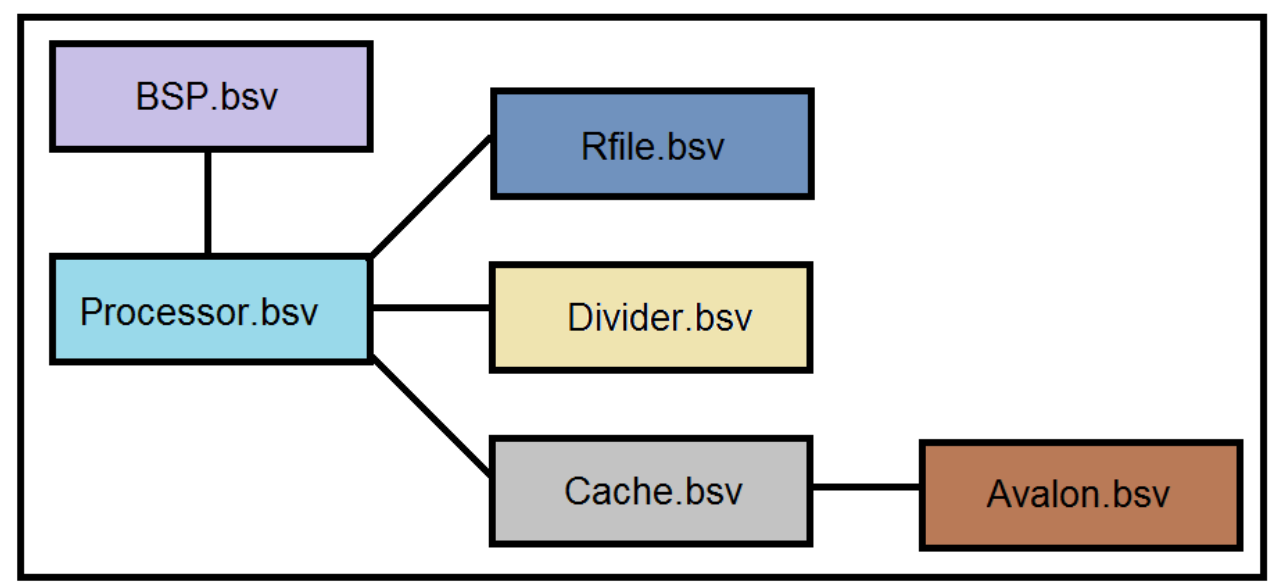

Figura 4.2: Módulos do Bluespec Soft-Processor 


\subsubsection{Conjunto de Instruções do BSP}

O ISA do Nios II possui um conjunto regular de 87 instruções, divididas em três tipos de formato: I-Type, R-Type e J-Type. Ademais, a linguagem assembly do Nios II inclui 19 pseudo instruções que são implementadas usando instruções equivalentes do conjunto regular. A Figura 4.3 ilustra a estrutura de cada um dos tipos de instrução do Nios II.

\begin{tabular}{|c|c|c|c|c|c|}
\hline & \multicolumn{5}{|c|}{ I-Type } \\
\hline Bits & $31: 27$ & $26: 22$ & \multicolumn{2}{|c|}{$21: 6$} & $5: 0$ \\
\hline Field description & A & B & \multicolumn{2}{|c|}{ IMM16 } & OP \\
\hline & \multicolumn{5}{|c|}{ R-Type } \\
\hline Bits & $31: 27$ & $26: 22$ & $21: 17$ & $16: 6$ & $5: 0$ \\
\hline \multirow[t]{2}{*}{ Field description } & A & B & $C$ & OPX & OP \\
\hline & \multicolumn{5}{|c|}{ J-Type } \\
\hline Bits & \multicolumn{4}{|c|}{$31: 6$} & $5: 0$ \\
\hline d descri & \multicolumn{4}{|c|}{ IMM26 } & OP \\
\hline
\end{tabular}

Figura 4.3: Formato binário das instruções dos tipos I, J e R

Com o intuito de alcançar a compatibilidade com o ISA do Nios II, a implementação das instruções do BSP obedecem ao formato das instruções do Nios II conforme apresentado na Figura 4.3. O Código a seguir exemplifica a definição de uma instrução do BSP codificada em Bluespec SystemVerilog.

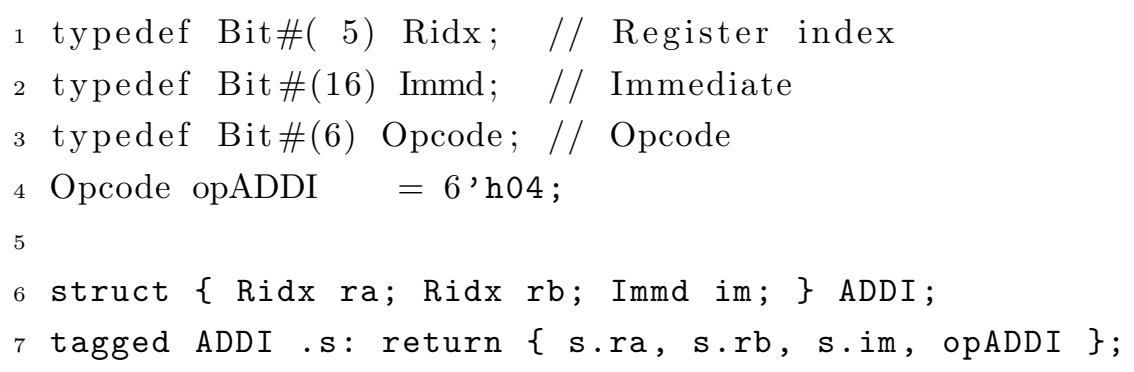

Entretanto, o BSP implementa 90\% do conjunto de instruções do Nios II, como pode ser observado na Tabela 4.1, que lista a quantidade total das instruções implementadas por tipo.

As instruções que não foram implementadas, incluem as que manipulam registradores específicos da arquitetura do Nios II, quando determinados blocos e ou unidades funcionais do processador estão presentes, como a MMU e a MPU, por exemplo. E também as instruções relacionadas com o tratamento de exceção do Nios II. O BSP não possui MMU nem MPU, e não possui uma unidade específica para controle e tratamento de exceção. 
Tabela 4.1: Instruções implementadas pelo BSP em relação ao ISA Nios II

\begin{tabular}{llll}
\hline $\begin{array}{l}\text { Instruçao } \\
\text { Tipo }\end{array}$ & Nios II & BSP & \\
\hline R-Type & 43 & 34 & 79 \\
I-Type & 42 & 41 & 97 \\
J-Type & 2 & 2 & 100 \\
Pseudo & 19 & 19 & 100 \\
Total (sem pseudo instrução) & 87 & 77 & 88 \\
Total (com pseudo instrução) & 106 & 96 & 90 \\
\hline
\end{tabular}

Portanto, ainda não foi possível alcançar uma total compatibilidade com o ISA do Nios II.

Contudo, considerando as instruções que foram implementadas, o BSP é capaz de executar conjuntos de programas sem erro, tais como os apresentados na Tabela 5.1, com código objeto gerado pelo compilador do Nios II. No entanto, programas que necessitam de MMU e MPU, como por exemplo, um sistema operacional, o BSP ainda não é capaz de executar. Dessa forma, a execução dos programas foi realizada através de simulação e também diretamente nas placas da Altera que contém os FPGAs Cyclone II ${ }^{1}$, Stratix IV ${ }^{2}$ e Stratix $V^{3}$.

Logo, cabe destacar que o BSP encontra-se integrado as ferramentas SOPC Builder e Qsys que fazem parte do Quartus II da Altera. No entanto, ainda não foi possível integrar o BSP ao ambiente gráfico para o desenvolvimento de programas em $\mathrm{C} / \mathrm{C}++$ do Nios II, a IDE Nios II EDS. Pois, sua integração depende do módulo de JTAG debug, que é implementado no core do Nios II. Esse módulo é o responsável pela integração do Nios II com a IDE. Portanto, devido ao código do Nios II ser encriptado e da falta de documentação especificando o módulo, ainda não foi encontrada uma solução para resolver esse problema de integração. Contudo, vale ressaltar que um ambiente de programação através de scripts é disponibilizado para compilação de códigos $C / C++$ para o BSP.

\subsection{Considerações Finais}

Neste Capítulo foi apresentado uma descrição do Bluespec Soft-Processor, sua arquitetura, conjunto de instruções e os módulos que compõem o core do processador e suas limitações.

No Capítulo 5 são detalhadas as fases de preparação e execução dos experimentos realizados com o Bluespec Soft-Processor.

\footnotetext{
${ }^{1}$ http://www.altera.com/devices/fpga/cyclone2/cy2-index.jsp

${ }^{2}$ http://www.altera.com/products/devkits/altera/kit-siv-gx.html

${ }^{3}$ http://www.altera.com/products/devkits/altera/kit-sv-gx-host.html
} 


\section{Preparação e Execução dos Experimentos Realizados}

\subsection{Considerações Iniciais}

Neste capítulo é definido a fase de preparação do ambiente e execução dos testes realizados com o processador desenvolvido neste projeto, o Bluespec Soft-Processor. Tanto a preparação do ambiente quanto a execução, são etapas que compõem a realização de testes. Na preparação são definidos os indivíduos que participarão dos testes e os recursos para a execução dos mesmos. Na execução os participantes desempenham as tarefas neles definidas, finalizando com a coleta de dados.

Na Seção 5.2 é apresentada a preparação para a realização dos testes, bem como o ambiente usado para realizá-los. Na Seção 5.3 são apresentados os testes realizados com o processador e na Seção 5.4 são apresentadas as considerações finais deste capítulo.

\subsection{Preparação para os Testes}

Antes que os testes fossem executados algumas tarefas foram realizadas, como a preparação do material e dos softwares a serem utilizados. 


\subsubsection{Ambiente de Testes}

O ambiente para realização dos testes foi construído usando as seguintes partes:

- Um computador com a seguinte configuração: Processador Intel core i7, com 16GB de memória $R A M$, rodando o sistema operacional Linux, distribuição Ubuntu versão 13.04;

- As ferramentas Bluespec - versão 2012.01.A, Quartus II e Nios II EDS devidamente instaladas e configuradas - versão 13.1;

- Seleção e instrumentação dos benchmarks utilizados, listados na Tabela 5.1;

- Uso da Placa Stratix V GX FPGA Development Kit;

Os benchmarks utilizados nos testes estão implementados na linguagem $C$, sendo que cada programa foi executado cem vezes na realização dos testes no FPGA.

A coluna "Kernel LOC"indica o número de linhas de código do kernel do benchmark, excluindo comentários e linhas vazias. Os kernels contêm uma grande variedade de tamanhos de código, de simples a complexos exemplos. As linhas de código variam entre 9-226. A coluna "Instruções assembly" indica o total de instruções assembly utilizadas na execução do benchmark.

\subsection{Execução dos Testes}

Nesta etapa os testes foram executados da seguinte forma:

Experimento I - Todos os benchmarks listados na Tabela 5.1, foram executados de forma simulada no Bluesim com a finalidade de encontrar erros de implementação na arquitetura do processador e do seu conjunto de instruções. Quando o BSP encontra uma instrução não implementada é gerada uma mensagem de erro e através do mecanismo de trace é possível localizar a instrução e ou módulo do processador que apresentou falha na execução. Na Subseção 5.3.1 são apresentados os resultados desse experimento;

Experimento II - Após a execução simulada, todos os benchmarks listados na Tabela 5.1, foram executados pelas versões do BSP (com e sem memória cache, com frequência de $50 \mathrm{MHz}$ ) no FPGA, onde foram feitas medidas de tempo de execução e contagem de ocorrências de miss e hit nas memórias cache de dados e instruções. Para as medidas de miss e hit foi implementado um monitor de cache em BSV no núcleo do BSP, os dados obtidos pelo monitor são lidos através de uma função em assembly direto no código $C$, o monitor foi implementado com o intuito de exemplificar uma customização que poder ser feita no BSP. Na Subseção 5.3.1 são apresentados os resultados desse experimento; 
Tabela 5.1: Benchmarks utilizados para realização dos testes

\begin{tabular}{|l|c|c|}
\hline \multicolumn{1}{|c|}{ Benchmark } & Kernel LOC & Instruções assembly \\
\hline adpcm_coder & 67 & 700 \\
\hline adpcm_decoder & 52 & 497 \\
\hline boundary & 18 & 1990 \\
\hline bubble_sort & 14 & 216 \\
\hline change_brightness & 24 & 219 \\
\hline compositing & 12 & 327 \\
\hline conv_3x3 & 81 & 295 \\
\hline crc32 & 15 & 893 \\
\hline divlu & 16 & 2350 \\
\hline gcd1 & 15 & 1652 \\
\hline idct_8x8 & 226 & 1739 \\
\hline isqrt1 & 21 & 930 \\
\hline isqrt2 & 16 & 916 \\
\hline isqrt3 & 17 & 239 \\
\hline isqrt4 & 18 & 226 \\
\hline mad_8x8 & 35 & 340 \\
\hline mad_16x16 & 36 & 464 \\
\hline median_3x3 & 82 & 781 \\
\hline modexp & 11 & 229 \\
\hline max & 9 & 1647 \\
\hline motion_estimation & 22 & 1703 \\
\hline perimeter & 35 & 451 \\
\hline pix_sat & 24 & 905 \\
\hline rgb_to_hsv & 57 & 529 \\
\hline rng & 177 & 377 \\
\hline sad_8x8 & 17 & 3123 \\
\hline sad_16x16 & 37 & 460 \\
\hline sobel & & \\
\hline viterbi_gsm & & \\
\hline & 17 & 170 \\
\hline
\end{tabular}

Experimento III - Para fins de comparação entre as versões do BSP e as dos cores (economy, standard e fast) do Nios II, foi feita a execução no FPGA dos benchmarks listados na Tabela 5.1 utilizando as versões do Nios II (frequência a $50 \mathrm{MHz}$ ). Na Subseção 5.3.1 são apresentados os resultados desse experimento;

Experimento IV - Foi gerado um conjunto de instruções (ISA) reduzido e específico do BSP para executar cada benchmark listado na Tabela 5.1. O ISA reduzido foi gerado através de um script (ilustrado na Figura 5.1) criado para tal finalidade, com o objetivo de avaliar a quantidade de elementos lógicos, frequência máxima, quantidade de registradores, Block Ram, estimação de potência consumida e DSPs utilizados do 
FPGA, em relação a uma versão do BSP com o ISA completo. Tal abordagem também serviu para complementar a justificativa do projeto, em desenvolver um processador de código open source, exemplificando a sua aplicabilidade e customizações que podem ser realizadas. Na Subseção 5.3.1 são apresentados os resultados desse experimento;

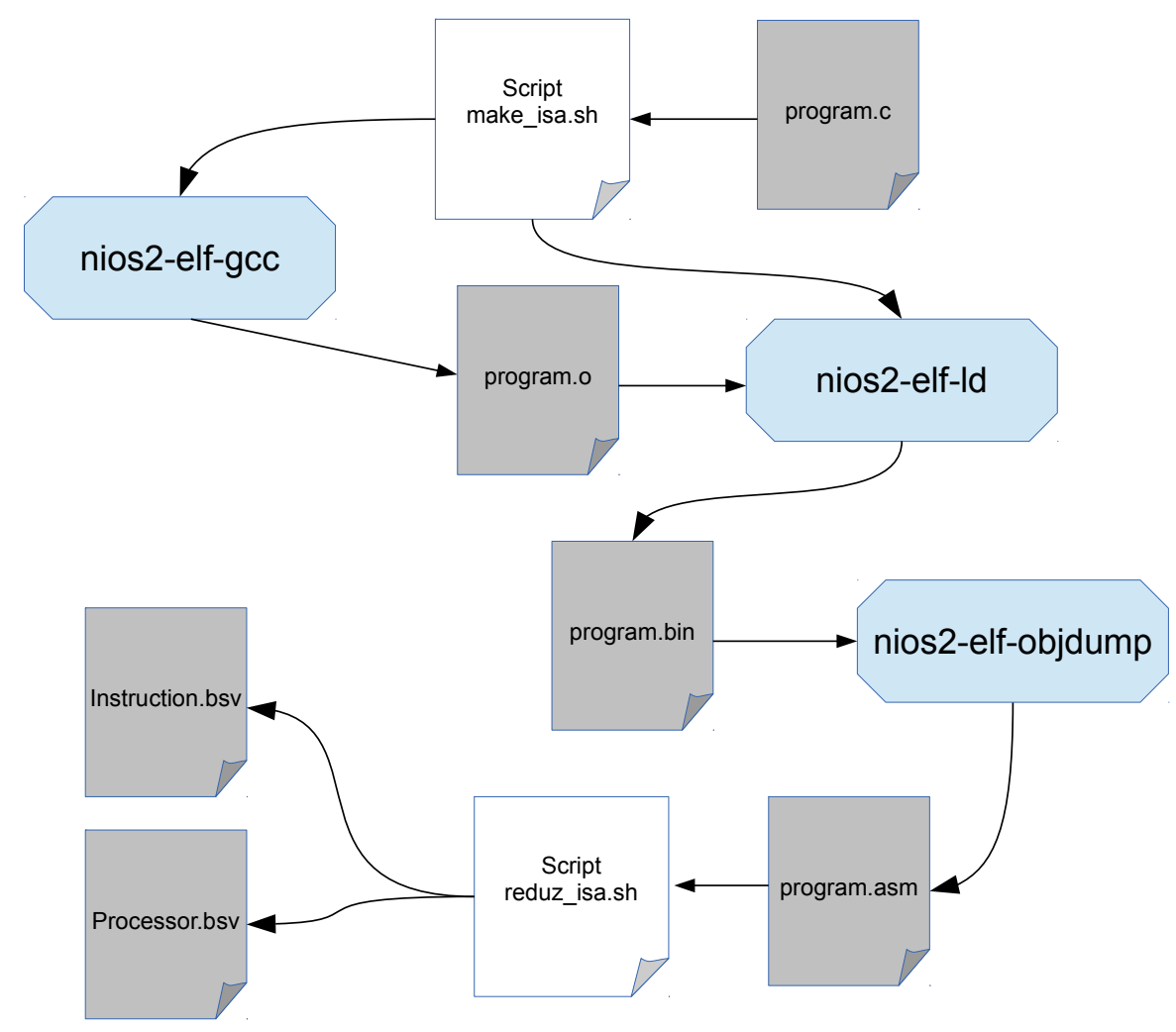

Figura 5.1: Estrutura interna do script make_isa.sh

O script make_isa.sh é responsável por gerar cores do BSP com ISA reduzido específico. Esse processo consiste em compilar (nios2-elf-gcc) o benchmark, que na Figura 5.1 é representado pelo program.c, gerando o program.o, o qual é usado como entrada para o nios2-elf-ld gerando o arquivo program.bin, que por sua vez é usado como entrada para o nios2-elf-objdump gerando o arquivo program.asm contendo o assembly do programa. $\mathrm{O}$ program.asm é lido pelo script reduz_isa.sh que identifica no arquivo as instruções que o program.c necessita para ser executado, gerando finalmente o arquivo Instruction.bsv, que contém as definições das instruções do processador e o arquivo Processor.bsv que contém a implementação das instruções. 


\subsubsection{Resultados}

\subsubsection{Experimento I}

Os dados obtidos na execução do Experimento I, são apresentados na Tabela 5.2. Esses dados correspondem ao número de ciclos que os programas levaram para serem simulados, e também aos números de da taxa de cache hit de dados (Dhit) e instruções (Ihit). Os dados de hit da cache exemplificam uma customização que pode ser no Bluespec Soft-Processor. Esses dados permitem avaliar o quão eficaz é o algoritmo de substituição da cache, permitindo ao usuário adequá-lo as suas necessidades. Outro fato a ser observado é que o número de ciclos indica uma estimativa de performance do BSP executando o programa, antes de sintetizá-lo para ser executado no FPGA.

Tabela 5.2: Dados obtidos na execução dos benchmarks descritos no Experimento I

\begin{tabular}{|c|c|c|c|}
\hline Benchmark & Ciclos & Taxa de Dhit & Taxa de Ihit \\
\hline adpcm-coder & 141557 & $81.11 \%$ & $98.84 \%$ \\
\hline adpcm-decoder & 113451 & $84.07 \%$ & $99.83 \%$ \\
\hline boundary & 376757 & $74.96 \%$ & $99.89 \%$ \\
\hline bubblesort & 103846 & $99.21 \%$ & $99.88 \%$ \\
\hline change_brightness & 31338 & $97.35 \%$ & $99.75 \%$ \\
\hline compositing & 91681 & $97.45 \%$ & $99.82 \%$ \\
\hline conv_3x3 & 37311 & $94.55 \%$ & $99.80 \%$ \\
\hline crc_32 & 168280 & $0.00 \%$ & $99.87 \%$ \\
\hline divlu & 1078644 & $0.00 \%$ & $99.89 \%$ \\
\hline $\operatorname{gcd} 1$ & 1161619 & $0.00 \%$ & $99.90 \%$ \\
\hline idct_8x8 & 389988 & $89.12 \%$ & $99.69 \%$ \\
\hline isqrt1 & 187864 & $0.50 \%$ & $99.79 \%$ \\
\hline isqrt2 & 394727 & $0.00 \%$ & $99.89 \%$ \\
\hline isqrt3 & 76437 & $4.76 \%$ & $99.86 \%$ \\
\hline isqrt4 & 64130 & $50.96 \%$ & $99.80 \%$ \\
\hline $\operatorname{mad} \_8 x 8$ & 532544 & $99.52 \%$ & $99.86 \%$ \\
\hline mad_16x16 & 2020547 & $99.76 \%$ & $99.88 \%$ \\
\hline $\max$ & 41057 & $0.00 \%$ & $99.87 \%$ \\
\hline median_3x3 & 213965 & $75.02 \%$ & $99.79 \%$ \\
\hline modexp & 1450296 & $97.31 \%$ & $99.87 \%$ \\
\hline motion_estimation & 2313494 & $98.53 \%$ & $99.19 \%$ \\
\hline perimeter & 38711 & $83.33 \%$ & $99.78 \%$ \\
\hline pixsat & 76875 & $62.49 \%$ & $99.89 \%$ \\
\hline rgbtohsv & 112547 & $88.46 \%$ & $99.74 \%$ \\
\hline rng & 85165 & $100 \%$ & $99.81 \%$ \\
\hline sad_8x8 & 57049 & $93.38 \%$ & $99.81 \%$ \\
\hline sad_16x16 & 105444 & $93.28 \%$ & $99.63 \%$ \\
\hline sobel & 128926 & $94.24 \%$ & $99.87 \%$ \\
\hline viterbi_gsm & 270357 & $98.76 \%$ & $99.80 \%$ \\
\hline
\end{tabular}




\subsubsection{Experimentos II e III}

Os dados obtidos ao executar os Experimentos II e III são apresentados na Tabela 5.3. Esses dados correspondem aos tempos de execução do BSP e dos cores do Nios II no FPGA. Com base nos dados, é possível observar que o BSP apresenta um desempenho melhor que a versão economy do Nios II. Esse fato é devido a esta versão do Nios II ser um core voltado para ocupar o menor espaço no FPGA, suas instruções de multiplicação e divisão não são implementadas em hardware, são emuladas em software, possui apenas um estágio de pipeline, e não possui memória cache de dados e instruções.

Entretanto, comparando o desempenho do BSP com o da versão standard em apenas três aplicações o BSP apresenta um melhor desempenho. Nas demais aplicações a versão standard do Nios II apresenta melhor desempenho, resultado semelhante ao apresentado pela versão fast, que comparada ao BSP apresenta desempenho pior em apenas duas aplicações.

Contudo, isso era o esperado, uma vez que podemos classificar a arquitetura do BSP como intermediária entre as versões standard e fast. Ademais, as versões standard e fast são bem mais otimizadas que a versão economy, pois ambas implementam as instruções de multiplicação e divisão em hardware, possuem cache de dados (apenas a fast) e instruções e possuem cinco e seis estágios de pipeline respectivamente.

Apesar das instruções de multiplicação e divisão do BSP serem implementadas em hardware, outros fatores impactam no seu desempenho em relação ao Nios II, tais como: não possuir branch predictor, possuir menos estágios de pipeline que as versões standard e fast, entre outros. Além disso, o Nios II é propriedade da Altera, o fabricante do FPGA em que os experimentos foram realizados, ou seja, ele é otimizado para esta plataforma. Por outro lado, o BSP teve sua implementação focada em atingir a maior compatibilidade com o conjunto de instruções do Nios II, e ser um soft-core open source de modo a permitir alterações diretas no código do processador. Por fim, na Figura 5.2 é apresentado um gráfico de speedup das versões do Nios II em relação ao BSP.

Ao observar o gráfico apresentado na Figura 5.2 é possível verificar os casos em que o desempenho apresentado pelo BSP foi melhor que as versões do Nios II. Analisando os casos em que o BSP obteve melhor desempenho em relação as versões standard e fast pode ser explicado pelo fato desses algoritmos realizarem uma grande quantidade de operações aritméticas. As operações de multiplicação do BSP, por exemplo, foram implementadas de modo a utilizar blocos de DSP do FPGA, sendo que na síntese da arquitetura do BSP são utilizados dezessete DSPs enquanto que as versões standard e fast do Nios II utilizam apenas dois, mesmo com o parâmetro de configuração de ambas as arquiteturas estar configurado para uso de DSPs para as instruções de divisão e multiplicação. Outro fator a ser levado em consideração é o fato do Nios II não estar executando apenas o algoritmo do programa em questão. Ele também executa pequenos trechos de código que fazem parte da biblioteca que compõe o projeto de software a ser executado, enquanto que o BSP executa apenas o código do algoritmo.

\subsubsection{Experimento IV}

Os dados obtidos com a realização do Experimento IV são apresentados na Tabela 5.4. Esses dados correspondem as sínteses feitas do BSP com ISA reduzido específico para os programas listados. Pode-se observar que a área ocupada no FPGA Stratix V foi reduzida 
Tabela 5.3: Dados obtidos na execução dos benchmarks descritos nos Experimentos II e III

\begin{tabular}{|c|c|c|c|c|}
\hline Benchmark & BSP $(\mathrm{ms})$ & Nios II_e (ms) & Nios II_s (ms) & Nios II_f (ms) \\
\hline adpcm-coder & 2.96 & 6.53 & 1.69 & 1.42 \\
\hline adpcm-decoder & 2.40 & 5.20 & 1.28 & 1.00 \\
\hline boundary & 7.59 & 18.25 & 3.45 & 3.28 \\
\hline bubblesort & 1.99 & 4.64 & 1.55 & 0.83 \\
\hline change_brightness & 0.78 & 1.42 & 0.37 & 0.22 \\
\hline compositing & 2.31 & 10.47 & 1.22 & 0.76 \\
\hline conv_3x3 & 0.78 & 10.89 & 0.54 & 0.24 \\
\hline crc_32 & 3.48 & 7.63 & 1.66 & 1.62 \\
\hline divlu & 21.61 & 91.15 & 11.13 & 8.47 \\
\hline gcd1 & 23.35 & 49.09 & 16.73 & 10.04 \\
\hline idct_8x8 & 6.74 & 42.15 & 4.43 & 2.62 \\
\hline isqrt1 & 3.87 & 102.91 & 4.06 & 3.78 \\
\hline isqrt2 & 8.01 & 19.20 & 4.72 & 3.37 \\
\hline isqrt3 & 1.68 & 4.00 & 0.56 & 0.57 \\
\hline isqrt4 & 1.44 & 3.08 & 0.50 & 0.46 \\
\hline mad_8x8 & 10.80 & 29.12 & 7.06 & 4.81 \\
\hline mad_16x16 & 40.55 & 112.16 & 27.18 & 18.08 \\
\hline max & 0.90 & 1.31 & 0.50 & 0.30 \\
\hline median_3x3 & 4.39 & 9.92 & 2.04 & 1.81 \\
\hline modexp & 29.17 & 941.51 & 19.12 & 15.75 \\
\hline motion_estimation & 46.35 & 119.19 & 30.78 & 20.42 \\
\hline perimeter & 0.91 & 1.91 & 0.44 & 0.24 \\
\hline pixsat & 1.64 & 3.24 & 0.78 & 0.63 \\
\hline rgbtohsv & 2.38 & 33.61 & 1.42 & 1.16 \\
\hline rng & 1.86 & 147.57 & 2.20 & 2.05 \\
\hline sad_8x8 & 1.29 & 3.06 & 0.70 & 0.47 \\
\hline sad_16x16 & 2.25 & 5.55 & 1.24 & 0.86 \\
\hline sobel & 2.72 & 6.77 & 1.52 & 0.82 \\
\hline viterbi_gsm & 5.55 & 13.68 & 3.14 & 1.84 \\
\hline & & & & \\
\hline & & & & \\
\hline
\end{tabular}




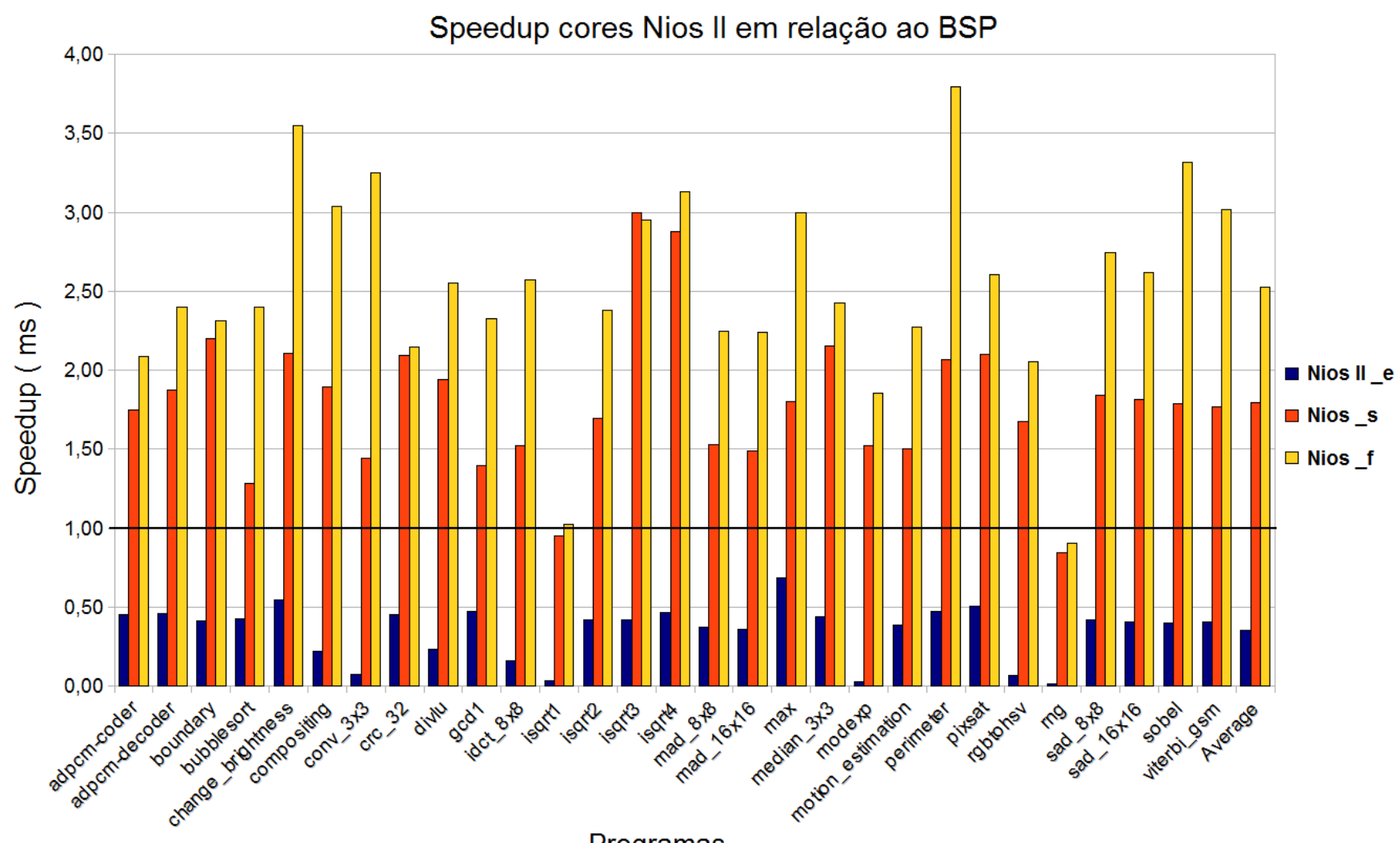

Programas

Figura 5.2: Speedup cores Nios II em relação ao BSP

em $50 \%$ para a maioria (19 de 27) dos programas analisados. O que é um bom indicativo para o experimento realizado, pois pode-se utilizar uma versão especifica do processador utilizando menos recursos no FPGA, se esse for um dos requisitos do projeto. Outra fato a ser observado é para os casos em que o uso de DSPs foi igual ou superior a $3 \%$ do total presente no FPGA houve redução na frequência do processador em relação a frequência atingida para os casos que utilizam $<1 \%$ e $2 \%$ do total (256). Na Figura 5.3 é apresentado um gráfico da porcentagem de elementos lógicos utilizados nos ISAs reduzidos específicos em função do total de elementos utilizados no ISA completo do BSP.

Ao observar o gráfico apresentado na Figura 5.3 é possível inferir que para essa classe de aplicações em específico (algoritmos para processamento de imagens) houve redução na utilização de elementos lógicos, pois, para 56\% dos programas que tiveram um ISA específico sintetizado houve uma redução de cerca de $30 \%$ dos elementos lógicos utilizados em relação ao ISA completo. Para $23 \%$ dos programas houve uma redução de cerca de $15 \%$, para $14 \%$ dos programas houve uma redução de cerca de $10 \%$ e para $7 \%$ dos programas uma redução de cerca $35 \%$.

A Figura 5.4 apresenta o gráfico da relação de utilização de registradores na síntese dos ISAs reduzidos específicos e do ISA completo do BSP. A partir do gráfico pode-se observar que a utilização média de registradores dos ISAs reduzidos é de $90,44 \%$ em relação ao ISA completo. Nesse sentido, a utilização de um core reduzido específico do BSP provê um ganho médio de 9,56\% em termos de redução da área utilizada do FPGA. Tal redução ocorre, pois o impacto que a redução média do número de registradores tem 
Tabela 5.4: Dados obtidos na execução dos programas descritos no Experimento IV

\begin{tabular}{|c|c|c|c|c|c|c|}
\hline \multicolumn{7}{|c|}{ FPGA: Stratix V - 5SGXEA7K2F40C2 } \\
\hline Benchmark & Fmax $(\mathrm{MHz})$ & & & $\mathrm{LMs}$ & & DSP Blocks \\
\hline & & Total ALMs & LUT & ALUT & Registradores & \\
\hline BSP ISA Completo & 76,59 & 4082 & 3150 & 5896 & 2386 & 17 \\
\hline adpcm-coder & 93,16 & 2667 & 1764 & 3667 & 2189 & 4 \\
\hline adpcm-decoder & 92,54 & 2587 & 1722 & 3610 & 2192 & 2 \\
\hline boundary & 89,81 & 3623 & 2692 & 5229 & 2383 & 4 \\
\hline bubblesort & 89,81 & 3623 & 2692 & 5229 & 2383 & 4 \\
\hline change_brightness & 75,91 & 2509 & 1602 & 3368 & 2188 & 7 \\
\hline compositing & 78,41 & 2623 & 1753 & 3578 & 2189 & 9 \\
\hline conv_3x3 & 92,87 & 2590 & 1715 & 3555 & 2189 & 4 \\
\hline crc_32 & 88,66 & 2785 & 2009 & 3787 & 2189 & 4 \\
\hline divlu & 75,66 & 2910 & 2045 & 4053 & 2189 & 12 \\
\hline $\operatorname{gcd} 1$ & 76,09 & 2797 & 1922 & 3834 & 2191 & 12 \\
\hline idct_8x8 & 94,48 & 2875 & 2017 & 3946 & 2189 & 4 \\
\hline isqrt1 & 77,84 & 3822 & 2920 & 5542 & 2384 & 12 \\
\hline isqrt2 & 76,1 & 2802 & 1960 & 3919 & 2191 & 12 \\
\hline isqrt3 & 97,97 & 2575 & 1706 & 3543 & 2187 & 2 \\
\hline isqrt4 & 99,69 & 2690 & 1834 & 3658 & 2188 & 2 \\
\hline mad_16x16 & 98,15 & 2602 & 1763 & 3596 & 2187 & 2 \\
\hline $\max$ & 87,89 & 3704 & 2755 & 5253 & 2386 & 4 \\
\hline median $\_3 x 3$ & 97,84 & 3445 & 2472 & 4964 & 2384 & 2 \\
\hline modexp & 93,64 & 3492 & 2568 & 5054 & 2382 & 2 \\
\hline motion_estimation & 87,21 & 3661 & 2730 & 5229 & 2386 & 4 \\
\hline perimeter & 98,55 & 2506 & 1618 & 3460 & 2188 & 2 \\
\hline pixsat & 87,69 & 2714 & 1866 & 3670 & 2189 & 4 \\
\hline rgbtohsv & 92,43 & 3759 & 2647 & 5224 & 2385 & 2 \\
\hline rng & 92,43 & 3759 & 2647 & 5224 & 2385 & 2 \\
\hline sad_16x16 & 68,9 & 3731 & 2880 & 5429 & 2384 & 12 \\
\hline sobel & 92,48 & 2507 & 1608 & 3410 & 2188 & 4 \\
\hline viterbi_gsm & 95,86 & 2474 & 1594 & 3447 & 2190 & 2 \\
\hline
\end{tabular}


CAPÍTULO 5. PREPARAÇÃO E EXECUÇÃO DOS EXPERIMENTOS

REALIZADOS

\section{Relação elementos lógicos utilizados BSP ISA reduzido X BSP ISA completo}

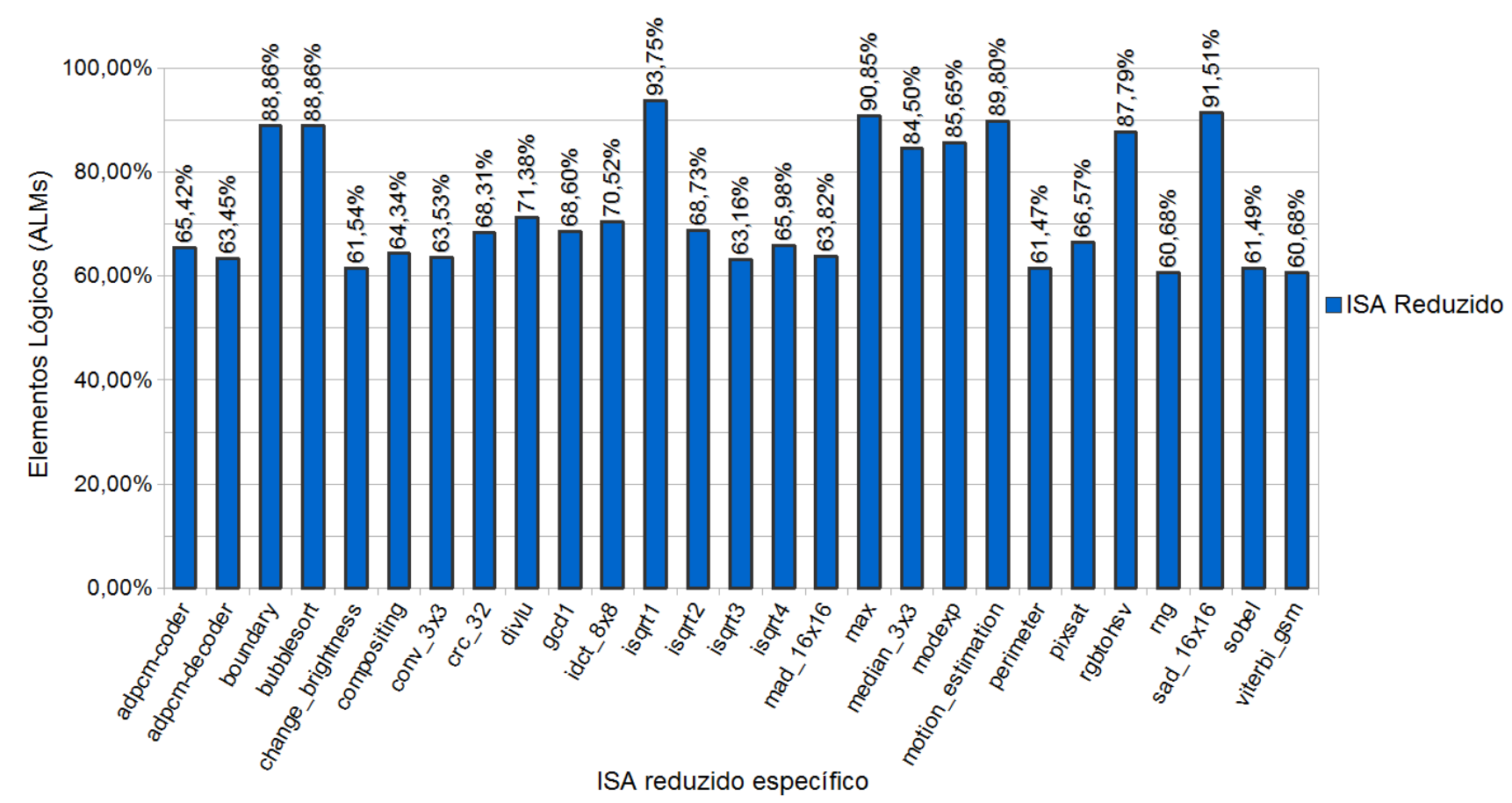

Figura 5.3: Relação de elementos lógicos utilizados entre o BSP ISA reduzido específico X BSP ISA completo

sobre a redução média das ALUTs, atua na redução média dos elementos lógicos utilizados (ALMs).

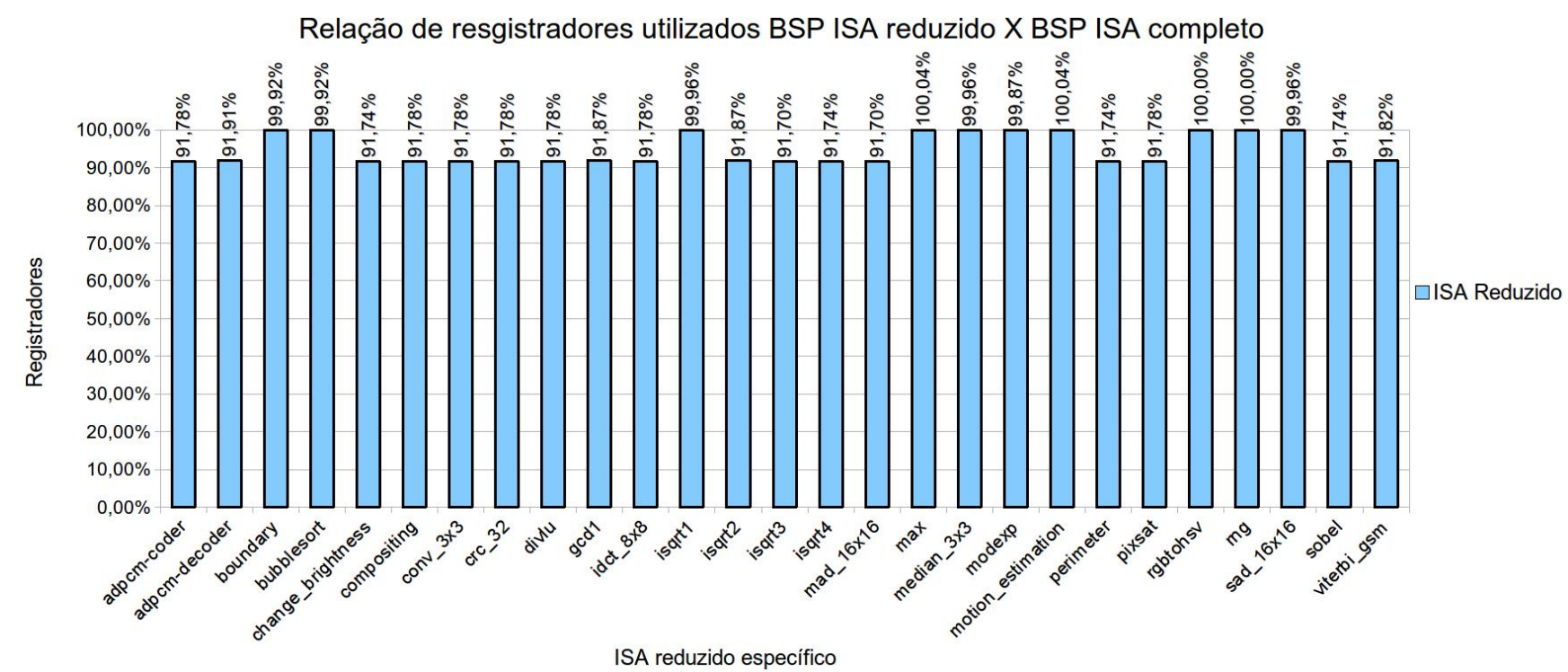

Figura 5.4: Relação de registradores utilizados entre BSP ISA reduzido específico X BSP ISA completo

A Figura 5.5 ilustra a estrutura de um ALM (Adaptive Logic Module) do FPGA Stratix V utilizado no experimento e colabora para o entendimento da relação redução do número de registradores com o número de elementos lógicos utilizados. Desse modo, 
como ilustrado na Figura 5.5, cada ALM é composto por recursos baseados em LUTs que podem ser divididos em duas ALUTs (Adaptive Look-up Tables) combinatórias e quatro registradores. Outro fator a ser considerado é a etapa de Place and Route, a qual faz a alocação e a destinação dos recursos utilizados no FPGA, sendo que as operações feitas no Place and Route ficam a cargo da ferramenta de síntese, também levando em consideração as restrições informadas pelo usuário, no caso do Quartus II ele configura os ALMs para obter o melhor desempenho e reduzir o tempo de compilação do projeto.

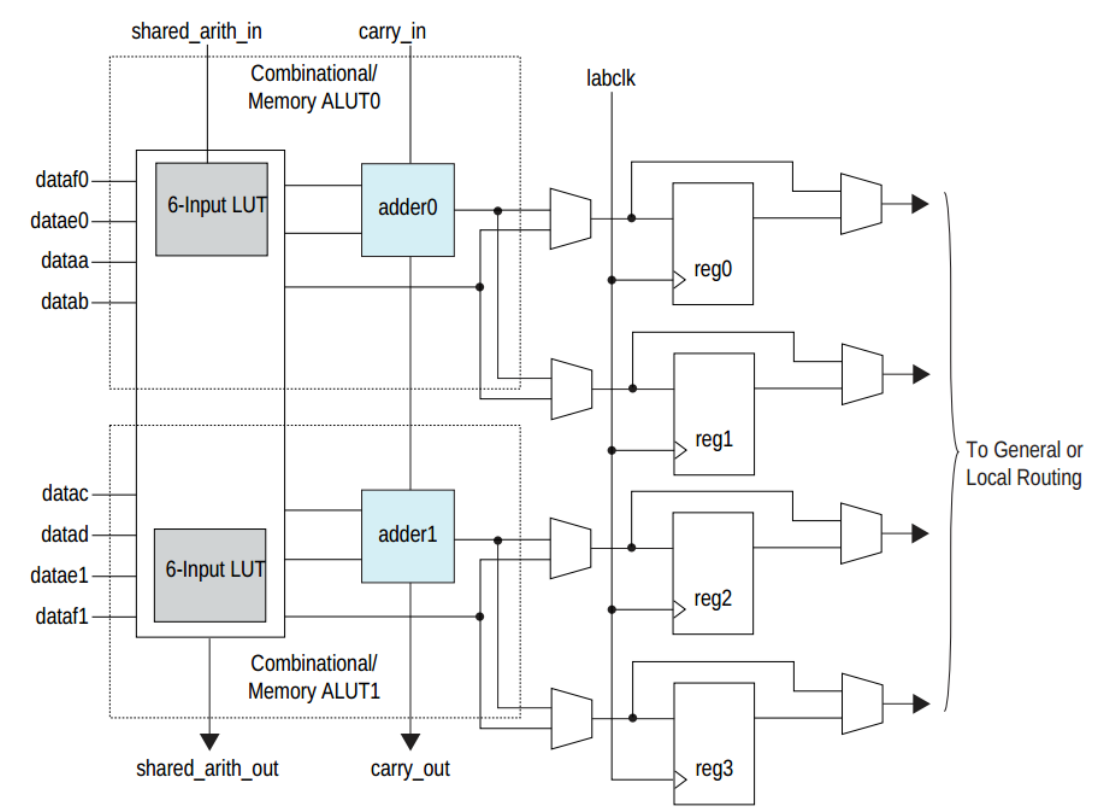

Figura 5.5: Estrutura de ALM FPGA Stratix V

Outra característica analisada no Experimento IV foi a frequência (em MHz) alcançada pelos cores com ISA reduzido específico em relação ao core com o ISA completo. A Figura 5.5 ilustra o gráfico gerado com base nos dados apresentados na Tabela 5.4. O gráfico apresenta as frequências alcançadas em termos de porcentagem. Dessa forma, é possível observar que o ganho médio no aumento da frequência foi de 120,68\% em relação ao core do BSP com ISA completo. De acordo com os dados apresentados na Tabela 5.4, a redução no número de elementos lógicos e DSPs utilizados, foram os fatores que impactaram no aumento da frequência do cores reduzidos, pois com a redução dos ALMs, há uma maior proximidade entre os elementos utilizados

As medições de estimação de potência foram realizadas utilizando a ferramenta Power Analyzer da Altera. Os dados referentes a estimação de potência são apresentados na Tabela ??. Para melhor visualização dos dados foi construído um gráfico que é ilustrado na Figura 5.7. Com base no gráfico é possível observar que houve redução do consumo estimado de potência entre os cores com ISA reduzido, assim como também houveram cores que obtiveram uma estimativa maior que o core com ISA completo. Logo é possível afirmar que há instruções que possuem um maior e ou menor consumo de potência em relação as outras, no entanto, para identificar as instrução com maior consumo, faz-se necessário um experimento mais específico de modo a isolar as instruções e realizar a medição. 
CAPÍTULO 5. PREPARAÇÃO E EXECUÇÃO DOS EXPERIMENTOS

Relação Fmax BSP ISA reduzido X BSP ISA completo

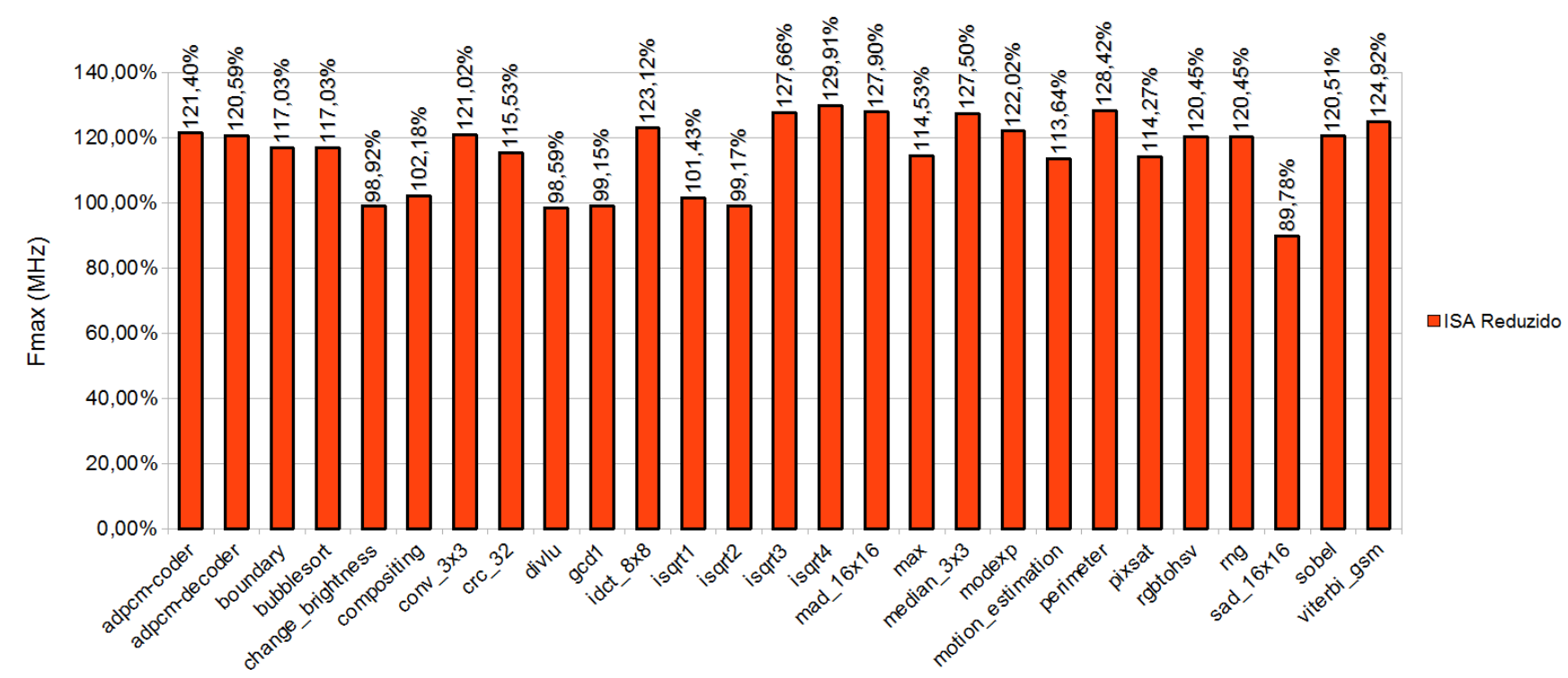

ISA reduzido específico

Figura 5.6: Relação de Fmax alcançada pelos cores específicos com ISA reduzido em relação ao ISA completo

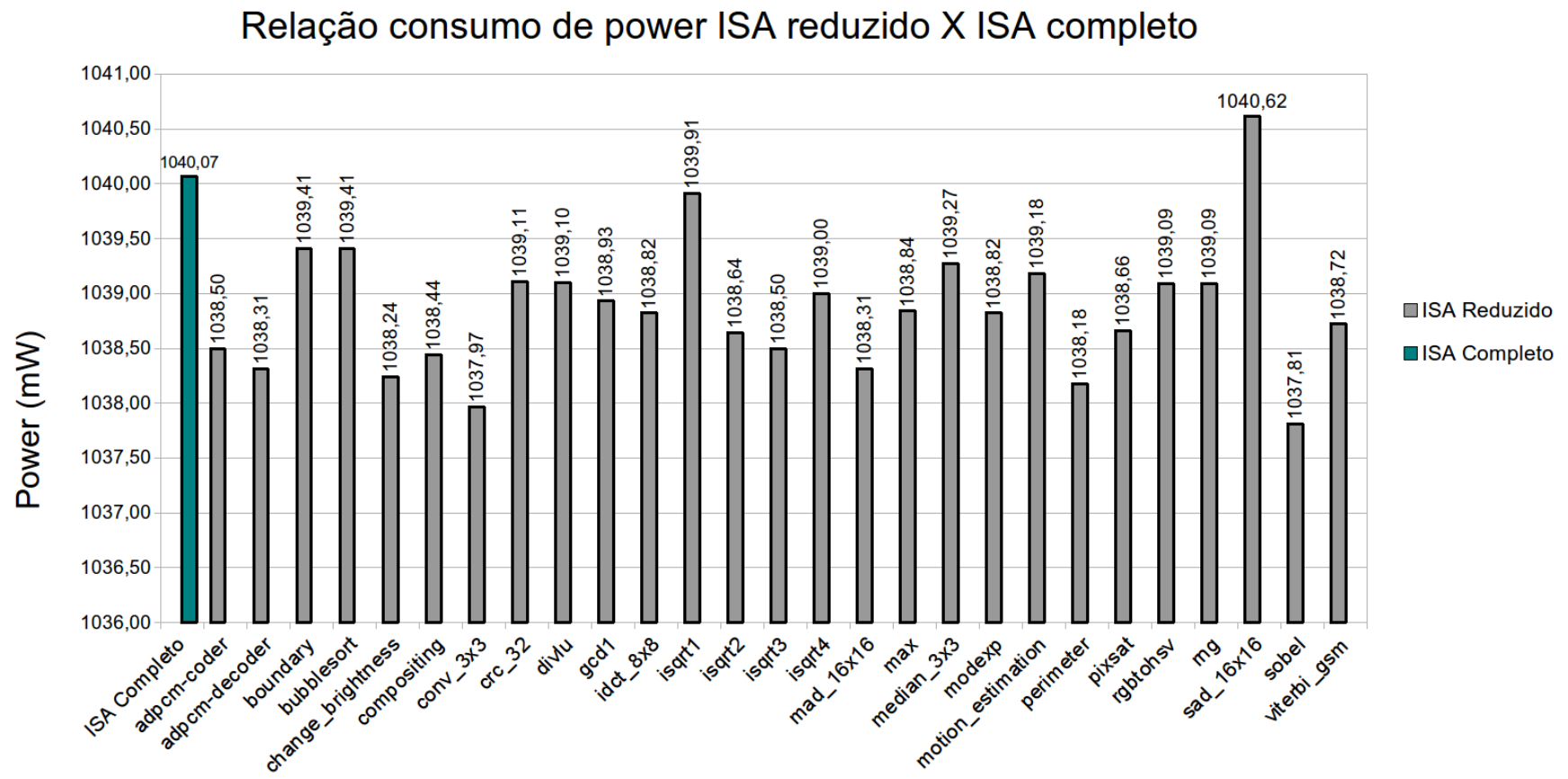

ISA específico reduzido

Figura 5.7: Relação de potência estimada pelos cores específicos com ISA reduzido em relação ao ISA completo

Por fim, é apresentado um gráfico da relação entre o número de DSPs utilizados nos ISAs reduzidos específicos e o BSP ISA completo, o gráfico é ilustrado na Figura 5.8. A partir do gráfico é possível observar a redução média de quatro DSPs utilizando um ISA específico em relação ao ISA completo. Outra observação a ser feita, é que o aumento do 
uso de DSPs implica na redução de ALMs utilizados, pois sem o uso dos blocos de DSP as operações que eles executam seriam implementadas utilizando os ALMs.

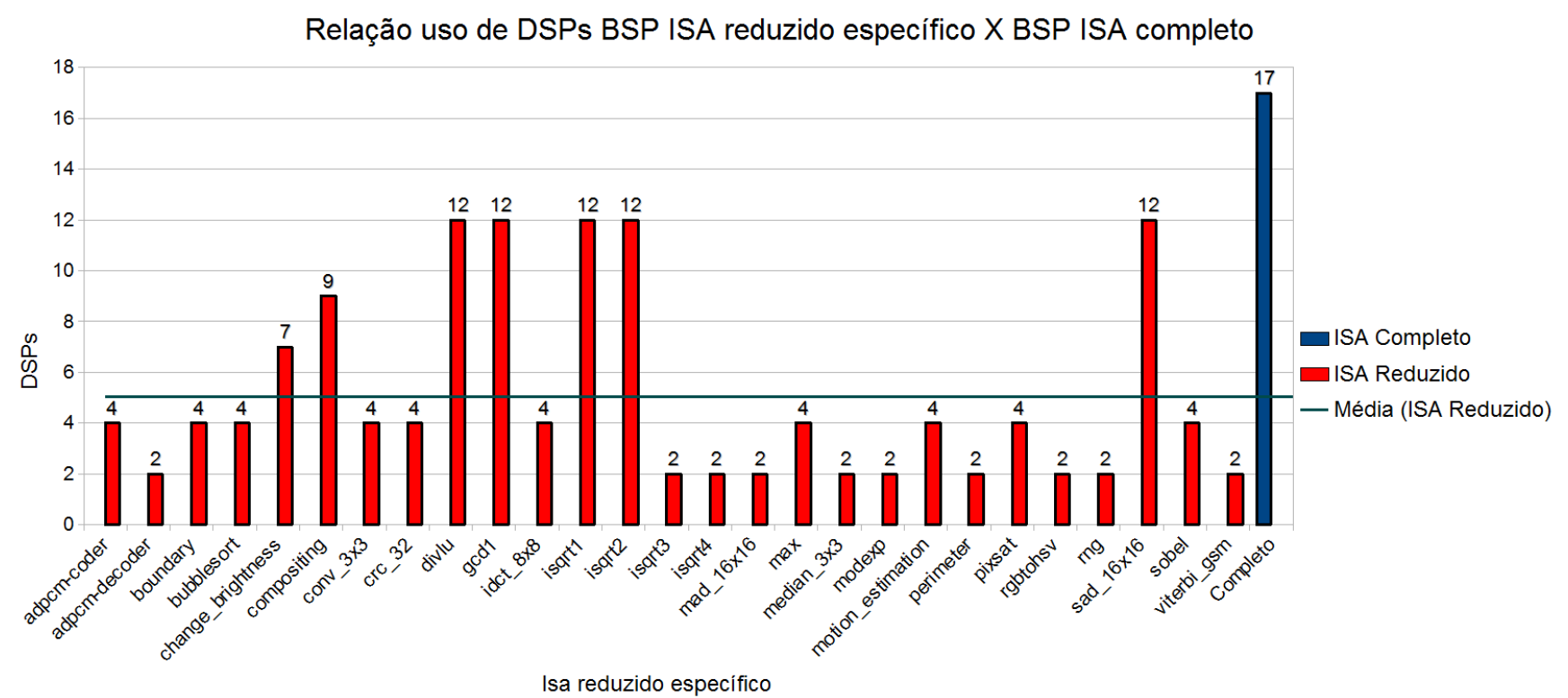

Figura 5.8: Número de DSPs utilizados nos ISAs reduzidos específicos em relação ao BSP ISA completo

Portanto, a realização desse experimento teve como objetivo avaliar os ganhos e ou perdas do BSP ISA completo em relação a um core com um ISA reduzido específico, e demonstrar o benefício em se utilizar um processador de código open source. Porque, reduzir o ISA do processador para executar uma aplicação específica, é uma abordagem usada para reduzir os elementos lógicos na síntese, eficiência energética, dentre outras. Uma vez que, num ISA completo nem todas as instruções são utilizadas, o que ocorre numa sobrecarga. Contudo, para obter uma melhor eficiência energética com a redução do ISA, faz-se necessário que haja um compilador que gere código otimizado para essa finalidade, pois, código otimizado impacta na redução do consumo de energia (She et al., 2008).

\subsection{Considerações Finais}

Neste capítulo foi descrito todo processo de execução dos testes realizados, desde a seleção das partes e o ambiente utilizado, até a execução dos testes para obtenção dos resultados e a apresentação dos resultados obtidos na realização dos testes. Para efeitos de replicação é importante a descrição da execução dos testes para facilitar a reprodução do mesmo. 



\section{Capítulo \\ 6 \\ Conclusão}

\subsection{Caracterização da Pesquisa Realizada}

Este trabalho teve por objetivo desenvolver um processador open source do tipo soft-core compatível com o conjunto de instruções do Nios II, possibilitando utilizar o rico conjunto de IPs e todo o ferramental disponibilizado pela Altera. Para isso foi utilizada a linguagem de descrição de hardware Bluespec System Verilog, por ser uma HDL baseada no paradigma ESL, com descrição e síntese em alto nível.

Este trabalho colabora com o desenvolvimento de arquiteturas de hardware que utilizam o Nios II como unidade de processamento, fornecendo uma alternativa para uma maior customização da CPU e utilizando o mesmo ambiente (ecossistema de ferramentas da Altera) do Nios II com exceção da IDE Nios II EDS. O Bluespec Soft-Processor apesar de implementar o conjunto de instruções do Nios II e o seu barramento, é independente de plataforma de FPGA, podendo ser sintetizado para FPGAs da Xilinx, por exemplo.

O fato do processador ter sido especificado numa linguagem ESL é uma grande vantagem no desenvolvimento e aprendizado de Arquitetura de Computadores, pois, o alto nível de abstração da linguagem possibilita um rápido aprendizado. Ademais, os experimentos realizados com o processador demonstram a sua funcionalidade e compatibilidade com o ISA do Nios II. Apesar dessa compatibilidade não ser 100\%, devido à unidades funcionais que o Nios II implementa e que o BSP não dispõe, vale destacar que a falta dessas instruções não o inviabiliza para os objetivos iniciais propostos neste trabalho.

\subsection{Dificuldades e Limitações}

Durante a execução do trabalho algumas dificuldades e limitações ocorreram: A primeira dificuldade encontrada foi durante a fase de implementação do processador executando programas em $C$ com variável global, uma vez que o resultado retornado ao término da execução não era o esperado. Após alguns meses de testes o problema foi solucionado 
corrigindo o script que convertia o binário do programa para o formato hexadecimal a ser copiado na memória.

Outra dificuldade encontrada foi na integração do BSP a ferramenta IDE Nios II EDS, uma vez que, para que tal fato ocorra é necessário a implementação do módulo de JTAG debug, que é interno ao Nios II (código fechado). Além disso, a documentação referente a esse módulo não fornece detalhes da sua implementação. As principais limitações a serem destacadas são: 1) a interface de desenvolvimento e compilação do código $C$, que atualmente é realizada através de scripts; 2) A falta de uma unidade de tratamento de exceções; 3) Não possuir total compatibilidade com o ISA do Nios II.

Contudo, apesar de não ser uma ideia inovadora, durante a pesquisa realizada não foi encontrado nenhum soft-core open source que implemente o conjunto de instruções do Nios II, mesmo que de forma parcial.

\subsection{Trabalhos Futuros}

Como trabalhos futuros destacam-se:

1. O desenvolvimento das unidades funcionais (ver Tabela 6.1) que o Nios II possui, permitindo dessa forma que sejam implementadas as instruções restantes no BSP. Assim como portar um sistema operacional que possa ser utilizado em conjunto com o BSP, e implementar e ou adaptar uma unidade de ponto flutuante. Implementar uma unidade de Tratamento de Exceção/Interrupção, a Figura 6.1 ilustra um diagrama para a implementação da unidade.

Tabela 6.1: Características das arquiteturas Nios II x BSP X BSP V2

\begin{tabular}{llll}
\hline & Nios II & BSP & BSP V2 \\
\hline Register File & $\mathrm{x}$ & $\mathrm{x}$ & $\mathrm{x}$ \\
Arithmetic Logic Unit & $\mathrm{x}$ & $\mathrm{x}$ & $\mathrm{x}$ \\
Custom Instruction Interface & $\mathrm{x}$ & $\mathrm{x}$ & $\mathrm{x}$ \\
Exception Handler & $\mathrm{x}$ & - & $\mathrm{x}$ \\
Interruption Controller & $\mathrm{x}$ & - & $\mathrm{x}$ \\
Data/Instruction Bus & $\mathrm{x}$ & $\mathrm{x}$ & $\mathrm{x}$ \\
Memory Management Unit - MMU & $\mathrm{x}$ & - & $\mathrm{x}$ \\
Memory Protection Unit - MPU & $\mathrm{x}$ & - & $\mathrm{x}$ \\
Data/Instruction Cache Memory & $\mathrm{x}$ & - & $\mathrm{x}$ \\
Data/Instruction Coupled Memory Interfaces & $\mathrm{x}$ & - & - \\
Multi-core & - & - & $\mathrm{x}$ \\
\hline
\end{tabular}

2. Intensificar o estudo de uma forma alternativa, que possa auxiliar na integração do BSP ao ambiente gráfico Nios II EDS, fornecendo assim uma interface amigável para o desenvolvimento e execução de programas em $C$. Pois, atualmente toda a programação é feita por meio de scripts, os quais são descritos neste trabalho.

3. Continuar com o desenvolvimento deste processador de forma a implementar as características apresentadas na Tabela 6.1, que fazem um comparativo entre a versão 


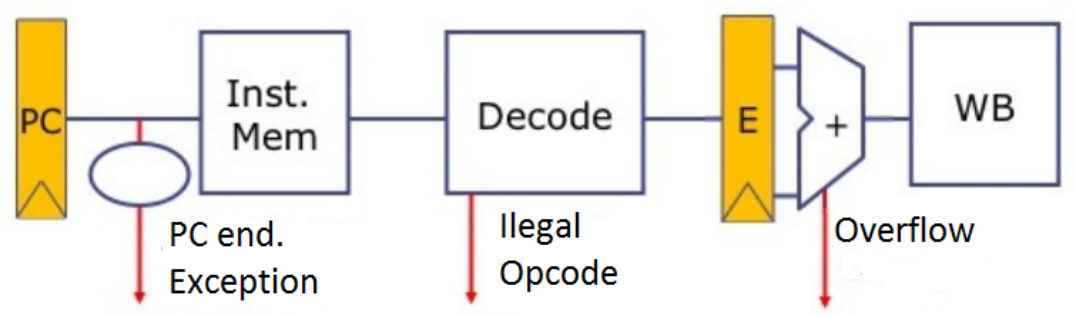

Figura 6.1: Manipulador de exceção/interrupção

atual do BSP com o Nios II e a segunda versão do BSP, a qual espera-se estar totalmente compatível com o Nios II, isso inclui instruções e unidades funcionais.

4. Implementar uma versão Multicore do BSP, fornecendo interfaces diretas de programação para os cores do BSP através de métodos (get e set). Esses métodos estaram acessíveis para os usários utilizarem em assembly direto. Sendo possível designar o que cada core irá executar, bem como obter o resultado de processamento de casa core separadamente. A Figura 6.2 ilustra a arquitetura proposta a ser desenvolvida.

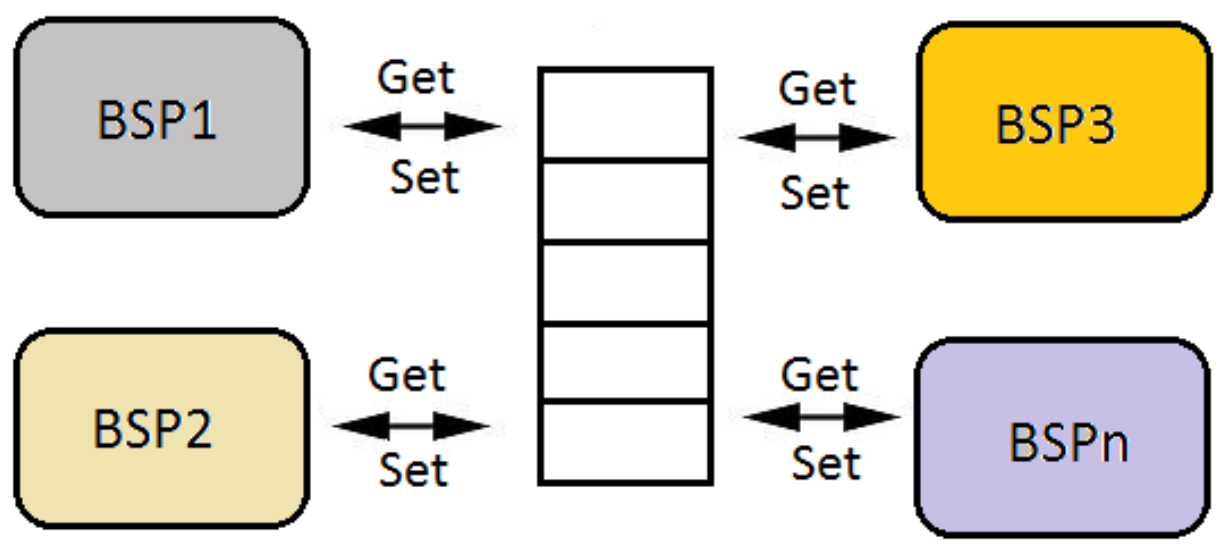

Figura 6.2: Proposta de arquitetura multicore

5. Realizar experimentos com a finalidade de demonstrar como o BSP pode ser utilizado para fins de ensino/aprendizado. Na Figura 6.3 estão presentes características que podem ser estudadas, tais como stall no pipeline, número de ciclos, números de miss e hit da cache de dados e de instruções, e dentre outras.

Já na Figura 6.4 é ilustrada uma das modificações pretendidas com os experimentos. Ao modificar o número de estágios de pipeline do BSP, pretende-se analisar o impacto dessa modificação em termos de frequência máxima alcançada, área ocupada no FPGA, dentre outras características. 


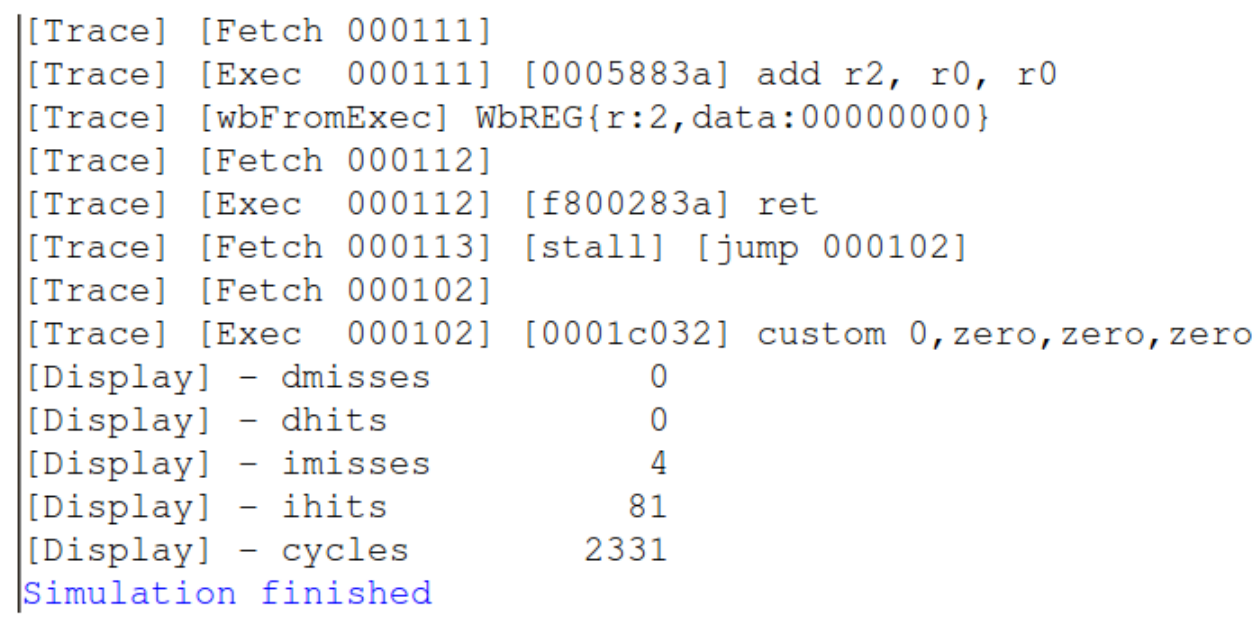

Figura 6.3: Exemplo de um trace do BSP executando em modo simulado

\begin{tabular}{|l|c|c|c||c|}
\hline & Nios II/e & Nios II/s & Nios II/f & BSP \\
\hline Fmax & $200 \mathrm{MHz}$ & $165 \mathrm{MHz}$ & $185 \mathrm{MHz}$ & $50 \mathrm{MHz}$ \\
\hline Área (LEs) & 700 & 1400 & 1800 & 2038 \\
\hline Pipeline & 1 & 5 & 6 & 3 \\
\hline
\end{tabular}

Figura 6.4: Exemplo de características a serem analisadas nos experimentos 


\section{Referências}

Agarwal, A.; Ng, M. C.; Arvind Comparison of high level design methodologies for algorithmic IPs: Bluespec and C-based synthesis, 2009.

Disponível em http://dspace.mit.edu/bitstream/handle/1721.1/46612/ 426039412.pdf?sequence=1 (Acessado em 07/2010)

Altera Nios II embedded processor backgrounder, 2007.

Disponível em http://www.altera.com/literature/pr/nios2_backgrounder.pdf (Acessado em 11/2007)

Altera Avalon interface specifications, 2011a.

Disponível em http://www.altera.com/literature/manual/mnl_avalon_spec.pdf (Acessado em 10/2012)

Altera Nios II processor reference handbook. 2011b.

Disponível em http://www.altera.com/literature/hb/nios2/n2cpu_nii5v1.pdf (Acessado em 05/2011)

Altera Processor architecture, user guide, 2011c.

Disponível em http://www.altera.com/literature/hb/nios2/n2cpu_nii51002. pdf

Altera Qsys system integration tool, 2011d.

Disponível em http://66.35.202.58/literature/po/ss-qsys.pdf (Acessado em 08/2011)

Arvind; Asanovic, K. Complex digital systems, 2005.

Disponível em http://csg.csail.mit.edu/6.884/index.html (Acessado em $09 / 2011)$

Bacon, D.; Rabbah, R.; Shukla, S. FPGA programming for the masses. Queue, v. 11, n. 2, p. 40:40-40:52, 2013.

Disponível em http://doi.acm.org/10.1145/2436696.2443836

Barros, A.; de Souza Lehfeld, N. Fundamentos de metodologia científica: um guia para a iniciação científica. 2 ed. Makron Books, 78 p., 2000.

Black, D. C.; Donovan, J. SystemC: from the ground up. USA: Springer, 244p, 2005. 
Bluespec Bluespec SystemVerilog user guide, 2011.

Disponível em http://www.bluespec.com/forum/download.php?id=107 (Acessado em 06/2011)

Bluespec 2014 .

Disponível em http://bluespec.com/high-level-synthesis-tools.html (Acessado em 01/2014)

Bobda, C. Introduction to reconfigurable computing: Architectures, algorithms, and applications. 1st ed. Springer Publishing Company, Incorporated, 2007.

Bonato, V.; Sanches, A. K.; Fernandes, M.; Cardoso, J. M. P.; Simoes, E.; Marques, E. A real time gesture recognition system for mobile robots. In: International Conference on Informatics in Control, Automation, and Robotics (ICINCO04), Portugal, 2004, p. $207-214$.

Chu, S.-L.; Li, G.-S.; Liu, R.-Q. Caliburn: A MIPS32 VLIW processor with hardware instruction morphing mechanism [caliburn - procesor VLIW MIPS32 ze sprzeogonektowym mechanizmem morfingu]. Przeglad Elektrotechniczny, v. 89, n. 3 B, p. 10-12, cited By (since 1996)0, 2013.

Coussy, P.; Gajski, D. D.; Meredith, M.; Takach, A. An introduction to high-level synthesis. IEEE Design and Test of Computers, v. 26, p. 8-17, 2009.

Coussy, P.; Morawiec, A. High-level synthesis: from algorithm to digital circuit. Springer, 300p, 2008.

Dave, N. H. Designing a processor in Bluespec. Dissertação de Mestrado, Department of Electrical Engineering and Computer Science at the Massachusetts Institute of Technology, 2005.

Densmore, D.; Sangiovanni-Vincentelli, A.; Passerone, R. A platform-based taxonomy for ESL design. IEEE Journal on Design $\&$ Test of Computers, v. 23, n. 5, p. 359-374, 2006 .

Drechsler, R. Towards formal verification on the system level. In: Proceedings of the 15th IEEE International Workshop on Rapid System Prototyping (RSP), Washington, DC (USA): IEEE Computer Society, 2004, p. 2-5.

Ekanadham, K.; Tseng, J.; Pattnaik, P. IBM PowerPC design in Bluespec. Relatório Técnico, IBM Research Division, 2008.

Gaisler, A. SPARC V8 32-bit processor LEON3/LEON3-FT companioncore data sheet, 2011.

Disponível em http://www.actel.com/ipdocs/LEON3_DS.pdf (Acessado em 07/2011)

Gerstlauer, A.; Haubelt, C.; Pimentel, A.; Stefanov, T.; Gajski, D.; Teich, J. Electronic system-level synthesis methodologies. Computer-Aided Design of Integrated Circuits and Systems, IEEE Transactions on, v. 28, n. 10, p. 1517-1530, 2009. 
Gokhale, M.; Graham, P. S. Reconfigurable computing accelerating computation with field-programmable gate arrays. 1st ed. Dordrecht, Netherlands: Springer, 2005.

Graphics, M. 2014.

Disponível em http://www.mentor.com/esl/ (Acessado em 01/2014)

Gruian, F.; Westmijze, M. BlueJEP: A flexible and high-performance java embedded processor. In: Proceedings of the JTRES 2007, Vienna, Austria: ACM Press, 2007, p. $222-230$.

Gruian, F.; Westmijze, M. VHDL vs. Bluespec SystemVerilog: a case study on a Java embedded architecture. In: SAC '08: Proceedings of the 2008 ACM symposium on Applied computing, New York, NY, USA: ACM, 2008, p. 1492-1497.

Gruian, F.; Westmijze, M. Investigating hardware micro-instruction folding in a java embedded processor. In: Proceedings of the 8th International Workshop on Java Technologies for Real-Time and Embedded Systems, New York, NY, USA: ACM, 2010, p. $102-108$.

Harris, D. M.; Harris, S. L. Digital design and computer architecture. 1st ed. Elsevier, Incorporated, 2007.

Hauck, S.; DeHon, A. Reconfigurable computing: the theory and practice of FPGA-based computation. 1st ed. Burlington, United States: Elsevier, 2008.

Hennessy, J.; Patterson, D. Arquitetura de computadores: uma abordagem quantitativa. 3st ed. Campus, 2003.

Hsiung, P.-A.; Santambrogio, M. D.; Huang, C.-H. Reconfigurable system design and verification. 1st ed. London, New York: Taylor \& Francis Group, CRC Press, 2009.

Jones, S. P. Haskell 98 Language and Libraries The Revised Report, 2014.

Disponível em <http://www.haskell.org/definition/haskell98-report.pdf (Acessado em 02/2014)

Lima, W. d. S.; Lobato, R. S.; da Silva, A. C. F.; e Roberta Spolon Ulson Simulação de execução de instruções do processador de nucleo virtual Nios II. In: XXXIV Conferencia Latinoamericana de Informatica (CLEI), 2008, p. 649-658.

Martin, G.; Bailey, B.; Piziali, A. ESL design and verification: A prescription for electronic system level methodology. USA: Morgan Kaufmann, 488p, 2007.

Martin, G.; Smith, G. High-level synthesis: Past, present, and future. IEEE Design and Test of Computers, v. 26, p. 18-25, 2009.

Marwedel, P. Embedded system design: Embedded systems foundations of cyber-physical systems. 2 st ed. Springer, 2011.

Moore, S. Bluepsec Examples-Cyan processor, 2010a.

Disponível em http://www.cl.cam.ac.uk/ swm11/examples/bluespec/CyanProc/ (Acessado em 01/2014) 
Moore, S. Bluepsec examplesNIOS custom instruction, 2010b.

Disponível em http://www.cl.cam.ac.uk/ swm11/examples/bluespec/ CustomInstruction/ (Acessado em 01/2014)

Moore, S. Avalon master and slave interfaces, 2011.

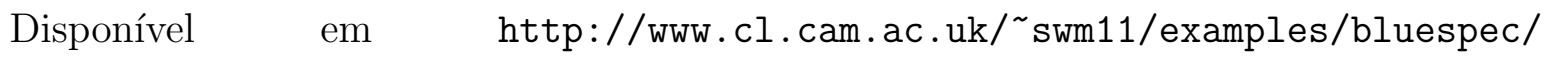
Avalon2ClientServer/ (Acessado em 10/2012)

Nikhil, R. S. Abstraction in hardware system design. Queue, v. 9, n. 8, p. 40:40-40:54, 2011.

Disponível em http://doi.acm.org/10.1145/2016036.2020861

Patel, H. D.; Shukla, S. K. Ingredients for successful system level design methodology. USA: Springer, 208p, 2008.

Plavec, F. Soft-core processor design. Tese de Doutoramento, Department of Electrical and Computer Engineering, University of Toronto, Toronto, 2004.

Plavec, F.; Fort, B.; Vranesic, Z.; Brown, S. Experiences with soft-core processor design. In: Parallel and Distributed Processing Symposium, 2005. Proceedings.19th IEEE International, 2005, p. 167b.

Rigo, S.; Azevedo, R.; Santos, L. Electronic system level design: An open-source approach. Springer, 2011.

Disponível em http://books.google.pt/books?id=v13thliIK1YC

Ruggiero, C. A.; Matias, P. Microprocessador didatico com 3 estagios de pipeline e conjunto de instrucoes compativel com mips, 2010.

Sangiovanni-Vincentelli, A. Quo vadis, sld ? reasoning about the trends and challenges of system level design. Proceedings of the IEEE, v. 95, n. 3, p. 467-506, 2007.

Schoeberl, M. JOP: a Java Optimized Processor for embedded real-time systems. Tese de Doutoramento, Vienna University of Technology, Vienna, 2005.

Schoeberl, M. A Java processor architecture for embedded real-time systems. Journal of Systems Architecture, v. 54, p. 265 - 286, 2008.

She, D.; He, Y.; Corporaal, H. An energy-efficient method of supporting flexible special instructions in an embedded processor with compact ISA. ACM Trans. Archit. Code Optim., v. 10, n. 3, p. 15:1-15:25, 2008.

Disponível em http://doi.acm.org/10.1145/2509420.2509426

Sheldon, D.; Kumar, R.; Lysecky, R.; Vahid, F.; Tullsen, D. Application-specific customization of parameterized FPGA soft-core processors. In: Proceedings of the 2006 IEEE/ACM International Conference on Computer-aided Design, New York, NY, USA: ACM, 2006, p. 261-268.

Shukla, S.; Pixley, C.; Smith, G. Guest editors' introduction: The true state of the art of ESL design. IEEE Journal on Design $\&$ Test of Computers, v. 23, n. 5, p. 335-337, 2006. 
Spear, C. SystemVerilog for verification: A guide to learning the testbench language features. USA: Springer, 436p, 2008.

Spring SMIPS processor specication, 2005.

Disponível em http://csg.csail.mit.edu/6.884/handouts/labs/smips-spec.pdf (Acessado em 09/2011)

Stallings, W. Arquitetura e organização de computadores. 8st ed. Pearson, 2010.

Stump, H.; Harper, G. ESL Synthesis + Power Analysis = optimal micro-architecture. 2011.

Disponível em http://chipdesignmag . com/display $\cdot$ php?articleId=963\&issueId= 20 (Acessado em 07/2011)

Sutherland, S.; Davidmann, S.; Flake, P. SystemVerilog for design: A guide to using System Verilog for hardware design and modeling. USA: Springer, 418p, 2006.

Tong, J.; Anderson, I.; Khalid, M. Soft-core processors for embedded systems. In: Microelectronics, 2006. ICM '06. International Conference on, 2006, p. 170-173.

Wain, R.; Bush, I.; Guest, M.; Deegan, M.; Kozin, I.; Kitchen, C.; Ad, C. W.; Wain, R.; Bush, I.; Guest, M.; Deegan, M.; Kozin, I.; Kitchen, C. An overview of FPGAs and FPGA programming; initial experiences at daresbury. Relatório Técnico, Computational Science and Engineering Department, CCLRC Daresbury Laboratory, 2006.

Disponível em www.cse.scitech.ac.uk/disco/publications/FPGA_overview.pdf

Watson, R. N. M. Bluespec extensible RISC implementation (BERI), 2014.

Disponível em http://www.cl.cam.ac.uk/research/security/ctsrd/beri.html (Acessado em 01/2014)

Xie, F.; Yang, G.; Song, X. Component-based hardware/software co-verification for building trustworthy embedded systems. Journal of Systems and Software, v. 80, n. 5, p. $643-654,2007$. 